\title{
Cyclic nucleotide signaling and synaptic plasticity
}

Citation for published version (APA):

Bollen, E. (2014). Cyclic nucleotide signaling and synaptic plasticity. [Doctoral Thesis, Maastricht University]. Maastricht University. https://doi.org/10.26481/dis.20141223eb

Document status and date:

Published: 01/01/2014

DOI:

10.26481/dis.20141223eb

Document Version:

Publisher's PDF, also known as Version of record

\section{Please check the document version of this publication:}

- A submitted manuscript is the version of the article upon submission and before peer-review. There can be important differences between the submitted version and the official published version of record.

People interested in the research are advised to contact the author for the final version of the publication, or visit the DOI to the publisher's website.

- The final author version and the galley proof are versions of the publication after peer review.

- The final published version features the final layout of the paper including the volume, issue and page numbers.

Link to publication

\footnotetext{
General rights rights.

- You may freely distribute the URL identifying the publication in the public portal. please follow below link for the End User Agreement:

www.umlib.nl/taverne-license

Take down policy

If you believe that this document breaches copyright please contact us at:

repository@maastrichtuniversity.nl

providing details and we will investigate your claim.
}

Copyright and moral rights for the publications made accessible in the public portal are retained by the authors and/or other copyright owners and it is a condition of accessing publications that users recognise and abide by the legal requirements associated with these

- Users may download and print one copy of any publication from the public portal for the purpose of private study or research.

- You may not further distribute the material or use it for any profit-making activity or commercial gain

If the publication is distributed under the terms of Article $25 \mathrm{fa}$ of the Dutch Copyright Act, indicated by the "Taverne" license above, 


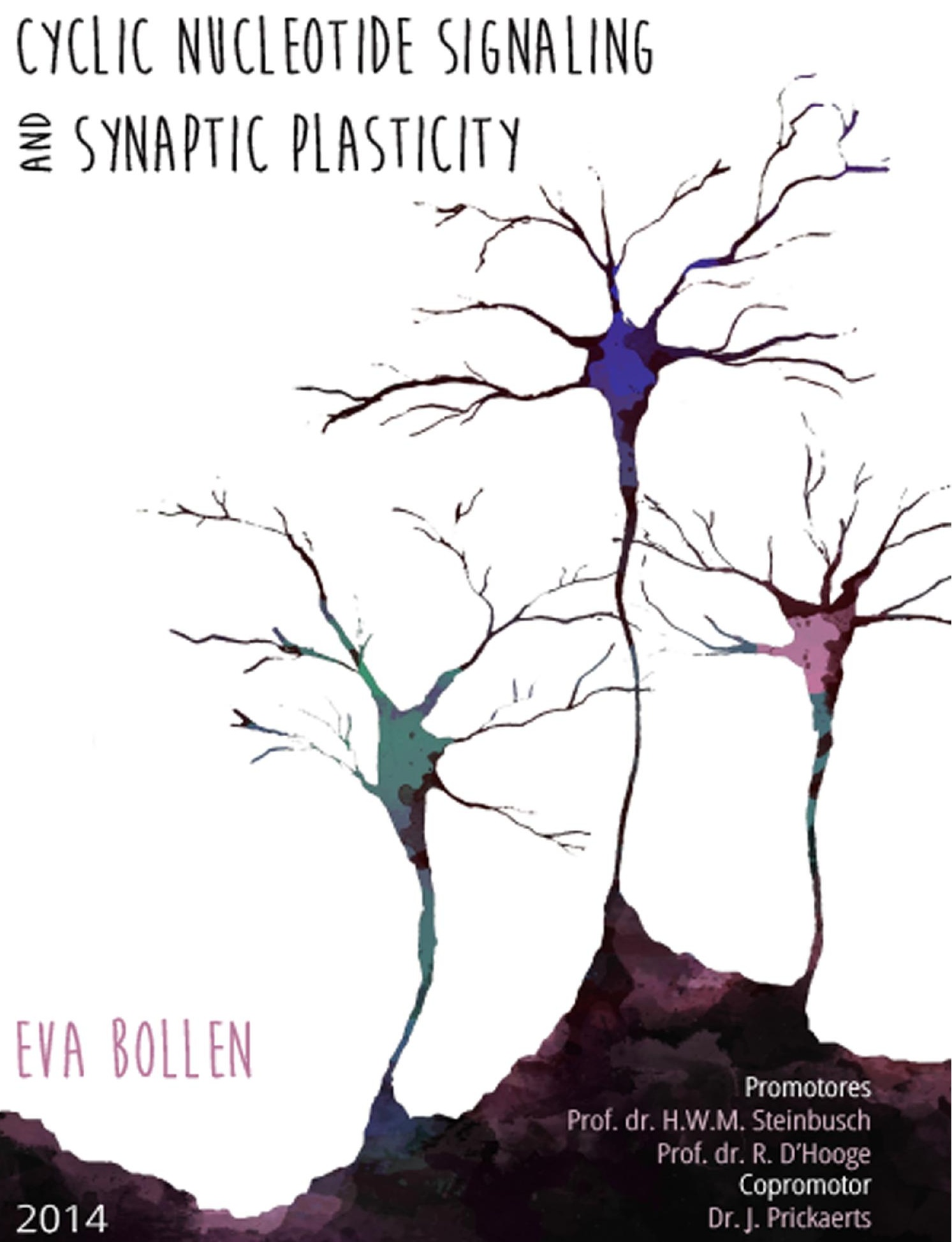

Proefschrift in het kader van een gezamenlijk doctoraat aan de Universiteit Maastricht en de KU Leuven 
Stellingen / Statements

Behorende bij het proefschrift / Belonging to the $\mathrm{PhD}$ thesis

\title{
CYCLIC NUCLEOTIDE SIGNALING AND SYNAPTIC PLASTICITY
}

\author{
EVA BOLLEN
}

Maastricht, 23 december 2014

1. Several neurodegenerative diseases are associated with aberrant cyclic nucleotide signaling, although it rarely represents the direct cause of the diseases. (this thesis)

2. To enhance memory via cGMP-signaling, intact cAMP signaling is a necessity. (this thesis)

3. Combination treatment with different types of phosphodiesterase inhibitors optimizes memory enhancing effects while minimizing possible side-effects. (this thesis)

4. Selective agonists of the TrkB receptor represent a promising treatment strategy for memory enhancement (this thesis).

5. The field of nootropics will keep gaining importance, as the ultimate goal of human beings is to outperform their own brain.

6. In scientific research, an apparent contradiction exists in that if you want something done right you better do it yourself, but if you want to reach further, you better do it together.

7. "Any man could, if he were so inclined, be the sculptor of his own brain." Santiago Ramon Y Cajal

8. "A failure is not always a mistake. It may simply be the best one can do under the circumstances. The real mistake is to stop trying." Burrhus Frederic Skinner

9. "The most beautiful experience we can have is the mysterious. It is the fundamental emotion which stands at the cradle of true art and true science." Albert Einstein 


\title{
CYCLIC NUCLEOTIDE SIGNALING
}

\author{
AND SYNAPTIC PLASTICITY
}


Copyright: Eva Bollen 2014

Cyclic nucleotide signaling and synaptic plasticity

All rights are reserved. No part of this book may be reproduced or transmitted in any form or by any means, without permission in writing from the copyright holder.

Cover design, typesetting and lay-out: Eva Bollen

Printed by CPI Koninklijke Wöhrmann B.V, Zutphen. 


\title{
CYCLIC NUCLEOTIDE SIGNALING
}

\section{AND SYNAPTIC PLASTICITY}

\author{
PROEFSCHRIFT \\ Ter verkijging van de graad van doctor \\ aan de Universiteit Maastricht en \\ doctor in de psychologie aan de KU Leuven \\ in het kader van een gemeenschappelijk doctoraat \\ op gezag van de Rector Magnifici, \\ Prof. Dr. L.L.G. Soete en Prof. Dr. R. Torfs \\ volgens het besluit van het College van Decanen \\ in het openbaar te verdedigen \\ op dinsdag 23 december 2014 om 12.00 uur
}

door

\section{Eva Bollen}

geboren op 26 juli 1985 te Tongeren 
Promotores:

Prof. Dr. H. W. M. Steinbusch

Prof. Dr. R. D'Hooge

\section{Copromotor:}

Dr. J. Prickaerts

\section{Beoordelingscommissie:}

Prof. Dr. H. Schmidt (Voorzitter)

Prof. Dr. P. Popik (Polish Academy of Sciences)

Prof. Dr. H. Op de Beeck (KU Leuven)

Prof. Dr. Y. Temel

Dr. A. Sambeth (Universiteit Maastricht)

The studies described in this thesis were partly funded by a Kootstra Talent Fellowship. 


\section{CONTENTS}

SAMENVATTING

SUMMARY

CHAPTER 1

General introduction

CHAPTER 2

Beyond erectile dysfunction: Understanding PDE5 activity in the central nervous system.

\section{CHAPTER 3}

Phosphodiesterases in neurodegenerative diseases.

CHAPTER 4

Improved long-term memory via enhancing CGMP-PKG signaling requires cAMP-PKA signaling.

CHAPTER 5

Object memory enhancement by combining sub-efficacious doses of specific phosphodiesterase inhibitors.

\section{CHAPTER 6}

7,8-Dihydroxyflavone improves memory consolidation processes in rats and mice. 
Dissociative effects of repeated rolipram administration in the hippocampus and nucleus accumbens on anhedonia in rats.

CHAPTER 8 145

General summary and discussion

VALORISATION

153

CURRICULUM VITAE

PUBLICATIONS

161

ACKNOWLEGDEMENTS

165 
SAMENVATTING 

Neuronen kunnen hun onderlinge connecties versterken om een verbeterde informatieoverdracht te bekomen. Dit kenmerk noemt men synaptische plasticiteit. Het is aangetoond dat synaptische plasticiteit van belang is bij cognitieve en affectieve processen, en in het bijzonder bij het vormen van geheugensporen. Deze plastische veranderingen worden bewerkstelligd door meerdere intracellulaire moleculaire paden die geactiveerd worden bij inkomende signalen in het neuron. In dit proefschrift hebben we ons gericht op een specifiek intracellulair pad, dat door activiteit van cyclisch nucleotiden wordt aangedreven. Het doel was na te gaan in welke mate verschillende cyclisch nucleotiden kunnen bijdragen tot gedragsveranderingen die synaptische plasticiteit als oorzaak hebben.

Met gedragspharmacologische en electrofysiologische technieken, hebben we aangetoond dat twee types cyclisch nucleotiden, CGMP en CAMP, respectievelijk enkel in vroege of late fase van geheugenconsolidatie betrokken zijn, en dat ze serieel geschakeld zijn. cGMP heeft in een latere fase CAMP-gerelateerde signalen namelijk nodig om geheugensporen te vormen. Verder tonen onze bevindingen aan dat verhoogde activiteit van hetzelfde cAMP-gerelateerde pad in verschillende hersenstructuren tegengestelde affectieve gedragingen tot gevolg kunnen heben. We stellen vervolgens ook nieuwe beloftevolle therapeutische strategiëen voor aandoeningen die gekarakteriseerd worden door cognitieve symptomen. Daarvoor hebben we ons in eerste plaats gericht op phosphodiesterase remmers. Deze remmen de afbraak van cyclisch nucleotiden, en resulteren dus direct in een verhoogde activiteit van CAMP en/of cGMP. In deze these hebben we aangetoond dat het combineren van lage doseringen van verschillende types phosphodiesterase remmers mogelijk een interessant alternatief biedt om geheugenvorming te verbeteren. Tenslotte hebben we ook gekeken naar BDNF, een molecule waarvan de intracellulaire niveaus door activatie van CAMP en CGMP verhoogd worden. Onze resultaten wijzen op het potentieel van een selectieve agonist van de belangrijkste receptor van BDNF voor geheugenverbetering. In het algemeen dragen de bevindingen hier beschreven bij tot een beter begrip van de onderliggende processen van geheugenvorming en zullen ze de ontwikkeling van verbeterde behandelingen voor cognitieve stoornissen faciliteren. 

SUMMARY 

Neurons have the fascinating ability to strengthen their connections to achieve enhanced information transmission. This feature is known as synaptic plasticity. It has been demonstrated that synaptic plasticity is of vital importance in cognitive and affective processes, and in particular in the formation of memory. The synaptic changes are attained by multiple intracellular molecular pathways that are activated in the neuron by incoming signals. In this thesis we have focused on a specific intracellular pathway which is centered around the activity of cyclic nucleotides. Our aim was to evaluate to what extent different cyclic nucleotides contribute to behavioral changes resulting from synaptic plasticity.

Using behavioral and electrophysiological techniques, we demonstrated that two types of cyclic nucleotides, i.e. CGMP and CAMP, are involved in respectively the early or late phase of memory consolidation, and that they are act in sequence. That is, CGMP requires CAMP-related signals in a later phase after learning to form a stable memory trace. In addition, our findings show that enhancing signaling in the same CAMP-related pathway can result in different behavioral outcomes depending on the brain structure targeted. Furthermore, we have proposed novel promising therapeutic strategies for diseases associated with cognitive symptoms. Firstly, we have focused on phosphodiesterase inhibitors. These inhibit the breakdown of cyclic nucleotides and thus result directly in an augmentation of CAMP and/or cGMP. In this thesis we have demonstrated that combining low dosages of different types of phosphodiesterase inhibitors potentially represent an interesting alternative to enhance memory formation. Secondly, we have focused on BDNF, a neurotrophin of which the intracellular levels are increased in response to cyclic nucleotide signaling. Our results point to the potential of a selective agonist of the most important receptor of BDNF in cognition enhancement. In general, our findings contribute to a better understanding of the underlying processes of memory formation, and will facilitate the development of novel and improved treatments for cognitive dysfunctions. 



\section{CHAPTER 1}

GENERAL INTRODUCTION 


\section{Neuronal signaling}

Our brain is without any doubt the most complex organ in the human body. Simply speaking, the brain represents a central location where raw data coming from our environment via our senses is constantly processed and combined with current needs and acquired knowledge. As a result of this process, our body undertakes action via coordinated motor responses and via hormonal secretion to influence other organs. The brain is mostly composed of two classes of cells, i.e. glia and neurons. Different types if glial cells are critically involved in an array of various functions, which are mostly supportive. However, neurons are considered the core components of the computational power of the brain. The billions of neurons that comprise our brain are all incorporated in a heavily interconnected neuronal network. This network is responsible for our every action, thoughts, feelings and experiences of the world surrounding us.

Cell-to-cell communication is accomplished by the unique capability of neurons to transfer electrical signals to other cells. The transmission of signals from one neuron to the next takes place in small structures called synapses. Many synapses have the special ability to change their strength according to the signals that move across them. Thus, neuronal connections can be dynamically modified. Learned skills, habits and memories are thought to arise from the shaping and reinforcement of certain patterns of activity in the neuronal network.

Most connections in our brain are so-called chemical synapses. In these connections, signal transduction is initiated by arrival of an action potential at the axon terminal of the neuron. Calcium influx via voltage-gated channels into the terminal triggers vesicles filled with neurotransmitters to fuse with the cell membrane. The neurotransmitters are subsequently released into the synaptic cleft and activate receptors on the post-synaptic membrane of the receiving neuron. As a response to neurotransmitters binding to its receptors, the post-synapse will depolarize. This may lead again to an action potential which propagates the signal further through the neuron. 


\section{Cyclic nucleotides}

Plastic changes of synapses require the activation of a number of intracellular signal transduction pathways. Second messengers are critical components of these pathways. They are molecules that relay and integrate incoming signals from receptors at the cell membrane to intracellular targets. By interfering with second messenger function, the binding of a ligand to a single receptor can cause massive changes on intracellular activity. Cyclic nucleotides represent a major class of second messengers. The two main forms are $3^{\prime}-5^{\prime}-$ cyclic adenosine monophosphate (cAMP) and $3^{\prime}-5^{\prime}$-cyclic guanosine monophosphate (cGMP). (1). They have a nucleotide conformation including a sugar (ribose), a nitrogenous aromatic base (adenine and guanine) and a phosphate group. The phosphate group is linked to the $3^{\prime}$ and $5^{\prime}$ hydroxyl group of the ribose, outlining the cyclic structure. Cyclic nucleotides are synthesized by cyclases. The main effector proteins can be divided into ion channels, protein kinases and phosphodiesterases (PDEs) (2).

The concept of second messengers was first described when the role of CAMP in glycogenolysis was discovered by Rall and Sutherland in 1957 (3). In the decennia afterwards, it became clear that cAMP is a vital component of a variety of functional pathways, including synaptic signal transduction. CAMP levels increase upon binding of a ligand to a Gs-protein coupled receptor, which activates the conversion of adenosine triphosphate (ATP) into CAMP by adenylyl cyclase. In addition to cyclic nucleotide gated ion channels and its specific degrading enzymes, a major target of CAMP is protein kinase $A$ (PKA) (4). PKA consists of two regulatory and two catalytic subunits. When cAMP is bound to regulatory subunits, PKA releases the catalytic subunits. The released catalytic subunits can then phosphorylate serine or threonine residues. In this way, CAMP-PKA signaling is able to change the activity of a protein kinase. In contrast, CGMP, is regulated by the gasous signaling molecule NO, which activates guanylyl cyclase. Similar to adenylyl cyclase, guanylyl cyclase converts guanosine triphosphate (GTP) into cGMP. cGMP activates protein kinase $G$, which is then able to trigger phosphorylation of downstream effectors (5) (for more details on CAMP and cGMP function, see chapters 2 and 3 ). 


\section{Downstream effectors of cAMP and cGMP}

To integrate the incoming complex signals into long-lasting changes, neurons show high translational activity. Activation of transcription factors regulate the transription of DNA into mRNA and its translation into new molecules that can be quickly incorporated in the cell, thus enabling the neuron to change its properties such as excitability and morphology. CAMP responsive element binding protein (CREB) is such a transcription factor that initiates stimulus-dependent gene transcription (6). Although multiple signaling pathways come together at CREB phosphorylation, CAMP-PKA signaling is a major mediator of CREB activation. In addition, CGMP-PKG signaling has shown to affect CREB phosphorylation (7). CREB can regulate the expression of a plethora of genes, including many crucial plasticityrelated proteins such as the neurotrophins and their receptors (8).

Neurotrophins represent a class of molecules that are essential to the development, growth and survival of neurons in the central nervous system (CNS). One specific type type of neurotrophin, brain-derived neurotrophic factor (BDNF), has been attributed a major role in the regulation of synaptic plasticity and neuronal survival (9). BDNF binds to tyrosine kinase receptor B (TrkB) with high-affinity and to the aspecific neurotrophin receptor p75 with low affinity (10). However, when focusing on synaptic plasticity, the TrkB receptor is generally regarded the most important. Binding of BDNF induces dimerization of the TrkB receptor, leading to the autophosphorylation of specific tyrosine residues. TrkB-signaling includes activation of three major pathways i.e. the PLCY pathway, PI3K/Akt pathway, and the ERK pathway (see chapter 6 for more information on BDNF signaling). Both BDNF itself and the TrkB receptor are direct targets of CREB-regulated gene transcription (9).

\section{Synaptic plasticity and behavior}

Synaptic plasticity is mostly known for its association with learning and memory. Indeed, the best documented form of synaptic plasticity is longterm potentiation (LTP), which is generally recognized as the cellular correlate of memory formation $(11,12)$. This phenomenon, in which an episode of strong stimulation of a neuron results in long-lasting potentiation of subsequent incoming signals, is extensively studied in the hippocampus. 
CAMP-PKA and CGMP-PKG signaling are both involved in synaptic plasticity as is CREB phosphorylation and BDNF-TrkB signaling $(9,13,14)$.

Although the field of synaptic plasticity has been dominated by memory research, there is now a steep increase in evidence that links defects in synaptic strength to other pathologies, including various neurodegenerative disorders and depression. In Alzheimer's disease (AD) for example, synaptic degeneration correlates with disease progression, and synaptic plasticity is impaired in several animal models of AD. As early diagnosis remains an obstacle in the successful targeting of the pathogenesis of many neurodegenerative disorders, repairing lost connections and functionality may prove to be a realistic alternative to slow down or halt disease progression. In depression, there is also substantial evidence for regionspecific changes in synaptic plasticity (15). The altered plasticity is thought to be caused by dysregulation of, among other pathways, CAMP-PKA and NOcGMP signaling. Thus, cAMP and/or cGMP regulation are a new promising therapeutic target for a wide range of CNS disorders. 


\section{AIM AND OUTLINE OF THIS THESIS}

The aim of this thesis was to assess the role of cyclic nucleotide signaling on behavioral processes that depend on synaptic plasticity, and to evaluate the efficacy of treatment aimed at enhancing cyclic nucleotide signaling and synaptic plasticity.

In chapter 2 and 3 we provide a comprehensive overview on the existing literature regarding the role of PDEs, which regulate CAMP and/or CGMP concentrations, in the central nervous system. Chapter $\mathbf{2}$ deals with the potential use of in particular the infamous PDE5 inhibitors in disorders related to central nervous system. In chapter $\mathbf{3}$ we have focused particularly on patient data indicative of a direct involvement of PDE enzymes in general in neurodegenerative disorders.

In our first experimental study, we aimed to increase understanding of the underlying mechanisms of PDE inhibitor induced memory improvement and synaptic plasticity. The study described in chapter $\mathbf{4}$ particularly assesses the relationship between CGMP-signaling and CAMP-signaling. In chapter 5, the acquired findings of the latter fundamental study were translated into a potential novel treatment strategy for memory decline by combining different sub-efficacious doses of PDE-I in rats.

In chapter 6, the efficacy of targeting a downstream effector of cyclic nucleotide signaling, i.e. BDNF, on memory formation is studied. We administered the novel TrkB receptor agonist, 7,8-dihydroxyflavone to healthy rats and to mice with the Alzheimer's disease-associated APP/PS1 gene mutation, and assessed effects on object memory performance.

Chapter 7 describes a study aimed at the understanding of differential outcomes of cyclic nucleotide signaling depending on different brain regions targeted in relation to depressive-like behavior. Specifically, the effects of enhanced CAMP signaling in the nucleus accumbens versus the hippocampus were studied in this respect.

Finally, chapter 8 summarizes and discusses the main findings of this thesis. 


\section{REFERENCES}

1. Beavo, J. A. \& Brunton, L. L. (2002) Cyclic nucleotide research -- still expanding after half a century. Nat Rev Mol Cell Biol 3(9):710-718.

2. Francis, S. H., Blount, M. A., \& Corbin, J. D. (2011) Mammalian cyclic nucleotide phosphodiesterases: molecular mechanisms and physiological functions. Physiol Rev 91(2):651-690.

3. Rall, T. W. \& Sutherland, E. W. (1962) Adenyl cyclase. II. The enzymatically catalyzed formation of adenosine 3',5'-phosphate and inorganic pyrophosphate from adenosine triphosphate. J Biol Chem 237:1228-1232.

4. Sassone-Corsi, P. (2012) The cyclic AMP pathway. Cold Spring Harb Perspect Biol 4(12).

5. Kleppisch, T. \& Feil, R. (2009) cGMP signalling in the mammalian brain: role in synaptic plasticity and behaviour. Handb Exp Pharmacol (191):549-579.

6. Sakamoto, K., Karelina, K., \& Obrietan, K. (2011) CREB: a multifaceted regulator of neuronal plasticity and protection. J Neurochem 116(1):1-9.

7. Paul, C., Stratil, C., Hofmann, F., \& Kleppisch, T. (2010) cGMP-dependent protein kinase type I promotes CREB/CRE-mediated gene expression in neurons of the lateral amygdala. Neurosci Lett 473(2):82-86.

8. Finkbeiner, S., Tavazoie, S. F., Maloratsky, A., Jacobs, K. M., Harris, K. M., et al. (1997) CREB: a major mediator of neuronal neurotrophin responses. Neuron 19(5):1031-1047.

9. Minichiello, L. (2009) TrkB signalling pathways in LTP and learning. Nat Rev Neurosci 10(12):850-860.

10. Skaper, S. D. (2012) The neurotrophin family of neurotrophic factors: an overview. Methods Mol Biol 846:1-12.

11. Bliss, T. V. \& Lomo, T. (1973) Long-lasting potentiation of synaptic transmission in the dentate area of the anaesthetized rabbit following stimulation of the perforant path. $J$ Physiol 232(2):331-356.

12. Whitlock, J. R., Heynen, A. J., Shuler, M. G., \& Bear, M. F. (2006) Learning induces longterm potentiation in the hippocampus. Science 313(5790):1093-1097.

13. Chien, W. L., Liang, K. C., Teng, C. M., Kuo, S. C., Lee, F. Y., et al. (2003) Enhancement of long-term potentiation by a potent nitric oxide-guanylyl cyclase activator, 3-(5hydroxymethyl-2-furyl)-1-benzyl-indazole. Mol Pharmacol 63(6):1322-1328.

14. Frey, U., Huang, Y. Y., \& Kandel, E. R. (1993) Effects of cAMP simulate a late stage of LTP in hippocampal CA1 neurons. Science 260(5114):1661-1664.

15. Marsden, W. N. (2013) Synaptic plasticity in depression: molecular, cellular and functional correlates. Prog Neuropsychopharmacol Biol Psychiatry 43:168-184. 



\section{CHAPTER 2}

\section{BEYOND ERECTILE DYSFUNCTION:}

\section{UNDERSTANDING PDE5 ACTIVITY IN THE}

CENTRAL NERVOUS SYSTEM

E Bollen, K Rutten, OAH Reneerkens, HMW Steinbusch, J Prickaerts

In: Cyclic-Nucleotide Phosphodiesterases In The Central Nervous System: From Biology to Drug Discovery. 2014, John Wiley \& Sons. 


\section{ABSTRACT}

Specific phosphodiesterase type 5 inhibitors (PDE5) have received an enormous amount of attention for the treatment of erectile dysfunction. This has lead to an interest in the efficacy of these cGMP-specific PDE5 inhibitors in other diseases. In this chapter we focus on the possible applications of PDE5 inhibition in disorders of the central nervous system (CNS). 


\section{INTRODUCTION}

Phosphodiesterases (PDEs) are widely-distributed enzymes in the body that break down cyclic adenosine monophoshate (CAMP) and cyclic guanosine monophosphate (cGMP) into their inactive form, 5'AMP and 5'GMP, respectively (1). CAMP and CGMP are cyclic nucleotides that are essential for signal transduction in several physiological functions. PDEs are represented as a superfamily, since they have been classified into 11 subtypes (PDE1PDE11) based largely on their sequence homology. Most of these subtypes have more than one gene product (e.g., PDE4A, PDE4B, PDE4C, PDE4D). In addition, each gene product may have multiple splice variants or isozymes (e.g., PDE4D1-PDE4D9). In total there are more than 100 specific PDEs (1). The different subtypes are discriminated using several criteria such as localization, subcellular distribution, mechanism of regulation, and enzymatic and kinetic properties. One fundamental distinction between subfamilies comprises the difference in affinity for the two distinct cyclic nucleotides. A differentiation is possible between cAMP-specific enzymes (PDE4,7,8), cGMPspecific enzymes (PDE5,6,9) and the so called dual substrate PDEs, that have affinity for both cyclic nucleotides (PDE1,2,3,10,11).

Because of the regulatory role of PDEs in essential cyclic nucleotide dependent signaling in various physiological systems, they have been identified as interesting drug targets for treatment of a wide array of disorders. Bender and Beavo described a number of possible factors that contribute to the current interest in PDEs as a drug target (1). One factor is the remarkably high number of members of the PDE family. An initial problem of the therapeutic application of PDE inhibitors was the lack of specificity. Early PDE inhibitors blocked virtually all PDE activity in the body, which often resulted in narrow therapeutic windows for these agents, which limited their applicability in humans. However, the identification of different PDE subfamilies and isozymes allowed the development of more specific pharmacological agents, which can often be targeted to only one subfamily or isozyme. Different subtypes and isozymes are thought to be involved in diverse physiological functions in the body as demonstrated by their unique distribution and specificity. As such, specific functions can be selectively targeted without causing off-target side-effects. In addition, the variety of 
PDEs and their different physiological roles promise multiple therapeutical purposes, which are not restricted to one particular pathology or medical application.

Two additional pharmacological properties make PDEs interesting targets for drug development. As enzymes, they participate in the degradation process of their substrates CAMP and CGMP. It is known that alteration in ligand levels is more effective when pharmacological intervention is directed at degradation processes when compared to synthesis processes (1). Furthermore, cyclic nucleotides are only available in relatively small amounts in the cell ( $<1$ to $10 \mu \mathrm{M}$ ). Therefore, PDE inhibitors have little competition in binding the targeted PDE enzyme.

The first report of clinical properties of a PDE inhibitor dates back to 1886 when the effects of caffeine on bronchodilation were described (2). However, it was only discovered several years later that these effects were caused by the caffeine-induced inhibition of CAMP-specific PDEs. In 1970 PDEs were identified in rat and bovine tissue and it was demonstrated that they hydrolyze the phosphodiesteric bond of cGMP and cAMP (3).

A first commercial success for the clinical application of PDE inhibitors was sildenafil, a selective inhibitor of PDE5. Although initially developed for the treatment of arterial hypertension and angina pectoris, sildenafil was approved by the US Food and Drug Administration (FDA) in 1998 for the treatment of erectile dysfunction (ED) and marketed by Pfizer under the name Viagra (4).

The discovery and success of sildenafil boosted the research and development of several other inhibitors of PDE5. At the same time it stimulated researchers to explore the therapeutic potential of other classes of PDEs in different disorders of the body and the brain. In addition, previously explored PDEs, such as PDE4, were reevaluated after first being dismissed as putative targets due to side-effects and lack of specificity or efficacy. For instance, in 1984 the PDE4 inhibitor rolipram was being developed as a putative antidepressant, but it never made it to the market due to severe emetic side-effects (e.g. nausea, vomiting). At present, several PDE inhibitors are in different phases of development for the treatment of a 
wide variety of pathologies. However, today only two more PDE3 inhibitors have been approved by the FDA for the treatment of congestive heart failure or intermittent claudication, respectively $(2,5,6)$. At this moment approximately 500 clinical trials involving PDE inhibitors are listed in the database of the U.S. National Institutes of Health (7).

The commercial success of the three FDA approved PDE5 inhibitors for ED (sildenafil as Viagra ${ }^{\circledR}$, tadalafil as Cialis ${ }^{\circledR}$ and vardenafil as Levitra $\mathbb{}(4,8,9)$ ) has been enormous, with the three major players (Pfizer, Eli Lilly and Bayer, respectively) posting sales of US\$ 3.1 billion in 2006. These compounds exert their effects throughout the entire body, and are therefore also considered for different disorders than ED. As a matter of fact, in 2005 sildenafil was additionally approved by the FDA under the name of Revatio ${ }^{\circledR}$ for therapy against pulmonary arterial hypertension $(\mathrm{PAH})$, recently followed by the approval of tadalafil (Adcirca $\left.{ }^{\circledR}\right)$ for the same purpose (10-13).

The availability and relative safety of PDE5 inhibitors make it worthwhile to evaluate its effects in many different species, conditions and disorders. This has led to a vast amount of preclinical and clinical data on the central effects of these drugs. In this chapter we will consider the possibilities for application of PDE5 inhibitors in disorders of the central nervous system (CNS). Firstly the properties of PDE5 in the CNS and the forthcoming physiological changes by PDE5 inhibition are evaluated. Secondly, we will review the relevance of PDE5 inhibition treatment for CNS disorders gathered in preclinical and clinical studies.

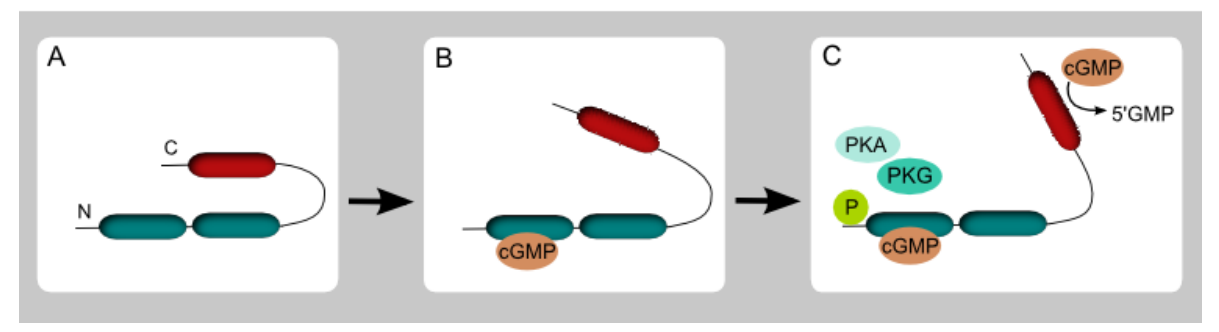

Figure 1: Enzymatic regulation of PDE5. [A] PDE5 consists of a C-term catalytic domain and an N-term regulatory domain. [B] CGMP can bind to the regulatory domain. [C] This promotes phosphorylation of the $\mathrm{N}$-term region and subsequent binding of PKG (and to a lesser extent PKA). These changes alter the shape of the enzyme, and thereby enhance the enzymatic activity at the catalytic domain. Adapted from Omori and Kotera (15). 


\section{Properties of PDE5 inhibition}

\section{PDE5}

PDE5 catalyzes specifically the breakdown of cGMP to 5'GMP. PDE5 has high affinity binding sites for CGMP and is therefore able to hydrolyze cGMP even in low substrate levels. PDE5 consists of two identical monomers, which both consist of a C-term catalytic domain and an $\mathrm{N}$-term regulatory domain (14, 15). The catalytic domain of the enzyme is responsible for the actual degradation of CGMP. However, CGMP can also bind to one of the noncatalytic allosteric domains available on the $\mathrm{N}$-terminal region (16). The occupation of this so-called GAF-A binding site by cGMP is critical for specific phosphorylation of Ser-92 by cGMP-dependent protein kinase (PKG) (and to a lesser extent CAMP-dependent protein kinase (PKA)). When bound, PKG activates the degradation of the catalytic domain and increases affinity for CGMP (17). This negative feedback mechanism closely regulates PDE5 activity (see Figure 1 ). The higher the available levels of $C G M P$ and PKG, the more likely PDE5 will be activated to reduce cGMP levels.

Thus far, a single gene, PDE5A, has been identified to produce PDE5 (18). PDE5A is considered a cytosolic protein, with rodent studies showing the highest levels of PDE5A mRNA in the kidneys, pancreas, cerebellum, lung and heart $(19,20)$. However, significant expression has also been observed in human vascular smooth muscle, placenta, platelets, several gastrointestinal tissues and the brain $(18,21,22)$. When focusing on the CNS, the highest levels of PDE5 mRNA expression are detected in the cerebellum, with large quantities found in the Purkinje cells (23). Additionally, in the cortex and hippocampus considerable amounts of PDE5A mRNA have been detected $(20,24,25)$. Three splice variants of the gene are known to exist (PDE5A1, PDE5A2 and PDE5A3) which differ in their N-terminal sequence (26). These variants show different localization patterns. Whereas PDE5A1 and PDE5A2 are ubiquitous, PDE5A3 is specifically located in smooth muscle tissue (26).

\section{PDE5 inhibitors}

The commercially available PDE5 inhibitors compete with cGMP to bind to the catalytic site of PDE5 (27). Their molecular structures are therefore mostly 
based on that of CGMP. Sildenafil and vardenafil have a similar CGMP-based molecular makeup, while the structure of the latest FDA approved PDE5 inhibitor tadalafil is rather different and is derived from B-carboline (See Figure 2). This structural difference has implications for the selectivity of the inhibitor to PDE5. Whereas vardenafil and sildenafil are selective for PDE5 isozymes with some affinity to PDE6, tadalafil has additional affinity for PDE11 (28). The functional relevance of PDE11 is relatively unknown in contrast to PDE6, which is involved in visual processes. The differences in chemical makeup between the PDE5 inhibitors also have consequences for their pharmacokinetic properties. The half-life of sildenafil and vardenafil is about 3-4 h. In contrast, tadalafil has a longer half-life of about $18 \mathrm{~h}$ (29). Vardenafil has a five-time greater inhibitory potential towards PDE5 than sildenafil and is the most potent of the three commercially available drugs $(27,28)$. Tadalafil is a second-generation drug, which is reflected in its long half-life, and long-lasting effects. All three compounds are rapidly absorbed in the gastrointestinal tract at the level of the small intestine. They are predominantly metabolized in the liver by CYP3A4 (30, 31). All three metabolized PDE5 inhibitors are excreted via both the liver and kidneys, but predominatly in faeces compared to urine.

When assessing the efficacy of PDE5 inhibitors in CNS-related disorders, an important issue is the ability of these compounds to cross the blood-brain barrier. Considering the lipophilic structure of sildenafil and vardenafil, they can be expected to penetrate into the brain. For both sildenafil as well as vardenafil this was confirmed in preclinical animal studies $(32,33)$. Tadalafil has been shown to not cross the blood brain barrier (32).

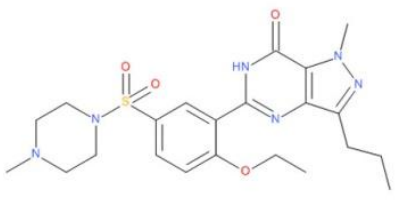

Sildenafil
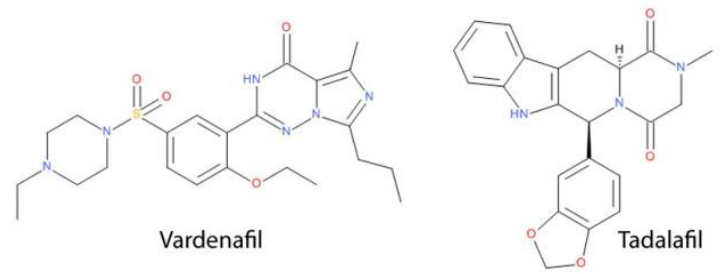

Figure 2. Molecular structures of the FDA approved PDE5 inhibitors 


\section{Mechanism}

Since the effects of PDE5 inhibition are generated through changes in cGMP levels, we will now focus on the functions of this cyclic nucleotide to further comprehend the effects of PDE5 inhibitors in the body and the brain.

cGMP is synthesized from guanosine triphosphate (GTP) by guanylyl cyclase (GC) (34). The latter enzyme is an important target of nitric oxide (NO) (35). $\mathrm{NO}$ is formed of L-arginine by catalysis by nitric oxide synthase (NOS). NO functions as a messenger in signal transduction, most notably in retrograde signaling. As a gaseous molecule, NO is able to diffuse through the cell membrane and pass on a signal to neighboring cells, where it activates GC functioning thereby promoting CGMP synthesis. Downstream, CGMP regulates PKG, PDEs and CGMP-gated ion channels (35). All these downstream targets of the NO-cGMP pathway mediate activity of different proteins involved in cell signal transduction, which eventually leads to a biological system-dependent cellular and physiological response.

NO has been studied for decades for its vasodilatory effects and its involvement in NMDA-mediated cell signaling in the brain $(34,36)$. Since PDE5 inhibitors and NO both increase cGMP levels, it is most likely that they also exert their effects by the same downstream mechanisms. As such, two main mechanisms are likely at the basis of the effects induced by PDE5 inhibition: changes in blood flow or neuronal signal transduction.

\section{Blood flow}

The most studied function of PDE5 is its regulatory role in hemodynamics. PDE5 modulates vascular smooth muscle contraction by regulation of cGMP levels (See Figure 3) (1). This characteristic lies at the base of the development of the commercially available PDE5 inhibitors. Inhibition of PDE5 increases levels of cGMP in the cavernosal smooth muscles, which in turn via PKG can act in diverse ways to promote erectile function, including activation of ion channels and contractile regulatory proteins that promote relaxation of the penile smooth muscle tissue (37). NO functions as a neurotransmitter, which links signals of central or peripheral sexual stimulation to smooth muscle relaxation, leading to penile erection (38). 
Treatment of ED with PDE5 inhibitors still requires presence of NO-mediated signals, i.e. sexual stimulation, since PDE5 is downstream of NO.

In addition to the treatment of ED, the FDA also approved sildenafil and tadalafil for the treatment of pulmonary hypertension $(12,13)$. In pulmonary hypertension, the small blood vessels in the lungs are more resistant to blood flow, causing increased stress on the right ventricle of the heart (39). Also in this condition, PDE5 inhibition can attenuate the stress on the heart by counteracting vasoconstriction and thereby lowering the resistance for blood flow in the lungs (40).

PDE5 inhibition induces changes in the central vascular system by similar mechanisms (See Figure 3). Administration of zaprinast, an early, relatively non-selective PDE5 inhibitor, dilates basilar and cerebral arteries in various animal models $(41,42)$, and a temporary increase in local cerebral blood flow (CBF) was also found after sildenafil administration (43). In humans, sildenafil also enhances cerebral vascular reactivity (44). Although PDE5 inhibitors can exhibit cerebrovascular effects, this effect cannot be generalized. Several studies could not find changes in CBF or vasodilation of cerebral arteries after inhibition of PDE5 (45-48). It is unclear what causes this discrepancy between studies, although the different techniques and dosages used, as well as interspecies differences may play a role.

\section{Neuronal signaling}

The NO-cGMP pathway is important in synaptic plasticity. Synaptic plasticity is the ability of neurons to actively enhance or depress their connectivity with neighboring neurons in order to induce changes in signal transduction efficiency. Connections between neurons can be strengthened by functional neuronal changes, such as enhanced neurotransmitter release and receptor efficacy and number, and by structural changes, such as the outgrowth of new synapses. Synaptic plasticity has been observed in various brain structures, such as the hippocampus, cerebral cortex and cerebellum. The most recognized form of synaptic plasticity is long-term potentiation (LTP), which is strongly associated with learning and memory. LTP was first discovered in the hippocampus, a structure renowned for its involvement in memory processes (49). Studies have shown that the NO-cGMP pathway is 


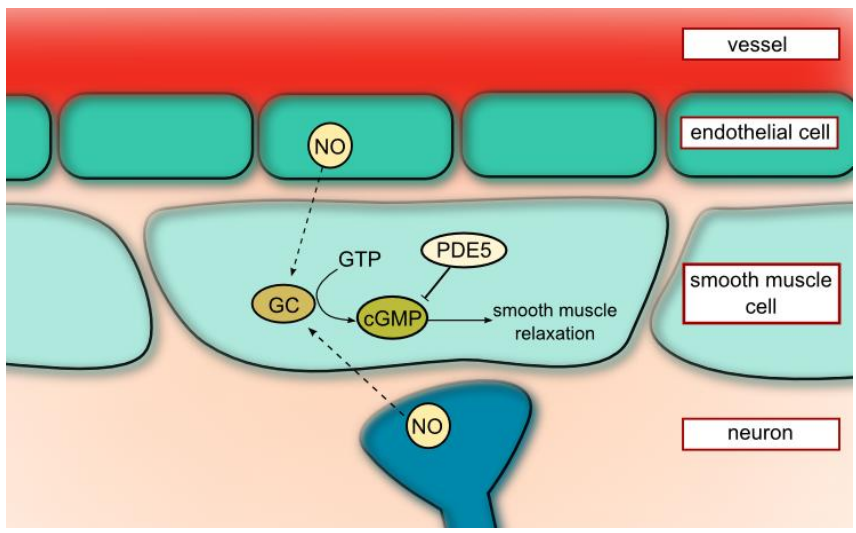

Figure 3. Role of PDE5 in blood flow regulation. Nitric oxide (NO) can diffuse from both the endothelial cells and neurons to the smooth muscle cell layer of vessels. NO activates guanylyl cyclase(GC), which produces cGMP from GTP. Heightened levels of cGMP lead to relaxation of the smooth muscles surrounding the vessel, thereby enhancing the blood flow in that vessel. PDE5 opposes to this process by degrading CGMP and thus preventing CGMP levels from rising. Inhibitors of PDE5 prevent the breakdown of CGMP and have therefore vasodilating properties.

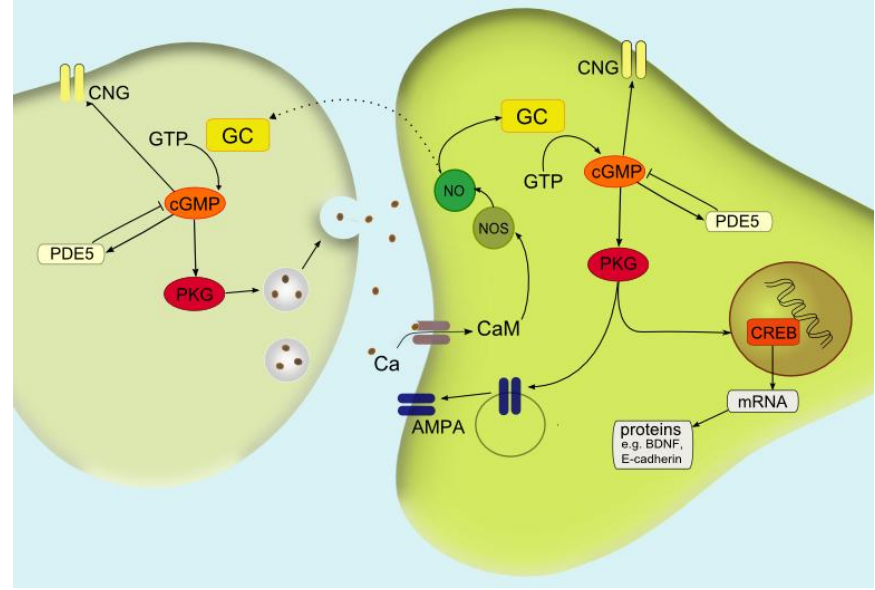

Figure 4. Role of PDE5 in synaptic plasticity. After the entrance of $\mathrm{Ca}^{2+}$ in the postsynapse, nitric oxide (NO) activates guanylyl cyclase either postsynaptically or presynaptically. cGMP synthesis is increased, which then leads to the opening of cyclic nucleotide gated channels (CNG)and to the activation protein kinase $\mathrm{G}$ (PKG). The influx of $\mathrm{Ca}^{2+}$ through the CNG channels further depolarizes the synaptic membranes. PKG acts in different ways. Presynaptically, it enhances neurotransmitter release into the synaptic cleft. In the postsynapse, the activation of PKG can lead to the insertion of functional AMPA receptors into the synapse, and to the synthesis of relevant proteins mediated through transcription factors, such as CREB (CAMP responsive element binding protein). All the changes bring about an enhanced signal transduction, and thus synaptic plasticity. PDE5 acts as a brake on these processes by controlling cGMP levels. Therefore, when inhibiting PDE5, synaptic plasticity is boosted. 
involved in at least the NMDA-dependent form of this specific type of synaptic plasticity. NO is activated by influx of calcium $\left(\mathrm{Ca}^{2+}\right)$ in the postsynapse, following binding of glutamate to NMDA-receptors (35). Next, the efficiency of signal transduction can be enhanced in several ways (See Figure 4).

Firstly, the gaseous nature of NO allows it to act as a retrograde messenger from the post-synapse back to the pre-synapse. There, the NO-cGMP-PKGpathway is activated, which then causes increased pre-synaptic glutamate release following depolarization of the post-synapse (50). In addition, in the post-synapse, the same pathway increases the insertion of AMPA receptors at the synaptic membrane, and mediates the activation of transcription factors such as CAMP-responsive element-binding protein (CREB) (51). CREB facilitates the synthesis of proteins, such as membrane channels and transporters, other transcription factors, cytokines and structural proteins (35). Besides PKG, other important effectors of cGMP are the cyclic nucleotide-gated (CNG) channels. The influx of $\mathrm{Ca}^{2+}$ through CNG channels further depolarizes the synaptic membrane, which promotes the abovementioned processes in pre- and post-synaptic membranes. PDE5 acts as a natural brake on this system by decreasing available levels of cGMP. Thus, inhibition of PDE5 enhances these processes, allowing more interaction of cGMP with PKG and CNG channels. 


\section{PDE5 INHIBITION AS POSSIBLE THERAPEUTIC CNS}

\section{TARGET}

\section{Sexual and erectile dysfunction}

The use of PDE5 inhibitors is recognized as a first-line therapy for men with $E D$, and is safe and effective in men with various causes of ED, including neurological disorders. Multiple sclerosis, systemic atrophy, Parkinson's disease and spinal cord injury are disorders that have their origin in the CNS, but can affect erectile functioning in men. PDE5 inhibitors improve erectile functioning in these patients, without causing significant side-effects (52-56).

In psychogenic ED, causes of the disorder are psychological in nature, rather than physical (57). ED is often observed in men facing stress or depression. Although most studies find an improvement after PDE5 inhibitor treatment in this group of patients $(57,58)$, the diagnostic criteria in these clinical studies for labeling ED as psychogenic are mostly unclear. It is difficult for clinicians to extricate psychological from physiological problems in ED. One study that focused on a specific population of psychogenic ED patients, i.e. soldiers with ED caused by post-traumatic stress disorder, could not find any beneficial effects of PDE5 inhibitor treatment (59).

Sildenafil has been successfully used to treat serotonin reuptake inhibitor (SSRI)-associated ED in men (60-62). In addition, the impact of treatment with sildenafil on the depressive symptoms and quality of life in male patients with ED who have untreated depressive symptoms, has recently been measured in a phase IV study (63). It was found that compared to placebo, sildenafil led to significant improvement in depressive symptoms. However, it will be difficult to disentangle whether a possible beneficial effect on mood is due to treatment of the sexual dysfunction or whether PDE5 inhibition directly leads to a reduction of depressive symptoms and thereby attenuates the erectile/sexual dysfunction. In a six week open label study in patients with erectile function, an improvement in depression was observed without changes in sexual function, indicating that PDE5 inhibition treatment in men has antidepressant effects (64). Moreover, the antidepressant 
potential of sildenafil has recently been shown in preclinical rodent studies $(65,66)$.

The same holds for female sexual arousal disorder (FSAD). Women who experience a lack of sexual arousal have been treated with PDE5 inhibitors to enhance sexual functioning (67-69). Again, PDE5 inhibitor treatment has been reported to be effective in FSAD secondary to neurological dysfunctions such as multiple sclerosis, spinal cord injury and SSRI-treatment due to major depression (70-72). Whether this improvement is due to genital or neurological changes remains controversial. PDE5 can be found in the clitoris, vagina and labia minora $(73,74)$. This implies that the improvement in sexual functioning and increase in arousal induced by PDE5 inhibition could be due to relaxation of vascular smooth muscles, causing enhanced genital blood flow, as well as of non-vascular smooth muscles, which causes increased genital arousal. In women however, there seems to be a discrepancy between genital and subjective arousal (75). Genital arousal is believed to have a minor influence on subjective feelings of arousal (76). Thus, increasing genital arousal would not, per se, stimulate feelings of desire or sexual pleasure (67-69). This suggests that, besides increased genital sensation, PDE5 inhibition induces changes in mental arousal processes in women. Oxytocin might be of importance in this regard, as a recent study showed that vardenafil treatment enhances the expression of this hormone which is associated with affiliation and sexual behavior, in the brain of rats (77). But again, the disentanglement of bodily versus mental processes sets hurdles for researchers, and up until now, it remains difficult to estimate the contribution of the CNS in enhanced sexual functioning due to PDE5 inhibitor treatment.

\section{Stroke}

\section{Ischemic stroke}

Preclinical research in rats has demonstrated beneficial effects of PDE5 inhibitor treatment on functional outcome after ischemic stroke. Ischemic stroke is characterized by a disturbance of blood and glucose supply to certain regions in the brain, which leads to infarction. As mentioned before, 
PDE5 inhibitors modulate vasorelaxation. Not only the peripheral, but most likely also the central vascular system is susceptible to PDE5induced changes in CBF. As mentioned above, PDE5 inhibitors can increase perfusion rates in the cerebral vessels in rats. Changes in local CBF were observed after sildenafil and tadalafil treatment, as well as after administration of PF-5, a new PDE5 inhibitor of Pfizer (78-80).

However, it is most unlikely that PDE5 inhibitors act only as protectors against vascular occlusion, since administration of a PDE5 inhibitor 24h or more after an ischemic insult still generated beneficial effects on functional outcome, while at that time point the main cerebral damage has already occurred (80). In accordance with this, the volume of the induced infarcts did not change with PDE5 inhibitor treatment after an ischemic insult $(80,81)$. Moreover, considerable debate exists when it comes to CBF changes caused by PDE5 inhibitor treatment. For example, a recent study using a mouse stroke model could not find any changes in CBF after vardenafil treatment, which may imply that CBF effects are species-specific (46). Furthermore, in healthy humans, SPECT and ultrasound measures after sildenafil treatment also did not reveal any changes in cerebral perfusion (82).

Several studies showed that besides CBF, PDE5 inhibitor treatment (sildenafil, tadalafil and zaprinast) affects angiogenesis and neurogenesis after stroke (80, 83-86). Thus, improved functional recovery could be caused by enhanced angio- and/or neurogenesis, rather than temporary changes in CBF. Angiogenesis is regulated in endothelial cells by vascular endothelial growth factor (VEFG) and angiopoietin (Ang-1) $(87,88)$. It is known that sildenafil promotes the VEGF/Ang-1 system. Blockage of VEGF disrupted sildenafil-induced angiogenesis (86). Moreover, PDE5 inhibitor treatment triggered angiogenic regulatory proteins and promoted phosphorylation of e-NOS and AKT (89). Also in neural progenitor cells, phosphorylation and activation of Akt was increased following sildenafil treatment (90). More specifically, activation of the PI3-K/Akt/GSK-3 pathway in response to elevated cGMP levels seems to underly sildenafil-induced enhancements in neural proliferation (90). It was recently demonstrated that sildenafil as well as tadalafil increased neurogenesis in the ischemic brain $(79,80)$. However, not only survival of new cells, but also structural changes in pre-existing 
neurons can facilitate functional recovery. Experimental studies showed synaptic sprouting and axonal remodeling in response to PDE5 inhibition after embolic stroke $(43,85)$. Elevated levels of cGMP in neurons stimulatetranscription factors that produce proteins necessary for these structural neuronal changes. Taken together, PDE5 inhibitors have been shown to enhance angiogenesis, neurogenesis and synaptogenesis after stroke, thereby promoting functional recovery.

The observation that changes induced by tadalafil treatment are not only vascular, but also neuronal in nature is in apparent contrast to the finding that tadalafil is unable to cross the blood-brain barrier (32). Two possible explanations can be given. On the one hand, it could be that all neuronal changes result from an increased blood supply caused by enhanced CBF and angiogenesis. On the other hand, it is possible that induction of an ischemic insult compromises the efficacy of the blood-brain barrier. In a preclinical study, Ko and colleagues, demonstrated that neuronal cGMP levels were enhanced by tadalafil only in gerbils that underwent an ischemic insult and not in control animals (91). These findings are in favor of a disrupted bloodbrain barrier after vascular occlusion.

Paradoxically, sildenafil has been associated with transient ischemic attack and ischemic stroke in patients with pre-existing cerebrovascular disease (92, 93). These effects were described in case reports, but in experimental conditions no association between sildenafil and risk for stroke have been reported (94). Seemingly, it is a rather rare side-effect, which might be caused by an interaction of sildenafil treatment with damaged blood vessels due to the pre-existing cerebrovascular disease $(92,94)$.

\section{Hemorrhagic stroke}

Besides stroke induced by lack of blood and glucose supply to the brain, a second category of stroke is due to intracranial hemorrhage. One specific type of hemorrhagic stroke is subarachnoid hemorrhage, in which blood accumulates between the arachnoid membrane and pia mater. A frequent complication in this type of stroke is vasospasm. The constriction of blood vessels can cause an ischemic insult in these patients, secondary to the initial hemorrhage. The spasms are likely caused by hemoglobin and its breakdown 
products (95). Hemoglobin as well as the by-products disrupt NO-signaling, which can lead to decreases in cGMP and consequently to vasoconstriction. In an experimental model of this specific type of stroke, sildenafil prevented the occurrence of vasospasms (96). It seems that in this case, PDE5 inhibitors are very potent relaxors of the cerebral vasculature. In clinical practice, papaverine is often used as vasodilator for vasospasm. Although a nonselective PDE10 inhibitor, papaverine is likely to mainly target cGMP breakdown. Whereas both PDE inhibitor treatments have similar mechanisms, inhibition of PDE5 seems to be more potent. Papaverine requires intra-arterially injections, whereas oral administration of PDE5 inhibitors is at least as effective $(97,98)$. For this specific subtype of stroke, PDE5 inhibitor treatment is therefore very promising.

Hemorrhage, and more specifically intracerebral hemorrhage, has been associated with use of all three commercially available PDE5 inhibitors in several case reports (99-104). The reason for this remains unclear, but it has been suggested that sildenafil redistributes $C B F$ by dilating the cerebral (micro)vasculature (105). This redistribution could ultimately lead to intracerebral hemorrhage $(99,106)$. Nevertheless, this seems to be a fairly rare adverse effect of PDE5 inhibitor treatment.

\section{Cognitive deficits}

The procognitive effect of PDE5 inhibition is probably the most studied possible CNS application in pre-clinical research. The evidence from these studies in several animal models is substantial (107-110). Zaprinast was the first PDE5 inhibitor that was reported to enhance memory (111). Because of additional affinity of zaprinast for PDE9, 10 and 11, no solid conclusions regarding the memory-enhancing effects of PDE5 inhibitor treatment could be drawn, especially since PDE9 and PDE10 are also considered interesting targets for cognition enhancement. However, the more selective PDE5 inhibitors sildenafil and vardenafil show similar procognitive effects in several learning and memory paradigms and across species (33, 108, 110, 112-115). Although prefrontal functions, such as executive functioning, are also 
improved by PDE5 inhibition $(108,116)$, its memory enhancing effects have received most attention in this regard. As such, PDE5 inhibitors mediate memory formation in spatial, fear and object memory, during acquisition as well as during consolidation of the memory trace (107). These pro-cognitive effects have also been studied in animal deficit models, which mimic memory decline due to various conditions. Memory deficits caused by experimental models of diabetes, hyperammonemia, stroke and electroconvulsive shock have been reversed by PDE5 inhibitor treatment $(91,117,118)$. Several studies have assessed the effects of PDE5 inhibitors in human subjects, but until now attempts to demonstrate cognition enhancing effects in humans were rather disappointing (119-121). However, changes in cognitionassociated event-related potentials (ERPs) suggest that PDE5 inhibitors do affect cognitive processes to some degree (121). Further studies with larger sample sizes and in patient populations are required to evaluate whether procognitive effects of PDE inhibitors observed in pre-clinical studies can be translated toward the human situation.

It is unlikely that the procognitive effects of PDE5 inhibitor treatment are related to cerebrovascular changes. A preclinical study found no changes in blood flow or glucose utilization in cognition-related brain regions at doses of vardenafil that effectively enhanced memory performance in rats (47). Compounds that do not cross the blood-brain barrier, e.g. tadalafil, should therefore not affect cognition. Whereas procognitive effects of sildenafil and vardenafil have repeatedly been reported in preclinical studies, to our knowledge only one study found an increased memory performance after tadalafil treatment (91). In this study, tadalafil treatment reversed a memory deficit caused by an ischemic insult. It might be speculated that stroke affected the integrity of the blood-brain barrier, thus allowing tadalafil to expand its effects into the brain. Further research in this area is required.

The effects of PDE inhibitors on cognition are thus most likely caused by increased synaptic connectivity. In the most established cellular model of memory, i.e. LTP, plasticity of the synapses is essential. It is theorized that the strengthening of the synaptic connections by facilitating signal transduction leads to a memory trace (122). The synaptic changes can be temporary or structural in nature, depending on the strength of the signal or memory. The 
NO-cGMP pathway has an important role in this process. Firstly, cGMP has a role in temporarily boosting pre-synaptic release of neurotransmitters upon depolarization of the post-synaptic cell via the retrograde action of NO. In addition, CGMP promotes structural synaptic changes by activating transcription factors, which are responsible for the synthesis of proteins such as growth factors.

It was shown that the NO-cGMP pathway is disrupted in an animal model of Alzheimer's disease (123). The latter finding together with the consistency of the observed memory improvements increased hopes for PDE5 inhibition efficacy in Alzheimer's disease. Indeed, in transgenic mice (APP/PS1) that have Alzheimer-like amyloid depositions, chronic treatment of sildenafil improved memory and synaptic function, and decreased amyloid- $\beta$ load (32). However, a recent study revealed that the expression of PDE5 is strongly reduced in the brains of healthy elderly and of patients with Alzheimer's disease (124), which was confirmed by a lack of efficacy of PDE5 inhibitor treatment in a memory paradigm in old animals (125). This suggests that PDE5 inhibition treatment might be less suited as a candidate for treatment of Alzheimer's disease. Several other PDEs that target CGMP, including PDE1, PDE2, PDE9 and PDE10 are present in the brains of aged subjects and inhibitors of these PDEs have been shown to improve memory as well (107). Therefore, inhibitors of PDE 1, 2, 9 or 10 might be more successful than PDE5 inhibitors in treating memory decline caused by Alzheimer's disease.

\section{Neuropathic pain}

PDE5 inhibitors have potential for the treatment of pain as antinociceptive effects have been reported after local peripheral and systemic administration in animal models $(39,126-133)$. Several lines of evidence point to an involvement of the NO-cGMP pathway in pain perception. However, there is still debate ongoing about the functional role of the NO-cGMP pathway in nociception. This can in part be explained by the seemingly contradictory results of nociceptive studies with sildenafil. As such, several preclinical 
studies have found antinociceptive effects of sildenafil, others have reported hyperalgesia $(133,134)$.

Whether PDE5 inhibition induces analgesic or hyperalgesic effects, could be dependent on location of administration. In one study, intrathecal and intracerebroventricular administration of L-arginine, the precursor of $\mathrm{NO}$, lead to hyperalgesic and antinoceptive effects, respectively (133). Since PDE5 inhibitors and L-arginine both affect the NO-cGMP pathway, similar effects should occur when inhibiting PDE5. Not only the administration site, but also the dosage of the PDE5 inhibitor applied may influence the outcome as cGMP-analogues produce hyperalgesia at high doses, while causing antinociception at low doses. Thus, the neuronal balance of cGMP concentrations is important for the up- or down-regulation of nociceptors (135). In animals models of neuropathic pain caused by sciatic nerve transsection, increases in neuronal NOS (nNOS) were observed (136). In contrast, the activity of nNOS is reduced in chronic neuropathic pain due to diabetes mellitus $(137,138)$. Therefore, the latter type of neuropathic pain seems to be a good candidate to be treated with PDE5 inhibitors, since it is likely that in this condition, CGMP levels are declined in accordance with the decreased nNOS activity. Indeed, sildenafil treatment had analgesic effects in a mouse model for diabetes $(127,131)$. Although the cause of pain symptoms in diabetic patients remains to be clarified, dysfunctional neuronal $\mathrm{NO}$ generation, and consequent decreases in CGMP levels in the dorsal root ganglion (DRG), have been suggested as factors involved in the pathogenesis of this specific type of neuropathy (138). PDE5 inhibitors increase cGMP levels, which leads to the activation of PKG. $\mathrm{K}+$ channels are targets of PKG, and are known to be involved in peripheral antinociception (139, 140). Several lines of evidence suggest a similar involvement of $K+$ channels in the DRG $(127,141)$. The influx of $\mathrm{K}+$ hyperpolarizes the central terminal of primary afferent neurons which causes antinociception (127).

Given the above, it can be concluded that for specific types of pain, such as chronic neuropathy due to diabetes mellitus, PDE5 inhibition might provide a new therapeutic option. 


\section{Side-effects}

Unwanted side-effects can severely limit the therapeutic potential of drug treatment candidates. The available PDE5 inhibitors are generally regarded as safe drugs, with some minor side-effects. Among the most commonly reported are headache, flushing and dyspepsia. A number of common and less common side-effects caused by PDE5 inhibition have a neurological origin. Headache or cephalgia is mostly reported as mild and transient; however there is also an association between PDE5 inhibitors and migraine (142). In general, headaches are thought to be caused by a complex interaction of factors, including excitatory thresholds, neurotransmitter levels and vascular dynamics (106). The induction of headaches and migraine after PDE5 inhibition were mostly regarded as being a result of cerebral vasodilatation. However, recent studies showed that the migraine attacks induced by PDE5 inhibition are independent of CBF changes in the main cerebral arteries, and electrophysiological measures did not reveal increases of neuronal excitability $(45,82,143)$. An alternative hypothesis is that an enhanced NO-cGMP pathway causes cortical spreading depression (CSD), in which a wave of hyperactivity and vasodilation in the brain is followed by a wave of inhibition and vasoconstriction (144). CSD has been strongly associated with migraine attacks preceded by an aura. PDE5 inhibition could be responsible for the initial increased CBF and cerebral hyperactivity, thereby instigating the consequent inhibition. Migraine is a risk factor for transient global amnesia, which also has been associated with PDE5 inhibition treatment in two case studies $(145,146)$. Again, CSD could explain transient global amnesia by vasoconstriction of vessels in the hippocampal area.

Blurred vision is another side-effect, which is reported in sildenafil and vardenafil treatment, but not in tadalafil treatment. The former PDE5 inhibitors have additional affinity to PDE6 (28), which is important for visual signal transduction. PDE6 is mainly found in the rod and cone cells in the retina. Inhibition of PDE6 disturbs normal visual processing at the level of the retina, and thereby induces visual deficiencies. Tadalafil does not affect PDE6, and is therefore not associated with this side-effect. 
Previously, we discussed the contra-indications of PDE5 inhibition in patients with pre-existing cerebrovascular diseases, considering the increased risk for stroke. Increased risk for seizures has been reported as another rare, though severe side-effect of PDE5 inhibition. Case reports described tonic-clonic seizures after intake of sildenafil and vardenafil $(147,148)$. Also in a seizure mouse model, sildenafil reduced the threshold for clonic seizures, which according to Riazi and colleagues was caused by hyper-excitability in the brain due to cGMP accumulation (149). It is known that endogenous NO is involved in NMDA-dependent excitatory neurotransmission. In addition, there are indications that the activity of GABAergic receptors is reduced by NO. A disturbance in the NO-cGMP pathway could in that manner lead to excessive glutamate neurotransmitter release and proconvulsant effects (150).

\section{CONCLUSIONS}

PDE5 inhibition has been shown successful in treating ED and pulmonary hypertension. The function and widespread localization of PDE5 in the body, as well as relative safety and availability of its inhibitors, has attracted a lot of researchers in different medical fields to evaluate PDE5 as a drug target. This has led to the identification of a number of CNS applications in which PDE5 inhibitors could produce beneficial effects, including stroke and cerebral vasospasm, specific types of neuropathy and memory decline. In ED and FSAD, PDE5 inhibition also effectively attenuated disease symptoms, even if the cause of the problem is neurological. However, for these disorders the actual contribution of CNS might be questioned.

It should be noted that in the literature several interspecies differences and several seemingly contrasting findings were encountered. PDE5 inhibition can have positive as well as negative effects on pain perception, and has been associated with increased risk for stroke, but at the same time can enhance functional outcome after stroke. This clearly shows the complexity of the underlying mechanisms. cGMP is involved in many bodily functions, and it is important to keep in mind that many of these functions will be 
affected when administering PDE5 inhibitors. Nevertheless, we believe that PDE5 inhibitors have potential in treating CNS-related disorders. Future research should aim to confirm the gathered findings in clinical studies and further elucidate the underlying mechanisms of action. 


\section{REFERENCES}

1. Bender AT \& Beavo JA (2006) Cyclic nucleotide phosphodiesterases: molecular regulation to clinical use. Pharmacological Reviews 58(3):488-520.

2. Boswell-Smith V, Spina D, \& Page CP (2006) Phosphodiesterase inhibitors. British Journal of Pharmacology 147 Suppl 1:S252-257.

3. Beavo JA, Hardman JG, \& Sutherland EW (1970) Hydrolysis of cyclic guanosine and adenosine 3',5'-monophosphates by rat and bovine tissues. Journal of Biological Chemistry 245(21):5649-5655.

4. U.S. Food and Drug Administration (1998) Viagra ${ }^{\circledR}$ (Center for Drug Evaluation and Research), (Department of health and human services).

5. Petersen JW \& Felker GM (2008) Inotropes in the management of acute heart failure. Critical Care Medicine 36(1 Suppl):S106-111.

6. Chapman TM \& Goa KL (2003) Cilostazol: a review of its use in intermittent claudication. American Journal of Cardiovascular Drugs 3(2):117-138.

7. U.S. National Institutes of Health (ClinicalTrials.gov.).

8. U.S. Food and Drug Administration (2003) Cialis ${ }^{\circledR}$ (Center for Drug Evaluation and Research), (Department of health and human services).

9. U.S. Food and Drug Administration (2003) Levitra ${ }^{\circledR}$ (Center for Drug Evaluation and Research), (Department of health and human services).

10. Patel MD \& Katz SD (2005) Phosphodiesterase 5 inhibition in chronic heart failure and pulmonary hypertension. American Journal of Cardiology 96(12B):47M-51M.

11. Lewis GD \& Semigran MJ (2004) Type 5 phosphodiesterase inhibition in heart failure and pulmonary hypertension. Current Heart Failure Reports 1(4):183-189.

12. U.S. Food and Drug Administration (2005) Revatio ${ }^{\circledR}$ (Center for Drug Evaluation and Research), (Department of health and human services).

13. U.S. Food and Drug Administration (2009) Adcirca ${ }^{\circledR}$ (Center for Drug Evaluation and Research), (Department of health and human services).

14. Corbin JD \& Francis SH (1999) Cyclic GMP phosphodiesterase-5: target of sildenafil. The Journal of Biological Chemistry 274(20):13729-13732.

15. Omori K \& Kotera J (2007) Overview of PDEs and their regulation. Circulation Research 100(3):309-327.

16. Liu L, Underwood T, Li H, Pamukcu R, \& Thompson WJ (2002) Specific cGMP binding by the cGMP binding domains of cGMP-binding cGMP specific phosphodiesterase. Cellular Signalling 14(1):45-51.

17. Corbin JD, Turko IV, Beasley A, \& Francis SH (2000) Phosphorylation of phosphodiesterase- 5 by cyclic nucleotide-dependent protein kinase alters its catalytic and allosteric cGMP-binding activities. European Journal of Biochemistry 267(9):27602767.

18. Yanaka N, et al. (1998) Expression, structure and chromosomal localization of the human cGMP-binding CGMP-specific phosphodiesterase PDE5A gene. European Journal of Biochemistry 255(2):391-399. 
19. Giordano D, De Stefano ME, Citro G, Modica A, \& Giorgi M (2001) Expression of cGMP-binding cGMP-specific phosphodiesterase (PDE5) in mouse tissues and cell lines using an antibody against the enzyme amino-terminal domain. Biochimica et Biophysica Acta 1539(1-2):16-27.

20. Kotera J, Fujishige K, \& Omori K (2000) Immunohistochemical localization of cGMPbinding CGMP-specific phosphodiesterase (PDE5) in rat tissues. The Journal of Histochemistry and Cytochemistry 48(5):685-693.

21. Loughney K, et al. (1998) Isolation and characterization of cDNAs encoding PDE5A, a human cGMP-binding, cGMP-specific 3',5'-cyclic nucleotide phosphodiesterase. Gene 216(1):139-147.

22. Stacey P, Rulten S, Dapling A, \& Phillips SC (1998) Molecular cloning and expression of human cGMP-binding CGMP-specific phosphodiesterase (PDE5). Biochemical and Biophysical Research Communications 247(2):249-254.

23. Shimizu-Albergine $M$, et al. (2003) Individual cerebellar Purkinje cells express different cGMP phosphodiesterases (PDEs): in vivo phosphorylation of cGMP-specific PDE (PDE5) as an indicator of cGMP-dependent protein kinase (PKG) activation. Journal of Neuroscience 23(16):6452-6459.

24. Marte A, Pepicelli O, Cavallero A, Raiteri M, \& Fedele E (2008) In vivo effects of phosphodiesterase inhibition on basal cyclic guanosine monophosphate levels in the prefrontal cortex, hippocampus and cerebellum of freely moving rats. Journal of Neuroscience Research 86(15):3338-3347.

25. Van Staveren WC, et al. (2003) mRNA expression patterns of the cGMP-hydrolyzing phosphodiesterases types 2, 5, and 9 during development of the rat brain. The Journal of Comparative Neurology 467(4):566-580.

26. Lin CS, Lau A, Tu R, \& Lue TF (2000) Expression of three isoforms of cGMP-binding cGMP-specific phosphodiesterase (PDE5) in human penile cavernosum. Biochemical and Biophysiological Research Communications 268(2):628-635.

27. Blount MA, et al. (2004) Binding of tritiated sildenafil, tadalafil, or vardenafil to the phosphodiesterase-5 catalytic site displays potency, specificity, heterogeneity, and cGMP stimulation. Molecular Pharmacology 66(1):144-152.

28. Bischoff E (2004) Potency, selectivity, and consequences of nonselectivity of PDE inhibition. International Journal of Impotence Research 16 Suppl 1:S11-14.

29. Kulkarni SK \& Patil CS (2004) Phosphodiesterase 5 enzyme and its inhibitors: update on pharmacological and therapeutical aspects. Methods and Findings in Experimental and Clinical Pharmacology 26(10):789-799.

30. Bischoff E (2004) Vardenafil preclinical trial data: potency, pharmacodynamics, pharmacokinetics, and adverse events. International Journal of Impotence Research 16 Suppl 1:S34-37.

31. Cirino G, Fusco F, Imbimbo C, \& Mirone V (2006) Pharmacology of erectile dysfunction in man. Pharmacology \& Therapeutics 111(2):400-423.

32. Puzzo D, et al. (2009) Phosphodiesterase 5 inhibition improves synaptic function, memory, and amyloid-beta load in an Alzheimer's disease mouse model. Journal of Neuroscience 29(25):8075-8086. 
33. Reneerkens OA, et al. (2012) Phosphodiesterase type 5 (PDE5) inhibition improves object recognition memory: indications for central and peripheral mechanisms. Neurobiology of Learning and Memory 97(4):370-379.

34. Friebe A \& Koesling D (2003) Regulation of nitric oxide-sensitive guanylyl cyclase. Circulation Research 93(2):96-105.

35. Kleppisch T \& Feil R (2009) cGMP signalling in the mammalian brain: role in synaptic plasticity and behaviour. Handbook of Experimental Pharmacology (191):549-579.

36. Puzzo D, Sapienza S, Arancio O, \& Palmeri A (2008) Role of phosphodiesterase 5 in synaptic plasticity and memory. Neuropsychiatric Disease and Treatment 4(2):371-387.

37. Corbin JD (2004) Mechanisms of action of PDE5 inhibition in erectile dysfunction. International Journal of Impotence Research 16 Suppl 1:S4-7.

38. Burnett AL (2005) Phosphodiesterase 5 mechanisms and therapeutic applications. The American Journal of Cardiology 96(12B):29M-31M.

39. Uthayathas $S$, et al. (2007) Versatile effects of sildenafil: recent pharmacological applications. Pharmacological Reports 59(2):150-163.

40. Archer SL \& Michelakis ED (2009) Phosphodiesterase type 5 inhibitors for pulmonary arterial hypertension. The New England Journal of Medicine 361(19):1864-1871.

41. Sobey CG \& Quan L (1999) Impaired cerebral vasodilator responses to NO and PDE V inhibition after subarachnoid hemorrhage. American Journal of Physiology 277(5 Pt 2):H1718-1724.

42. Kim P, Schini VB, Sundt TM, Jr., \& Vanhoutte PM (1992) Reduced production of cGMP underlies the loss of endothelium-dependent relaxations in the canine basilar artery after subarachnoid hemorrhage. Circulation Research 70(2):248-256.

43. Ding $\mathrm{G}$, et al. (2008) Magnetic resonance imaging investigation of axonal remodeling and angiogenesis after embolic stroke in sildenafil-treated rats. Journal of Cerebral Blood Flow and Metabolism 28(8):1440-1448.

44. Diomedi $\mathrm{M}$, et al. (2005) Sildenafil increases cerebrovascular reactivity: A transcranial Doppler study Neurology 65(6):919-921.

45. Kruuse C, Thomsen LL, Birk S, \& Olesen J (2003) Migraine can be induced by sildenafil without changes in middle cerebral artery diameter. Brain 126(Pt 1):241-247.

46. Royl G, et al. (2009) Effects of the PDE5inhibitor vardenafil in a mouse stroke model. Brain Research 1265:148-157.

47. Rutten K, et al. (2009) Phosphodiesterase inhibitors enhance object memory independent of cerebral blood flow and glucose utilization in rats. Neuropsychopharmacology 34(8):1914-1925.

48. Kruuse C, Gupta S, Nilsson E, Kruse L, \& Edvinsson L (2012) Differential vasoactive effects of sildenafil and tadalafil on cerebral arteries. European Journal of Pharmacology 674(2-3):345-351.

49. Bliss TV \& Lomo T (1973) Long-lasting potentiation of synaptic transmission in the dentate area of the anaesthetized rabbit following stimulation of the perforant path. Journal of Physiology 232(2):331-356.

50. Arancio O, et al. (1996) Nitric oxide acts directly in the presynaptic neuron to produce long-term potentiation in cultured hippocampal neurons. Cell 87(6):1025-1035. 
51. Lu YF, Kandel ER, \& Hawkins RD (1999) Nitric oxide signaling contributes to late-phase LTP and CREB phosphorylation in the hippocampus. Journal of Neuroscience 19(23):10250-10261.

52. Fowler CJ, et al. (2005) A double blind, randomised study of sildenafil citrate for erectile dysfunction in men with multiple sclerosis. Journal of Neurology, Neurosurgery and Psychiatry 76(5):700-705.

53. Nehra A \& Moreland RB (2001) Neurologic erectile dysfunction. The Urologic Clinics of North America 28(2):289-308.

54. Giammusso B, et al. (2002) Sildenafil in the treatment of erectile dysfunction in elderly depressed patients with idiopathic Parkinson's disease. Archives of Gerontology and Geriatrics. Supplement 8:157-163.

55. Giuliano F, et al. (1999) Randomized trial of sildenafil for the treatment of erectile dysfunction in spinal cord injury. Sildenafil Study Group. Annals of Neurology 46(1):1521.

56. Zesiewicz TA, Helal M, \& Hauser RA (2000) Sildenafil citrate (Viagra) for the treatment of erectile dysfunction in men with Parkinson's disease. Movement Disorders 15(2):305308.

57. Donatucci C, et al. (2004) Vardenafil improves erectile function in men with erectile dysfunction irrespective of disease severity and disease classification. The Journal of Sexual Medicine 1(3):301-309.

58. Goldenberg MM (1998) Safety and efficacy of sildenafil citrate in the treatment of male erectile dysfunction. Clinical Therapeutics 20(6):1033-1048.

59. Safarinejad MR, Kolahi AA, \& Ghaedi G (2009) Safety and efficacy of sildenafil citrate in treating erectile dysfunction in patients with combat-related post-traumatic stress disorder: a double-blind, randomized and placebo-controlled study. BJU International 104(3):376-383.

60. Damis M, Patel Y, \& Simpson GM (1999) Sildenafil in the Treatment of SSRI-Induced Sexual Dysfunction: A Pilot Study. Primary Care Companion to the Journal of Clinical Psychiatry 1(6):184-187.

61. Nurnberg HG, et al. (2001) Efficacy of sildenafil citrate for the treatment of erectile dysfunction in men taking serotonin reuptake inhibitors. American Journal of Psychiatry 158(11):1926-1928.

62. Nurnberg HG, et al. (2003) Treatment of antidepressant-associated sexual dysfunction with sildenafil: a randomized controlled trial. Journal of the American Medical Association 289(1):56-64.

63. Pfizer (2008) Efficacy study measuring the impact of treatment with Viagra on the depressive symptoms of men with erectile dysfunction. (ClinicalTrials.gov (Internet). Bethesda (MD): National Library of Medicine (US).Available from: http://clinicaltrials.gov/ct2/show/NCT00159809 NLM identifier: NCT00159809).

64. Orr GS, Stuart N.; Weiser, Mark ; Gershon, Ari A.; Dubrov, Yael BA; Klein, Donald F. (2008) An Open-Label Pilot Study to Evaluate the Efficacy of Sildenafil Citrate in Middle-Aged Men With Late-Onset Dysthymia. Journal of Nervous and Mental Disease 196(6):496-500.

65. Brink CB, Clapton JD, Eagar BE, \& Harvey BH (2008) Appearance of antidepressant-like effect by sildenafil in rats after central muscarinic receptor blockade: evidence from 
behavioural and neuro-receptor studies. Journal of Neural Transmission 115(1):117125.

66. Liebenberg NH, B. H.; Brand, L.; Brink, C. B. (2010) Antidepressant-like properties of phosphodiesterase type 5 inhibitors and cholinergic dependency in a genetic rat model of depression. Behavioural Pharmacology 21(5-6):540-547.

67. Foster R, Mears A, \& Goldmeier D (2009) A literature review and case reports series on the use of phosphodiesterase inhibitors in the treatment of female sexual dysfunction. International Journal of STD \& AIDS 20(3):152-157.

68. Caruso S, Intelisano G, Lupo L, \& Agnello C (2001) Premenopausal women affected by sexual arousal disorder treated with sildenafil: a double-blind, cross-over, placebocontrolled study. BJOG: An International Journal of Obstetrics and Gynaecology 108(6):623-628.

69. Berman JR, Berman LA, Toler SM, Gill J, \& Haughie S (2003) Safety and efficacy of sildenafil citrate for the treatment of female sexual arousal disorder: a double-blind, placebo controlled study. Journal of Urology 170(6 Pt 1):2333-2338.

70. Sipski ML, Rosen RC, Alexander CJ, \& Hamer RM (2000) Sildenafil effects on sexual and cardiovascular responses in women with spinal cord injury. Urology 55(6):812-815.

71. Dasgupta R, Wiseman OJ, Kanabar G, Fowler CJ, \& Mikol DD (2004) Efficacy of sildenafil in the treatment of female sexual dysfunction due to multiple sclerosis. Journal of Urology 171(3):1189-1193; discussion 1193.

72. Nurnberg HG, et al. (2008) Sildenafil treatment of women with antidepressantassociated sexual dysfunction: a randomized controlled trial. Journal of the American Medical Association 300(4):395-404.

73. Park K, Moreland RB, Goldstein I, Atala A, \& Traish A (1998) Sildenafil inhibits phosphodiesterase type 5 in human clitoral corpus cavernosum smooth muscle. Biochemical and Biophysical Research Communications 249(3):612-617.

74. D'Amati $G$, et al. (2002) Type 5 phosphodiesterase expression in the human vagina. Urology 60(1):191-195.

75. Leiblum SR \& Chivers ML (2007) Normal and persistent genital arousal in women: new perspectives. Journal of Sex \& Marital Therapy 33(4):357-373.

76. Basson R, et al. (2004) Revised definitions of women's sexual dysfunction. The Journal of Sexual Medicine 1(1):40-48.

77. Shin MS, et al. (2010) Vardenafil Enhances Oxytocin Expression in the Paraventricular Nucleus without Sexual Stimulation. International Neurourology Journal 14(4):213-219.

78. Menniti FS, et al. (2009) PDE5A inhibitors improve functional recovery after stroke in rats: optimized dosing regimen with implications for mechanism. The Journal of Pharmacology and Experimental Therapeutics.

79. Zhang L, et al. (2006) Tadalafil, a long-acting type 5 phosphodiesterase isoenzyme inhibitor, improves neurological functional recovery in a rat model of embolic stroke. Brain Research 1118(1):192-198.

80. Zhang $\mathrm{R}$, et al. (2002) Sildenafil (Viagra) induces neurogenesis and promotes functional recovery after stroke in rats. Stroke 33(11):2675-2680.

81. Li L, et al. (2007) Angiogenesis and improved cerebral blood flow in the ischemic boundary area detected by MRI after administration of sildenafil to rats with embolic stroke. Brain Research 1132(1):185-192. 
82. Kruuse C, Thomsen LL, Jacobsen TB, \& Olesen J (2002) The phosphodiesterase 5 inhibitor sildenafil has no effect on cerebral blood flow or blood velocity, but nevertheless induces headache in healthy subjects. Journal of Cerebral Blood Flow and Metabolism 22(9):1124-1131.

83. Ding $G$, et al. (2008) Angiogenesis detected after embolic stroke in rat brain using magnetic resonance T2*WI. Stroke 39(5):1563-1568.

84. Gao F, Sugita M, \& Nukui H (2005) Phosphodiesterase 5 inhibitor, zaprinast, selectively increases cerebral blood flow in the ischemic penumbra in the rat brain. Neurological Research 27(6):638-643.

85. Zhang L, et al. (2005) Functional recovery in aged and young rats after embolic stroke: treatment with a phosphodiesterase type 5 inhibitor. Stroke 36(4):847-852.

86. Zhang $R$, et al. (2003) Nitric oxide enhances angiogenesis via the synthesis of vascular endothelial growth factor and CGMP after stroke in the rat. Circulation Research 92(3):308-313.

87. Hanahan D (1997) Signaling vascular morphogenesis and maintenance. Science 277(5322):48-50.

88. Risau W (1997) Mechanisms of angiogenesis. Nature 386(6626):671-674.

89. Koneru S, et al. (2008) Sildenafil-mediated neovascularization and protection against myocardial ischaemia reperfusion injury in rats: role of VEGF/angiopoietin-1. Journal of Cellular and Molecular Medicine 12(6B):2651-2664.

90. Wang L, Gang Zhang Z, Lan Zhang R, \& Chopp M (2005) Activation of the PI3-K/Akt pathway mediates CGMP enhanced-neurogenesis in the adult progenitor cells derived from the subventricular zone. Journal of Cerebral Blood Flow and Metabolism 25(9):1150-1158.

91. Ko IG, et al. (2009) Tadalafil improves short-term memory by suppressing ischemiainduced apoptosis of hippocampal neuronal cells in gerbils. Pharmacology, Biochemistry and Behavior 91(4):629-635.

92. Habek M \& Petravic D (2006) Stroke--an adverse reaction to sildenafil. Clinical Neuropharmacology 29(3):165-167.

93. Morgan JC, Alhatou M, Oberlies J, \& Johnston KC (2001) Transient ischemic attack and stroke associated with sildenafil (Viagra) use. Neurology 57(9):1730-1731.

94. Morales A, Gingell C, Collins M, Wicker PA, \& Osterloh IH (1998) Clinical safety of oral sildenafil citrate (VIAGRA) in the treatment of erectile dysfunction. International Journal of Impotence Research 10(2):69-73; discussion 73-64.

95. Pluta RM (2005) Delayed cerebral vasospasm and nitric oxide: review, new hypothesis, and proposed treatment. Pharmacology \& Therapeutics 105(1):23-56.

96. Atalay B, et al. (2006) Systemic administration of phosphodiesterase $V$ inhibitor, sildenafil citrate, for attenuation of cerebral vasospasm after experimental subarachnoid hemorrhage. Neurosurgery 59(5):1102-1107; discussion 1107-1108.

97. Inoha $\mathrm{S}$, et al. (2002) Type $\mathrm{V}$ phosphodiesterase expression in cerebral arteries with vasospasm after subarachnoid hemorrhage in a canine model. Neurological Research 24(6):607-612.

98. Firlik KS, Kaufmann AM, Firlik AD, Jungreis CA, \& Yonas $H$ (1999) Intra-arterial papaverine for the treatment of cerebral vasospasm following aneurysmal subarachnoid hemorrhage. Surgical Neurology 51(1):66-74. 
99. Alpsan $\mathrm{MH}$, et al. (2008) Intracerebral hemorrhage associated with sildenafil use: a case report. Journal of Neurology 255(6):932-933.

100. Buxton N, Flannery T, Wild D, \& Bassi S (2001) Sildenafil (Viagra)-induced spontaneous intracerebral haemorrhage. British Journal of Neurosurgery 15(4):347-349.

101. Gazzeri R, Neroni M, Galarza M, \& Esposito S (2008) Intracerebral hemorrhage associated with use of tadalafil (Cialis). Neurology 70(15):1289-1290.

102. Marti I \& Marti Masso JF (2004) Hemiballism due to sildenafil use. Neurology 63(3):534.

103. McGee HT, Egan RA, \& Clark WM (2005) Visual field defect and intracerebral hemorrhage associated with use of vardenafil (Levitra). Neurology 64(6):1095-1096.

104. Monastero R, Pipia C, Camarda LK, \& Camarda R (2001) Intracerebral haemorrhage associated with sildenafil citrate. Journal of Neurology 248(2):141-142.

105. Ballard SA et al. (1998) Effects of sildenafil on the relaxation of human corpus cavernosum tissue in vitro and on the activities of cyclic nucleotide phosphodiesterase isozymes. Journal of Urology 159(6):2164-2171.

106. Farooq MU, et al. (2008) Role of sildenafil in neurological disorders. Clinical Neuropharmacology 31(6):353-362.

107. Reneerkens OA, Rutten K, Steinbusch HW, Blokland A, \& Prickaerts J (2009) Selective phosphodiesterase inhibitors: a promising target for cognition enhancement. Psychopharmacology (Berl) 202(1-3):419-443.

108. Rutten K, Basile JL, Prickaerts J, Blokland A, \& Vivian JA (2008) Selective PDE inhibitors rolipram and sildenafil improve object retrieval performance in adult cynomolgus macaques. Psychopharmacology (Berl) 196(4):643-648.

109. Rutten K, et al. (2007) Time-dependent involvement of cAMP and cGMP in consolidation of object memory: studies using selective phosphodiesterase type 2, 4 and 5 inhibitors. European Journal of Pharmacology 558(1-3):107-112.

110. Rutten K, et al. (2005) The selective PDE5 inhibitor, sildenafil, improves object memory in Swiss mice and increases CGMP levels in hippocampal slices. Behavioral Brain Research 164(1):11-16.

111. Prickaerts J, Steinbusch HW, Smits JF, \& de Vente J (1997) Possible role of nitric oxidecyclic GMP pathway in object recognition memory: effects of 7-nitroindazole and zaprinast. European Journal of Pharmacology 337(2-3):125-136.

112. Campbell E \& Edwards T (2006) Zaprinast consolidates long-term memory when administered to neonate chicks trained using a weakly reinforced single trial passive avoidance task. Behavioural Brain Research 169(1):181-185.

113. Shafiei M, Mahmoudian M, Rostami P, \& Nemati F (2006) Effect of sildenafil (Viagra) on memory retention of a passive avoidance response in rats. Acta Physiologica Academiae Scientiarum Hungaricae 93(1):53-59.

114. Baratti CM \& Boccia MM (1999) Effects of sildenafil on long-term retention of an inhibitory avoidance response in mice. Behavioural Pharmacology 10(8):731-737.

115. Boccia MM, Blake MG, Krawczyk MC, \& Baratti CM (2011) Sildenafil, a selective phosphodiesterase type 5 inhibitor, enhances memory reconsolidation of an inhibitory avoidance task in mice. Behavorial Brain Research 220(2):319-324. 
116. Rodefer JS, Saland SK, \& Eckrich SJ (2012) Selective phosphodiesterase inhibitors improve performance on the ED/ID cognitive task in rats. Neuropharmacology 62(3):1182-1190.

117. Erceg S, et al. (2006) Role of extracellular cGMP and of hyperammonemia in the impairment of learning in rats with chronic hepatic failure. Therapeutic implications. Neurochemistry International 48(6-7):441-446.

118. Patil CS, Singh VP, \& Kulkarni SK (2006) Modulatory effect of sildenafil in diabetes and electroconvulsive shock-induced cognitive dysfunction in rats. Pharmacological Reports 58(3):373-380.

119. Goff DC, et al. (2009) A placebo-controlled study of sildenafil effects on cognition in schizophrenia. Psychopharmacology (Berl) 202(1-3):411-417.

120. Grass H, et al. (2001) Sildenafil (Viagra): is there an influence on psychological performance? International Urology and Nephrology 32(3):409-412.

121. Schultheiss D, et al. (2001) Central effects of sildenafil (Viagra) on auditory selective attention and verbal recognition memory in humans: a study with event-related brain potentials. World Journal of Urology 19(1):46-50.

122. Hebb DO (1949) The Organization of Behavior (Wiley, New York).

123. Puzzo D, Palmeri A, \& Arancio O (2006) Involvement of the nitric oxide pathway in synaptic dysfunction following amyloid elevation in Alzheimer's disease. Reviews in the Neurosciences 17(5):497-523.

124. Reyes-Irisarri E, Markerink-Van Ittersum M, Mengod G, \& de Vente J (2007) Expression of the cGMP-specific phosphodiesterases 2 and 9 in normal and Alzheimer's disease human brains. European Journal of Neuroscience 25(11):3332-3338.

125. Domek-Lopacinska K \& Strosznajder JB (2008) The effect of selective inhibition of cyclic GMP hydrolyzing phosphodiesterases 2 and 5 on learning and memory processes and nitric oxide synthase activity in brain during aging. Brain Research 1216:68-77.

126. Jain NK, Patil CS, Singh A, \& Kulkarni SK (2001) Sildenafil-induced peripheral analgesia and activation of the nitric oxide-cyclic GMP pathway. Brain Research 909(1-2):170178.

127. Araiza-Saldana CI, Reyes-Garcia G, Bermudez-Ocana DY, Perez-Severiano F, \& Granados-Soto V (2005) Effect of diabetes on the mechanisms of intrathecal antinociception of sildenafil in rats. European Journal of Pharmacology 527(1-3):60-70.

128. Patil CS, Jain NK, Singh VP, \& Kulkarni SK (2004) Cholinergic-NO-cGMP mediation of sildenafil-induced antinociception. Indian Journal of Experimental Biology 42(4):361367.

129. Jain NK, Patil CS, Singh A, \& Kulkarni SK (2003) Sildenafil, a phosphodiesterase-5 inhibitor, enhances the antinociceptive effect of morphine. Pharmacology 67(3):150156.

130. Asomoza-Espinosa R, et al. (2001) Sildenafil increases diclofenac antinociception in the formalin test. European Journal of Pharmacology 418(3):195-200.

131. Patil CS, Singh VP, Singh S, \& Kulkarni SK (2004) Modulatory effect of the PDE-5 inhibitor sildenafil in diabetic neuropathy. Pharmacology 72(3):190-195. 
132. Mixcoatl-Zecuatl T, Aguirre-Banuelos P, \& Granados-Soto V (2000) Sildenafil produces antinociception and increases morphine antinociception in the formalin test. European Journal of Pharmacology 400(1):81-87.

133. Kitto KF, Haley JE, \& Wilcox GL (1992) Involvement of nitric oxide in spinally mediated hyperalgesia in the mouse. Neuroscience Letters 148(1-2):1-5.

134. Patil CS, Padi SV, Singh VP, \& Kulkarni SK (2006) Sildenafil induces hyperalgesia via activation of the NO-cGMP pathway in the rat neuropathic pain model. Inflammopharmacology 14(1-2):22-27.

135. Torres-Lopez JE, Arguelles CF, \& Granados-Soto V (2002) Participation of peripheral and spinal phosphodiesterases 4 and 5 in inflammatory pain. Proceedings of the Western Pharmacology Society 45:141-143.

136. Guedes RP, et al. (2009) Sciatic nerve transection increases gluthatione antioxidant system activity and neuronal nitric oxide synthase expression in the spinal cord. Brain Research Bulletin 80(6):422-427.

137. Rodella L, Rezzani R, Corsetti G, \& Bianchi R (2000) Nitric oxide involvement in the trigeminal hyperalgesia in diabetic rats. Brain Research 865(1):112-115.

138. Sasaki T, Yasuda H, Maeda K, \& Kikkawa R (1998) Hyperalgesia and decreased neuronal nitric oxide synthase in diabetic rats. Neuroreport 9(2):243-247.

139. Ambriz-Tututi M, Velazquez-Zamora DA, Urquiza-Marin H, \& Granados-Soto V (2005) Analysis of the mechanism underlying the peripheral antinociceptive action of sildenafil in the formalin test. European Journal of Pharmacology 512(2-3):121-127.

140. Sachs D, Cunha FQ, \& Ferreira SH (2004) Peripheral analgesic blockade of hypernociception: activation of arginine/NO/cGMP/protein kinase G/ATP-sensitive K+ channel pathway. Proc Natl Acad Sci U S A 101(10):3680-3685.

141. Yamazumi I, Okuda T, \& Koga Y (2001) Involvement of potassium channels in spinal antinociceptions induced by fentanyl, clonidine and bethanechol in rats. Japanese Journal of Pharmacology 87(4):268-276.

142. Evans RW \& Kruuse C (2004) Phosphodiesterase-5 inhibitors and migraine. Headache 44(9):925-926.

143. Kruuse C, Hansen AE, Larsson HB, Lauritzen $M$, \& Rostrup E (2009) Cerebral haemodynamic response or excitability is not affected by sildenafil. Journal of Cerebral Blood Flow and Metabolism 29(4):830-839.

144. Tfelt-Hansen PC (2010) History of migraine with aura and cortical spreading depression from 1941 and onwards. Cephalalgia 30(7):780-792.

145. Savitz SA \& Caplan LR (2002) Transient global amnesia after sildenafil (Viagra) use. Neurology 59(5):778.

146. Gandolfo C, Sugo A, \& Del Sette M (2003) Sildenafil and transient global amnesia. Neurological Sciences 24(3):145-146.

147. Gilad R, Lampl Y, Eshel Y, \& Sadeh M (2002) Tonic-clonic seizures in patients taking sildenafil. British Medical Journal 325(7369):869.

148. Striano P, Zara F, Minetti C, \& Striano S (2006) Epileptic seizures can follow high doses of oral vardenafil. British Medical Journal 333(7572):785.

149. Riazi K, et al. (2006) The proconvulsant effect of sildenafil in mice: role of nitric oxidecGMP pathway. British Journal of Pharmacology 147(8):935-943. 
150. Robello M, et al. (1996) Nitric oxide and GABAA receptor function in the rat cerebral cortex and cerebellar granule cells. Neuroscience 74(1):99-105 


\title{
CHAPTER 3
}

\section{PHOSPHODIESTERASES IN}

\section{NEURODEGENERATIVE DISORDERS}

\author{
E Bollen and J Prickaerts
}

IUBMB Life, 2012, 64 (12): 965-70 


\section{ABSTRACT}

Cyclic nucleotide phosphodiesterases (PDEs) are responsible for the breakdown of cyclic nucleotides CAMP and CGMP. As such, they are crucial regulators of levels of cyclic nucleotide-mediated signaling. CAMP- as well as cGMP-signaling have been associated with neuroplasticity and -protection, and influencing their levels in the cell by inhibition of PDEs has become a much studied target for treatment in a wide array of disorders, including neurodegenerative disorders. In this review, we will focus on the involvement of phosphodiesterases in neurodegenerative disorders. In comparison to preclinical work, data on human patients are scarce. Alzheimer's disease is associated with changes in PDE4, PDE7 and PDE8 expression in the brain. Altered functioning of PDE4 as well as PDE11 is associated with major depressive disorder. In multiple sclerosis, there are indications of alterations in expression of several PDE subtypes in the CNS, although evidence is indirect. In Huntington's disease and Parkinson's disease most research has focused on PDE1B and PDE10, because of their abundant presence in striatal neurons. In another rare, neurodegenerative striatal motor disorder, i.e. autosomal-dominant striatal degeneration, genetic defects in PDE8B gene are thought to underlie the neurodegenerative processes. Whereas the latter disorder has showed a causative dysfunction of PDEs, this does not hold for the neurodegenerative disorders discussed above, in which changes in PDE levels seemingly rather represent secondary changes and compensation to prior existing dysfunction. However, normalizing cyclic nucleotide signaling via PDE inhibition remains interesting for treatment of neurodegenerative disorders. 


\section{INTRODUCTION}

Cyclic adenosine monophosphate (cAMP) and cyclic guanosine monophosphate (cGMP) are both cyclic nucleotides. This nomenclature originates from the fact that their phosphate group is attached to two sugar hydroxyl groups, forming a ring or 'cyclic' structure. Cyclic nucleotides function as second messengers, which serve to relay and strongly amplify incoming signals at receptors on the cell surface. Cyclic nucleotides are thus important elements in signal transduction cascades (1). cAMP and cGMP are hydrophilic and therefore transmit signals within the cytosol, activating mainly protein kinases and ion channels. The study of cyclic nucleotide signaling in the last decades has revealed a stunning complexity (2). Not only is their effect dependent on concentration changes, there are temporary as well as spatial components to cyclic nucleotide signaling. Signals can vary in timeframe, from milliseconds to hours and often show a very strict compartmentalization in a specific part of the cell. This enables a wide variety of outcomes of CAMP and CGMP signaling, enabling the cell to react appropriately and nuanced on stimulation. These characteristics expose the requirement for a meticulous regulation of cyclic nucleotides. CAMP is synthesized from ATP by membrane-bound adenylyl cyclase (AC), which is mainly regulated in neurons by $G$-proteins and additionally stimulated by $\mathrm{Ca}^{2+}$ and calmodulin. Synthesis of ${ }^{2}$ GMP is regulated by guanylyl cyclase (GC), which converts GTP into cGMP. The key activator of the most common $\mathrm{GC}$ in neurons, i.e. soluble $\mathrm{GC}(\mathrm{sGC}$ ) is the gaseous signaling molecule nitric oxide (NO). However, the most important regulation of cyclic nucleotides is seemingly not achieved by its synthesis, but by the breakdown of cAMP and CGMP in their inactive forms, 5'AMP and 5'GMP respectively. The enzymes responsible for this process are phosphodiesterases (PDEs). The PDE superfamily consists of 11 subtypes (PDE1-PDE11) based largely on their sequence homology and are coded by 21 identified genes. In addition, each gene product may have multiple splice variants (e.g., PDE4D1-PDE4D9), which add up to a total of more than 100 different PDE proteins (3). Subtypes are differentiated based on several characteristics, such as 


\section{$\begin{array}{llllll}\text { Dual substrate } & 1 & 2 & 3 & 10 & 11\end{array}$ \\ $\begin{array}{llll}\text { CAMP } & \mathbf{4} & \mathbf{7} & \mathbf{8}\end{array}$ \\ CGMP $\quad 5 \quad 6 \quad 9$}

Figure 1. Scheme representing an overview of the specificity of the different PDE subfamilies for cAMP and/or cGMP.

localization, subcellular distribution, regulatory mechanisms, and enzymatic and kinetic properties. Most of these subtypes have more than one gene product (e.g., PDE4A, PDE4B, PDE4C, PDE4D). One fundamental distinction

between subfamilies is made on basis of the difference in affinity for the two distinct cyclic nucleotides. A differentiation is possible between cAMPspecific enzymes (PDE4,7,8), cGMP-specific enzymes (PDE5,6,9) and the so called dual substrate PDEs, that have affinity for both cyclic nucleotides (PDE1,2,3,10,11; for an overview see figure 1).

\section{CYCLIC NUCLEOTIDES AND PDES IN NEUROPLASTICITY}

As mentioned before, CAMP and CGMP, and concomitantly also adequate PDE functioning, are essential in cellular signaling and a variety of cellular functions. Furthermore, there are indications that they also affect neuronal cell survival, and when functioning incorrectly, may be involved in neurodegenerative processes (4).

Multiple downstream signaling targets of cyclic nucleotide signaling may account for these neuroprotective effects.

An important target of both cyclic nucleotides CAMP and CGMP in neuronal signaling is CAMP-responsive element binding protein (CREB) $(5,6)$. CREB is 
an activity-inducible transcription factor. Crucial to activation of CREB is its Serine 133 region, where multiple kinases can bind, including protein kinase A (PKA) and MAPK. Upon phosphorylation of Ser133, transcription coactivators CREB-binding protein and p300 bind to CREB, which offsets CREmediated transcription. Studies investigating CRE-regulated gene expression have associated CREB with up-regulation of neurotransmitters, growth factors and other signaling molecules with important functions in neuroplasticity and neuronal survival (6). Changes in phosphodiesterase expression and subsequent cyclic nucleotide signaling, will therefore affect the level of neuroprotection via CREB (7). Furthermore, CAMP and CGMP trigger the signal translocation of mitogen-actived protein kinase (MAPK) to the nucleus, resulting in downstream activation of anti-apoptotic factors such as bcl-2, and conversely inactivation of pro-apoptotic Bad (8-12). In vitro, CAMP elevation can rapidly recruit Tyrosine-kinase B (TrkB) receptors at the membrane surface by translocation from intracellular stores, which are the main receptors of brain-derived neurotropic factor (BDNF), thereby enhancing responsiveness to these neurotrophic factors which are essential in neuronal growth and survival (13). BDNF, which activates the MAPK pathway, is also one of the major gene products of CREB-mediated transcription which will be up-regulated upon cyclic nucleotide level elevation. Furthermore, BDNF/TrkB signaling is also able to activate phosphatidylinositol-3-kinase (PI3-K)/Akt cascades, which are generally renowned for their beneficial effects on neuronal survival neuronal survival via bcl-2 activation and Bad inactivation (12).

After acute damage to the CNS, elevation of cyclic nucleotide levels via inhibition of PDEs are able to ameliorate recovery processes. In various in vitro neurotoxicity models, including hypoxia/hypoglycemia-induced and glutamate-induced neurotoxicity, inhibition of PDEs shows a neuroprotective profile, possibly via the suppression of pro-apoptotic caspase-3 activity (14). Stimulation of CGMP signaling via CGMP analogues and selective inhibition of CGMP-specific PDE5 protects motor and non-motor neurons to acute reactive oxygen species (ROS)-induced neurotoxicity in vitro $(15,16)$. In that same study, no beneficial effects of other dual-substrate or cAMP-specific PDE inhibitors were reported. However, others have found that after spinal cord injury in preclinical settings, elevation of CAMP levels, e.g. via inhibition 
of PDE4, can enhance myelination, survival and growth of axons as well as functional recovery (17-19). Further, it was demonstrated that in preclinical models of ischemia PDE3 and PDE5 inhibition increase neurogenesis $(20,21)$ and also initiate structural changes in pre-existing neurons, such as synaptic sprouting and axonal remodeling, to facilitate functional recovery (21-23).

Because the importance of adequate cyclic nucleotide signaling in neuroplasticity and the distinct characteristics of the different PDE isoforms, PDE inhibition is being evaluated as a target for treatment of a broad spectrum of neurodegenerative disorders. However, in this review we chose to focus on genetic and protein expression studies on PDEs in neurodegeneration. Literature involving possible therapeutic effects of inhibition of PDEs are beyond the scope of this review (for review on PDE inhibition and CNS disorders see (24)).

\section{NEURODEGENERATIVE DISORDERS}

\section{Alzheimer's disease}

The most studied age-related neurodegenerative disorder is without any doubt Alzheimer's Disease (AD). The most prominent symptoms of the disease are the progressive decline in cognitive functions, in particular memory. Underlying these symptoms, the disease is characterized by synaptic and neuronal loss, leading to atrophy in mainly temporal and parietal lobe areas. Although the precise causes of the disease are still to be unraveled, the presence of amyloid $\beta$ plaques and neurofibrillary tangles in the brain are thought to be critical in these processes.

Both CAMP and CGMP have been suggested to be affected in AD. CAMP and especially its main target protein kinase, PKA, are thought to play a role in the etiology of neurofibrillary tangles via phosphorylation of tau $(25,26)$. A down-regulation of the AC/CAMP/PKA signaling pathway has been reported in human Alzheimer patients (27-29). As a main activator of CREB, a decrease 
in AC/CAMP/PKA signaling can also account for loss in synaptic plasticity and memory decline in $A D(30)$.

A number of studies have showed changes in expression of CAMP-specific PDEs mRNAs in $A D$ brains. Specifically, an increase in expression of PDE4A, PDE4B and PDE7A are observed in early stages of $A D$, whereas the severest clinical stages are associated with an increase in PDE8B expression in the brain regions associated with memory such as the enthorhinal cortex (31). Further, a decrease of CAMP-specific PDE7A mRNA was reported in white matter tracts, probably representing loss of oligodendrocytes (32). In addition, McLachlan and collegues examined the expression of isoforms of PDE4D, which in preclinical research has been suggested to be of particular importance for cognition, in the hippocampus of an $\operatorname{AD}$ patient $(33,34)$. Whereas they reported a reduction in expression of most isoforms of PDE4D (PDE4D3,5,6,7,8 and 9), the predominant short form of PDE4D in the human brain, PDE4D1, was strongly increased (33). These findings are in line with expectations of decreased CAMP-signaling in AD. Since activity of some subtypes of PDEs, such as PDE4, are regulated among other pathways by CAMP/PKA signaling itself $(3,35)$, PDE activity and expression are disturbed due to dysfunctional cell signaling. This implies that changes are secondary to the neuropathology rather than causative.

Similar to the CAMP/PKA pathway, the NO/cGMP pathway is also thought to play an important role in memory processes, and is known to be altered in aged brains $(36,37)$. Therefore, in literature CGMP is suggested to be linked to $A D$ (36). Just as for CAMP, the eventual downstream activation of CREB provides an interesting link to cognitive dysfunction and decreased synaptic plasticity in $A D(5,38)$. Along this line, anti-apoptotic effects of NO/cGMP have also been attributed to upregulation of $\mathrm{BCl}-2$, an anti-apoptotic protein of which the expression is decreased in $A D$ (39). However, in $A D$ postmortem brains, no changes in expression of CGMP-specific PDE9 or dualsubstrate PDE2 mRNA was found in comparison to control brains (40). 


\section{Depression}

Major depressive disorder (MDD) is generally considered a neurodegenerative disease, as it is thought to be associated with a decrease in neurogenesis in hippocampal dentate gyrus (41) and neuronal atrophy in the hippocampal CA3 area (42-45).

There is ample evidence from post-mortem human brain material that multiple components of the CAMP signaling cascade including AC, PKA and CREB are down-regulated in MDD (46-49). One subtype that has been of particular interest in this regard is the CAMP-specific PDE4. A very recent study quantified in vivo the binding of $11 \mathrm{C}$-(R)-rolipram, a specific PDE4 inhibitor, using PET-scans in unmedicated MDD patients (50). MDD patients were reported to show a significant reduction in PDE4 levels, representing a compensatory mechanism in response to decreased cAMP-signaling caused by decreased neurotransmission (51).

Wong and colleagues genotyped SNPs in all 21 genes coding for the phosphodiesterase superfamily, in a patient and control population (52). They found strong evidence for an association between certain polymorphisms in PDE9A and PDE11A and the diagnosis of MDD. In addition, their data are suggestive of an involvement of other PDE genes (PDE2A, PDE5A, PDE6C and PDE10A) in MDD (52). Furthermore, the PDE11A global haplotype was not only associated with the diagnosis of MDD, but also with response to antidepressant treatment (53), with some polymorphisms of PDE11A showing an significant correlation with remission on antidepressants.

\section{Multiple sclerosis}

Multiple Sclerosis (MS) is an auto-inflammatory disease of the CNS characterized by white matter lesions. Although the main cause of dysfunctions is due to inflammatory processes in CNS, disease progression and especially irreversible neurological disability are associated with axonal loss (54). CAMP has been identified as an important player in regulatory $T$ cell-mediated suppression (55). It is also known that increasing CAMP levels 
reduces inflammatory cellullar responses (56-58). A recent study reported that MS patients show increased mRNA expression in peripheral blood lymphocytes of several CAMP-targeting PDE subfamilies, I.e. PDE2, 3, 4 and 7 (59). Levels of expression in the brain itself are however lacking to our knowledge. Taken together, this suggests an important involvement of cAMP-signaling in neuro-inflammatory processes, possibly originating from changes in PDE levels.

\section{Striatal motor disorders}

PDEs are also thought to play a role in the pathological mechanisms leading to diseases characterized by striatal degeneration, such as Huntington's disease (HD) and Parkinson's disease (PD). In these disorders, specific interneuron populations in the striatum show disturbed dopaminergic innervations (60). This causes severe motor dysfunction, with HD being characterized by aberrant uncontrollable movement, while in PD the hallmark symptoms include slowness of movement and tremor. With regard to striatal neurodegeneration, the most studied PDE in this respect is dual substrate enzyme PDE10A, since PDE10A mRNA is being expressed at highest levels in the striatum (61). More specifically, PDE10A seems to be localized at the membrane of dendrites and dendritic spines in the GABAergic spiny projection interneurons (62). In postmortem brains of patients with severe HD, decreased levels of PDE10A in caudate nucleus, putamen and nucleus accumbens were reported when compared to control subjects (63).

Yet another dual substrate $\mathrm{PDE}, \mathrm{Ca}^{2+} /$ calmodulin-dependent $\mathrm{PDE} 1 \mathrm{~B}$, is expressed in a similar localization pattern as PDE10A, with highest levels in caudate putamen and nucleus accumbens $(61,64)$. In general, localization of PDE1B coincides with brain areas rich in D1 dopamine receptors and dopaminergic innervation. In the striatum, PDE1B is localized in spiny interneurons and is this strongly suggests that PDE1B is critically involved in its dopaminergic signaling. The fact that PDE1B and PDE10A have opposite effects on motor behavior points towards a differential involvement of the PDE subtypes in striatal intracellular signaling cascades. That is, PDE10A is predominantly expressed in medial spinal neurons in the striatopallidal $D_{2}$ 
indirect pathway. $D_{2}$ receptors are negatively coupled to $A C$ and their stimulation decreases CAMP levels leading to behavioral inhibition (65). In contrast, PDE1B is mainly expressed in the striatonigral $D_{1}$ direct pathway. $D_{1}$ receptors enhance $A C$ activation, leading to an increase of CAMP levels and behavioral activation (65).

Beyond motor function, HD is characterized by cognitive problems which occur even before onset of motor symptoms (66-68). A recent study has reported a hippocampal hyperactivity of PKA signaling in human HD patients (69). This was associated with a down-regulation in the expression of a number of PDE4 isoforms, including PDE4D1, in hippocampal areas which suggests that a hyperactivity of CAMP signaling could underlie early cognitive problems in HD.

A disease that is related to $\mathrm{HD}$ and $\mathrm{PD}$ is the rare Autosomal-dominant Striatal Degeneration (ADSD), which is characterized by dysfunction and morphological changes of the striatum (70). Clinical features resemble PD, however tremor is absent and response to L-Dopa treatment is poor. Recently it was shown using genetic linkage analysis of an ADSD family that $A D S D$ is caused by a complex frameshift mutation in the gene coding for PDE8B (71). This CAMP-specific PDE8B is highly expressed throughout the brain, with highest levels present in the putamen (71). In ADSD, PDE8B proteins are severely truncated with 5 out of 6 isoforms having lost all their functional domains. In this light, it might be relevant to take PDE8B into account for other striatal motor disorders, such as PD, although it might be easoned that, considering the unresponsiveness to L-Dopa treatment, ADSD is caused by mechanisms downstream of dopaminergic striatal signaling whereas the cause of PD is upstream.

\section{CONCLUSION}

Cyclic nucleotides are vital in intracellular signaling and neuroplasticity throughout the brain. Therefore, dysfunctional signaling can be expected to lead to important changes in functioning of cells and thus might lead to pathological outcomes. Indeed, many neurodegenerative diseases are 
associated with aberrant cyclic nucleotide signaling related to PDE expression. In some cases, such as in ADSD, evidence even points towards a direct causative link between PDE dysfunction and the disorder. In most other disorders however, such a straightforward association can not be made and the relationship seems rather a compensatory mechanism in response to dysfunctional signal transduction rather than the cause of neuropathology. Nevertheless abnormal PDE expression and function can be linked to abnormal cyclic nucleotide signaling and thus cellular function possibly leading to neurodegenerative processes. Normalizing cyclic nucleotide levels therefore represents at least a symptomatic approach in the treatment of neurodegenerative disorders. This explains the current large interest in PDE inhibitors as a pharmaceutical drug target. However, given the limited amount of studies that examined PDE expression in human patients, more research should be conducted in order to obtain a better understanding of the relationship between PDE functioning and neuropathology. 


\section{REFERENCES}

1. Francis, S. H., Blount, M. A., \& Corbin, J. D. (2011) Mammalian cyclic nucleotide phosphodiesterases: molecular mechanisms and physiological functions. Physiol Rev 91(2):651690.

2. Conti, M. \& Beavo, J. (2007) Biochemistry and physiology of cyclic nucleotide phosphodiesterases: essential components in cyclic nucleotide signaling. Annu Rev Biochem 76:481-511.

3. Bender, A. T. \& Beavo, J. A. (2006) Cyclic nucleotide phosphodiesterases: molecular regulation to clinical use. Pharmacol Rev 58(3):488-520.

4. Cui, Q. \& So, K. F. (2004) Involvement of cAMP in neuronal survival and axonal regeneration. Anat Sci Int 79(4):209-212.

5. Lu, Y. F. \& Hawkins, R. D. (2002) Ryanodine receptors contribute to cGMP-induced late-phase LTP and CREB phosphorylation in the hippocampus. J Neurophysiol 88(3):1270-1278.

6. Merz, K., Herold, S., \& Lie, D. C. (2011) CREB in adult neurogenesis--master and partner in the development of adult-born neurons? Eur J Neurosci 33(6):1078-1086.

7. Jancic, D., Lopez de Armentia, M., Valor, L. M., Olivares, R., \& Barco, A. (2009) Inhibition of cAMP response element-binding protein reduces neuronal excitability and plasticity, and triggers neurodegeneration. Cereb Cortex 19(11):2535-2547.

8. Doronzo, G., Viretto, M., Russo, I., Mattiello, L., Di Martino, L., et al. (2011) Nitric oxide activates PI3-K and MAPK signalling pathways in human and rat vascular smooth muscle cells: influence of insulin resistance and oxidative stress. Atherosclerosis 216(1):44-53.

9. Bonni, A., Brunet, A., West, A. E., Datta, S. R., Takasu, M. A., et al. (1999) Cell survival promoted by the Ras-MAPK signaling pathway by transcription-dependent and -independent mechanisms. Science 286(5443):1358-1362.

10. Boucher, M. J., Morisset, J., Vachon, P. H., Reed, J. C., Laine, J., et al. (2000) MEK/ERK signaling pathway regulates the expression of $\mathrm{Bcl}-2, \mathrm{Bcl}-\mathrm{X}(\mathrm{L})$, and $\mathrm{Mcl}-1$ and promotes survival of human pancreatic cancer cells. J Cell Biochem 79(3):355-369.

11. Jin, K., Mao, X. O., Zhu, Y., \& Greenberg, D. A. (2002) MEK and ERK protect hypoxic cortical neurons via phosphorylation of Bad. J Neurochem 80(1):119-125.

12. Brunet, A., Datta, S. R., \& Greenberg, M. E. (2001) Transcription-dependent and -independent control of neuronal survival by the PI3K-Akt signaling pathway. Curr Opin Neurobiol 11(3):297305.

13. Meyer-Franke, A., Wilkinson, G. A., Kruttgen, A., Hu, M., Munro, E., et al. (1998) Depolarization and CAMP elevation rapidly recruit TrkB to the plasma membrane of CNS neurons. Neuron 21(4):681-693.

14. Chen, R. W., Williams, A. J., Liao, Z., Yao, C., Tortella, F. C., et al. (2007) Broad spectrum neuroprotection profile of phosphodiesterase inhibitors as related to modulation of cell-cycle elements and caspase-3 activation. Neurosci Lett 418(2):165-169.

15. Nakamizo, T., Kawamata, J., Yoshida, K., Kawai, Y., Kanki, R., et al. (2003) Phosphodiesterase inhibitors are neuroprotective to cultured spinal motor neurons. J Neurosci Res 71(4):485-495.

16. Urushitani, M., Inoue, R., Nakamizo, T., Sawada, H., Shibasaki, H., et al. (2000) Neuroprotective effect of cyclic GMP against radical-induced toxicity in cultured spinal motor neurons. J Neurosci Res 61(4):443-448.

17. Neumann, S., Bradke, F., Tessier-Lavigne, M., \& Basbaum, A. I. (2002) Regeneration of sensory axons within the injured spinal cord induced by intraganglionic cAMP elevation. Neuron 34(6):885-893. 
18. Nikulina, E., Tidwell, J. L., Dai, H. N., Bregman, B. S., \& Filbin, M. T. (2004) The phosphodiesterase inhibitor rolipram delivered after a spinal cord lesion promotes axonal regeneration and functional recovery. Proc Natl Acad Sci U S A 101(23):8786-8790.

19. Qiu, J., Cai, D., Dai, H., McAtee, M., Hoffman, P. N., et al. (2002) Spinal axon regeneration induced by elevation of cyclic AMP. Neuron 34(6):895-903.

20. Tanaka, Y., Tanaka, R., Liu, M., Hattori, N., \& Urabe, T. (2010) Cilostazol attenuates ischemic brain injury and enhances neurogenesis in the subventricular zone of adult mice after transient focal cerebral ischemia. Neuroscience 171(4):1367-1376.

21. Zhang, R., Wang, Y., Zhang, L., Zhang, Z., Tsang, W., et al. (2002) Sildenafil (Viagra) induces neurogenesis and promotes functional recovery after stroke in rats. Stroke 33(11):2675-2680.

22. Ding, G., Jiang, Q., Li, L., Zhang, L., Zhang, Z. G., et al. (2008) Magnetic resonance imaging investigation of axonal remodeling and angiogenesis after embolic stroke in sildenafil-treated rats. J Cereb Blood Flow Metab 28(8):1440-1448.

23. Zhang, L., Zhang, R. L., Wang, Y., Zhang, C., Zhang, Z. G., et al. (2005) Functional recovery in aged and young rats after embolic stroke: treatment with a phosphodiesterase type 5 inhibitor. Stroke 36(4):847-852.

24. Menniti, F. S., Faraci, W. S., \& Schmidt, C. J. (2006) Phosphodiesterases in the CNS: targets for drug development. Nat Rev Drug Discov 5(8):660-670.

25. Shi, J., Qian, W., Yin, X., Iqbal, K., Grundke-Iqbal, I., et al. (2011) Cyclic AMP-dependent protein kinase regulates the alternative splicing of tau exon 10: a mechanism involved in tau pathology of Alzheimer disease. 286(16):14639-14648.

26. Hanger, D. P., Anderton, B. H., \& Noble, W. (2009) Tau phosphorylation: the therapeutic challenge for neurodegenerative disease. Trends Mol Med 15(3):112-119.

27. Bonkale, W. L., Cowburn, R. F., Ohm, T. G., Bogdanovic, N., \& Fastbom, J. (1999) A quantitative autoradiographic study of [3H]cAMP binding to cytosolic and particulate protein kinase $A$ in postmortem brain staged for Alzheimer's disease neurofibrillary changes and amyloid deposits. Brain Res 818(2):383-396.

28. Garcia-Jimenez, A., Cowburn, R. F., Ohm, T. G., Bogdanovic, N., Winblad, B., et al. (1999) Quantitative autoradiography of [3H]forskolin binding sites in post-mortem brain staged for Alzheimer's disease neurofibrillary changes and amyloid deposits. Brain Res 850(1-2):104-117.

29. Liang, Z., Liu, F., Grundke-Iqbal, I., Iqbal, K., \& Gong, C.-X. (2007) Down-regulation of cAMPdependent protein kinase by over-activated calpain in Alzheimer disease brain. $J$ Neurochem 103(6):2462-2470.

30. Scott Bitner, R. (2011) Cyclic AMP response element-binding protein (CREB) phosphorylation: a mechanistic marker in the development of memory enhancing Alzheimer's disease therapeutics. Biochem Pharmacol 83:705-714.

31. Perez-Torres, S., Cortes, R., Tolnay, M., Probst, A., Palacios, J. M., et al. (2003) Alterations on phosphodiesterase type 7 and 8 isozyme mRNA expression in Alzheimer's disease brains examined by in situ hybridization. Exp Neurol 182(2):322-334.

32. Brun, A. \& Englund, E. (1986) A white matter disorder in dementia of the Alzheimer type: a pathoanatomical study. Ann Neurol 19:253-262.

33. McLachlan, C. S., Chen, M. L., Lynex, C. N., Goh, D. L., Brenner, S., et al. (2007) Changes in PDE4D isoforms in the hippocampus of a patient with advanced Alzheimer disease. Arch Neurol 64(3):456-457.

34. Zhang, H. T., Huang, Y., Suvarna, N. U., Deng, C., Crissman, A. M., et al. (2005) Effects of the novel PDE4 inhibitors MEM1018 and MEM1091 on memory in the radial-arm maze and inhibitory avoidance tests in rats. Psychopharmacology 179(3):613-619. 
35. Sette, C. \& Conti, M. (1996) Phosphorylation and activation of a cAMP-specific phosphodiesterase by the cAMP-dependent protein kinase. Involvement of serine 54 in the enzyme activation. J Biol Chem 271(28):16526-16534.

36. Domek-Lopacinska, K. U. \& Strosznajder, J. B. (2010) Cyclic GMP and nitric oxide synthase in aging and Alzheimer's disease. Mol Neurobiol 41(2-3):129-137.

37. Blokland, A., Schreiber, R., \& Prickaerts, J. (2006) Improving memory: a role for phosphodiesterases. Curr Pharm Des 12(20):2511-2523.

38. Saura, C. A. \& Valero, J. (2011) The role of CREB signaling in Alzheimer's disease and other cognitive disorders. Rev Neurosci 22(2):153-169.

39. Ciani, E., Guidi, S., Bartesaghi, R., \& Contestabile, A. (2002) Nitric oxide regulates cGMPdependent cAMP-responsive element binding protein phosphorylation and $\mathrm{Bcl}-2$ expression in cerebellar neurons: implication for a survival role of nitric oxide. J Neurochem 82(5):1282-1289.

40. Reyes-Irisarri, E., Markerink-Van Ittersum, M., Mengod, G., \& de Vente, J. (2007) Expression of the cGMP-specific phosphodiesterases 2 and 9 in normal and Alzheimer's disease human brains. Eur $J$ Neurosci 25(11):3332-3338.

41. Boldrini, M., Underwood, M. D., Hen, R., Rosoklija, G. B., Dwork, A. J., et al. (2009) Antidepressants increase neural progenitor cells in the human hippocampus. Neuropsychopharmacology 34(11):2376-2389.

42. Bremner, J. D., Narayan, M., Anderson, E. R., Staib, L. H., Miller, H. L., et al. (2000) Hippocampal volume reduction in major depression. Am J Psychiatry 157(1):115-118.

43. Sheline, Y. I., Gado, M. H., \& Kraemer, H. C. (2003) Untreated depression and hippocampal volume loss. Am J Psychiatry 160(8):1516-1518.

44. Sheline, Y. I., Wang, P. W., Gado, M. H., Csernansky, J. G., \& Vannier, M. W. (1996) Hippocampal atrophy in recurrent major depression. Proc Natl Acad Sci U S A 93(9):3908-3913.

45. Tsopelas, C., Stewart, R., Savva, G. M., Brayne, C., Ince, P., et al. (2011) Neuropathological correlates of late-life depression in older people. Br J Psychiatry 198(2):109-114.

46. Cowburn, R. F., Marcusson, J. O., Eriksson, A., Wiehager, B., \& O'Neill, C. (1994) Adenylyl cyclase activity and G-protein subunit levels in postmortem frontal cortex of suicide victims. Brain Res 633(1-2):297-304.

47. Dowlatshahi, D., MacQueen, G. M., Wang, J. F., \& Young, L. T. (1998) Increased temporal cortex CREB concentrations and antidepressant treatment in major depression. Lancet 352(9142):17541755.

48. Dwivedi, Y., Conley, R. R., Roberts, R. C., Tamminga, C. A., \& Pandey, G. N. (2002) [(3)H]cAMP binding sites and protein kinase a activity in the prefrontal cortex of suicide victims. Am $J$ Psychiatry 159(1):66-73.

49. Reiach, J. S., Li, P. P., Warsh, J. J., Kish, S. J., \& Young, L. T. (1999) Reduced adenylyl cyclase immunolabeling and activity in postmortem temporal cortex of depressed suicide victims. J Affect Disord 56(2-3):141-151.

50. Fujita, M., Hines, C. S., Zoghbi, S. S., Mallinger, A. G., Dickstein, L. P., et al. (2012) Downregulation of Brain Phosphodiesterase Type IV Measured with (11)C-(R)-Rolipram Positron Emission Tomography in Major Depressive Disorder. Biol Psychiatry 72(7):548-554.

51. O'Donnell, J. M. \& Xu, Y. (2012) Evidence for global reduction in brain cyclic adenosine monophosphate signaling in depression. Biol Psychiatry 72(7):524-525.

52. Wong, M. L., Whelan, F., Deloukas, P., Whittaker, P., Delgado, M., et al. (2006) Phosphodiesterase genes are associated with susceptibility to major depression and antidepressant treatment response. Proc Natl Acad Sci U S A 103(41):15124-15129.

53. Luo, H. R., Wu, G. S., Dong, C., Arcos-Burgos, M., Ribeiro, L., et al. (2009) Association of PDE11A global haplotype with major depression and antidepressant drug response. Neuropsychiatr Dis Treat 5:163-170. 
54. Reynolds, R., Roncaroli, F., Nicholas, R., Radotra, B., Gveric, D., et al. (2011) The neuropathological basis of clinical progression in multiple sclerosis. Acta Neuropathol 122(2):155-170.

55. Bopp, T., Becker, C., Klein, M., Klein-Hessling, S., Palmetshofer, A., et al. (2007) Cyclic adenosine monophosphate is a key component of regulatory $\mathrm{T}$ cell-mediated suppression. J Exp Med 204(6):1303-1310.

56. Dong, R. P., Umezawa, Y., Ikushima, H., Munakata, Y., Schlossman, S. F., et al. (1997) Different regulatory effects of pentoxifylline on human $\mathrm{T}$ cell activation pathways. J Clin Immunol 17(3):247-252.

57. Silva, J. C., Rocha, M. F., Lima, A. A., Brito, G. A., de Menezes, D. B., et al. (2000) Effects of pentoxifylline and nabumetone on the serum levels of IL-1beta and TNFalpha in rats with adjuvant arthritis. Inflamm Res 49(1):14-19.

58. Folcik, V. A., Smith, T., O'Bryant, S., Kawczak, J. A., Zhu, B., et al. (1999) Treatment with BBB022A or rolipram stabilizes the blood-brain barrier in experimental autoimmune encephalomyelitis: an additional mechanism for the therapeutic effect of type IV phosphodiesterase inhibitors. J Neuroimmunol 97(1-2):119-128.

59. Mizrachi, K., Aricha, R., Feferman, T., Kela-Madar, N., Mandel, I., et al. (2010) Involvement of phosphodiesterases in autoimmune diseases. J Neuroimmunol 220(1-2):43-51.

60. Vonsattel, J. P., Myers, R. H., Stevens, T. J., Ferrante, R. J., Bird, E. D., et al. (1985) Neuropathological classification of Hungtington's disease. J Neuropathol Exp Neurol 44:559-577.

61. Lakics, V., Karran, E. H., \& Boess, F. G. (2010) Quantitative comparison of phosphodiesterase mRNA distribution in human brain and peripheral tissues. Neuropharmacology 59(6):367-374.

62. Xie, Z., Adamowicz, W. O., Eldred, W. D., Jakowski, A. B., Kleiman, R. J., et al. (2006) Cellular and subcellular localization of PDE10A, a striatum-enriched phosphodiesterase. Neuroscience 139(2):597-607.

63. Hebb, A. L., Robertson, H. A., \& Denovan-Wright, E. M. (2004) Striatal phosphodiesterase mRNA and protein levels are reduced in Huntington's disease transgenic mice prior to the onset of motor symptoms. Neuroscience 123(4):967-981.

64. Polli, J. W. \& Kincaid, R. L. (1994) Expression of a calmodulin-dependent phosphodiesterase isoform (PDE1B1) correlates with brain regions having extensive dopaminergic innervation. $J$ Neurosci 14(3 Pt 1):1251-1261.

65. Nishi, A. \& Snyder, G. L. (2010) Advanced research on dopamine signaling to develop drugs for the treatment of mental disorders: biochemical and behavioral profiles of phosphodiesterase inhibition in dopaminergic neurotransmission. J Pharmacol Sci 114(1):6-16.

66. Foroud, T., Siemers, E., Kleindorfer, D., Bill, D. J., Hodes, M. E., et al. (1995) Cognitive scores in carriers of Huntington's disease gene compared to noncarriers. Ann Neurol 37(5):657-664.

67. Lawrence, A. D., Sahakian, B. J., Hodges, J. R., Rosser, A. E., Lange, K. W., et al. (1996) Executive and mnemonic functions in early Huntington's disease. Brain 119 ( Pt 5):1633-1645.

68. Lemiere, J., Decruyenaere, M., Evers-Kiebooms, G., Vandenbussche, E., \& Dom, R. (2004) Cognitive changes in patients with Huntington's disease (HD) and asymptomatic carriers of the HD mutation--a longitudinal follow-up study. J Neurol 251(8):935-942.

69. Giralt, A., Saavedra, A., Carreton, O., Xifro, X., Alberch, J., et al. (2011) Increased PKA signaling disrupts recognition memory and spatial memory: role in Huntington's disease. Hum Mol Genet 20(21):4232-4247.

70. Kuhlenbaumer, G., Ludemann, P., Schirmacher, A., De Vriendt, E., Hunermund, G., et al. (2004) Autosomal dominant striatal degeneration (ADSD): clinical description and mapping to 5q135q14. Neurology 62(12):2203-2208.

71. Appenzeller, S., Schirmacher, A., Halfter, H., Baumer, S., Pendziwiat, M., et al. (2010) Autosomaldominant striatal degeneration is caused by a mutation in the phosphodiesterase $8 \mathrm{~B}$ gene. Am J Hum Genet 86(1):83-87. 



\section{CHAPTER 4}

\section{IMPROVED LONG-TERM MEMORY VIA \\ ENHANCING CGMP-PKG SIGNALING REQUIRES \\ CAMP-PKA SIGNALING}

Bollen E*, Puzzo D*, Rutten K, Privitera L, De Vry J, Vanmierlo T, Kenis G, Palmeri A, D'Hooge R, Balschun D, Steinbusch HWM, Blokland A, Prickaerts J. 


\section{ABSTRACT}

Memory consolidation is defined by the stabilization of a memory trace after acquisition, and consists of numerous molecular cascades that mediate synaptic plasticity. Commonly, a distinction is made between an early and a late consolidation phase, in which early refers to the first hours in which labile synaptic changes occur, whereas late consolidation relates to stable and long-lasting synaptic changes induced by de novo protein synthesis. How these phases are linked at a molecular level is not yet clear. Here we studied the interaction of the cyclic nucleotide-mediated pathways during the different phases of memory consolidation in rodents. In addition, the same pathways were studied in a model of neuronal plasticity, long-term potentiation (LTP). We demonstrated that CGMP/PKG signaling mediates early memory consolidation as well as early phase-LTP, while cAMP/PKA signaling mediates late consolidation and late-phase-like LTP. Additionally, we show for the first time that early-phase cGMP/PKG-signaling requires late-phase CAMP/PKA-signaling in both LTP and long-term memory formation. 


\section{INTRODUCTION}

Memory is a complex, multifaceted phenomenon, in which a differentiation is made between acquisition, consolidation and retrieval processes. Each of these processes relies on specific molecular mechanisms $(1,2)$. Consolidation is a temporally graded process, in which newly acquired information becomes stabilized and stored in memory traces (3). The cellular substrates of memory consolidation are molecular transformations at the participating synapses. They are labile and protein-synthesis independent during the first hours $(<3 \mathrm{~h})$ after learning, but implement long-lasting structural modifications during later phases which rely on de novo protein synthesis. It has become evident that cyclic nucleotides, i.e. cyclic AMP (cAMP) and cyclic GMP (cGMP), play an important role in memory consolidation and in a specific neuroplasticity phenomenon which is generally regarded as the neural correlate of memory, i.e. long-term potentiation (LTP) (4-10). Furthermore, cyclic nucleotides have been suggested to be differentially involved in distinct phases of the memory consolidation process. That is, cGMP has been attributed a role in early consolidation, while CAMP is implicated in late consolidation processes $(11,12)$. However, how these cyclic nucleotide-mediated memory processes are linked to each other is not clear.

Phosphodiesterases (PDEs) are enzymes that hydrolyze CAMP and/or cGMP, in the body and the brain. It has been previously shown that different inhibitors of PDEs enhance memory formation in rodents in a wide array of memory tasks (13). These studies led to the identification of a number of PDE subfamilies as promising targets for memory improvement, in specific the PDE1, PDE2, PDE4, PDE5 and PDE9 subtype. In this study we focused on cAMP-selective PDE4 (14-17), cGMP-selective PDE5 $(18,19)$, and PDE2, which hydrolyzes both CAMP and $\operatorname{CGMP}(11,20)$. It has been suggested that the cognition-enhancing effects of PDE inhibitors are related to activation of CAMP/protein kinase A (PKA)/CAMP responsive element binding protein (CREB) and CGMP/protein kinase G (PKG)/CREB signaling pathways $(11,13$, 21), which are both associated with late phase LTP (L-LTP). In contrast to the transient early phase of LTP (E-LTP), this long-lasting form of LTP is dependent on protein synthesis via CREB phosphorylation $(5-7,14)$. In the 
present study, the exact role of hippocampal cyclic nucleotides in early versus late phases of memory consolidation in the ORT as well as in an early and late phase of LTP was investigated.

We hypothesized that early consolidation of object memory is dependent on CGMP-PKG signaling and that late consolidation is dependent on CAMP-PKA signaling in the hippocampus. To investigate these mechanisms and their relationship in an in vivo behavioral setup, we co-administered PDE inhibitors peripherally and protein kinase (PK) inhibitors intra-hippocampally. We assessed the effect of PDE inhibition on early and late consolidation processes in an object recognition task (ORT) and whenever memory improvement was observed, we aimed to block this effect with centrally administered PKG and PKA inhibitors. In addition, the involvement of the two cyclic nucleotide-mediated pathways was evaluated in different phases of LTP in hippocampal slices in vitro. This study provides further evidence for differential time-dependent contribution of CAMP and CGMP in memory consolidation and synaptic plasticity, and it shows that for long-term memory improvement the CAMP-PKA pathway is required after CGMP signaling.

\section{METHODS}

\section{Subjects}

All experimental procedures were approved by the local ethical committee for animal experiments of Maastricht University or of University of Catania, and were in agreement with the respective governmental guidelines. For behavioral experiments, 3 to 6 -months old male Wistar rats (Charles River, Sulzfeld, Germany) were used. For electrophysiological studies C57BL/6J male mice, 3-months old, were obtained from a breeding colony housed in the animal facility of the University of Catania.

Rats were individually housed in standard type 3 Makrolon cages on sawdust bedding. The animals were held in an air-conditioned room (approximately $21^{\circ} \mathrm{C}$ ) and had free access to food and water. A softly playing radio provided 
background noise. A reversed light-dark cycle was applied in the room (lights on between 7.00 PM and 7.00 AM) in order to test the animals during their naturally active period. Housing conditions of the mice were the same as for rats, except that they were housed socially with 5 animals per cage.

\section{Object recognition}

Apparatus. Animals were subjected to the object recognition task (ORT). This task was performed in a circular arena with a diameter of $83 \mathrm{~cm}$ and walls of $40 \mathrm{~cm}$ high. The backside half of the arena wall was made of grey polyvinyl chloride, and the front half of transparent polyvinyl chloride. The objects consisted of four sets including 1) a cone made of brass, 2) a transparent glass bottle, 3) a massive metal beam with two holes and 4) a massive aluminum cube with a tapered top. The animals were unable to displace the objects. All objects were present in three-fold and were cleaned thoroughly after each trial to remove all olfactory traces.

Procedure. During the first weeks of the experiment, the animals were habituated to handling and observation by the experimenter. In addition, animals were familiarized to the environment and procedures.

ORT procedures were adapted from previous studies (36), with modifications as described previously (37). During the ORT, rats were put in a circular arena, facing the middle of the transparent wall. In the arena, two identical objects were placed approximately $10 \mathrm{~cm}$ from the wall. The animal was given 3 minutes to explore the environment and objects. The time spent exploring the separate objects was manually scored using a personal computer by an experimenter that was blinded to the conditions tested. Exploration was defined as directing the nose to the object, with a maximal distance between nose and object of $2 \mathrm{~cm}$. Leaning or sitting on the object was not considered exploratory behavior. After $24 \mathrm{~h}$, the rat was put back in the arena. In this second trial, one of the objects from the initial trial was replaced by another object. Again the rat was allowed to explore the objects for 3 minutes and object exploration times were recorded. An increase in time spent exploring the new object was interpreted as recognition of the previously encountered objects. A relative measure of discrimination 
between the old and new object was calculated, which was corrected for total exploration time. The resulting discrimination index (exploration time new object - exploration time old object)/(exploration time new object + exploration time old object) reflects recognition memory independent of normal exploratory behavior (38). Animals that did not show normal exploration $(<7 \mathrm{sec})$ were excluded from analysis.

The test regime included two $24 \mathrm{~h}$ interval testing sessions a week. We opted for a delay interval of $24 \mathrm{~h}$, at which under normal, non-treated circumstances, no discrimination between the objects occurs, which allows for an improvement of long-term memory performance following drug treatment. Testing was done between 9.00 AM and 17.00 PM under red light conditions.

\section{Drug administration}

Cannula placement. To inject into the CA1 of the hippocampus, cannulae were implanted by means of stereotaxic surgery. Animals were fixed in a stereotaxic frame after induction of full anesthesia with isoflurane (induction: $5 \%$; maintenance: $2 \%$ ). Cannulae were placed bilaterally in hand drilled holes above the CA1 region of the hippocampus at following coordinates: $3.6 \mathrm{~mm}$ anterior, $\pm 3.0 \mathrm{~mm}$ lateral and $3.0 \mathrm{~mm}$ ventral from bregma (39). When cannulae were in place they were fixed to the skull using acrylic dental cement $\left(\right.$ Paladur $^{\circledR}$ ) and small screws. Animals were allowed to recover from surgery for two weeks before the testing procedures started. In order to verify correct cannula location, the central infusion procedure was repeated at the end of the experiment injecting $1 \mu \mathrm{l} 5 \%$ methylene blue/95\% saline bilaterally. Ten minutes after the methylene blue injections, animals were decapitated and their brains were rapidly removed. The correct injection location was verified by evaluating of the methylene blue discoloration of the hippocampus.

Treatments. We administered three selective PDE inhibitors: PDE2 inhibitor BAY 60-7550 (IC50 4.7 nM; kindly donated by BAYER AG, Wuppertal, Germany), PDE4 inhibitor rolipram (IC50 1.5 nM; Sigma Aldrich, Zwijndrecht, 
Netherlands) and PDE5 inhibitor vardenafil (IC50 $0.7 \mathrm{nM}$; kindly donated by BAYER AG). All three PDE inhibitors have been shown to cross the bloodbrain barrier (40-42). The PKA inhibitor Rp-8-Br-cAMPS and PKG inhibitor $\mathrm{Rp}-8-\mathrm{Br}-\mathrm{cGMPS}$ were obtained from Biolog (Bremen, Germany). First, rats were treated solely with the PDE inhibitors (combined with central vehicle (saline) infusion) on both time points. Whenever a PDE inhibitor significantly improved memory performance, we subsequently attempted to block this effect using co-infusion of a PKG or PKA inhibitor. Drugs were administrated immediately (i.e. 4-10 minutes after the start of the learning trial) or $3 \mathrm{~h}$ after the first trial. This resulted in a total of 17 treatment combinations of different PDE inhibitors (vehicle, PDE2, PDE4 or PDE5 inhibition) with the protein kinase inhibitors (vehicle, PKA or PKG inhibitor) on the different time points of administration ( $\mathrm{T} 1+\mathrm{Oh}$ or $\mathrm{T} 1+3 \mathrm{~h})$. All solutions were freshly dissolved on the day of testing. Peripheral drug administration of the PDEi was done either orally (BAY 60-7550 $3 \mathrm{mg} / \mathrm{kg}$ and vardenafil $1 \mathrm{mg} / \mathrm{kg}$ ) or intraperitoneally (rolipram $0.03 \mathrm{mg} / \mathrm{kg}$ ). All PDE inhibitors were dissolved in the same vehicle (98\% methyl cellulose [tylose] solution $(0.5 \%$ ) and $2 \%$ tween80) and administered in a volume of $2 \mathrm{ml} / \mathrm{kg}$. Inhibitors of protein kinases were administered directly into the hippocampus via the surgically implanted guiding cannulae. Using a micropump, $0.5 \mu \mathrm{l}$ saline $(0.9 \% \mathrm{NaCl})$ or a saline solution containing RP-8-Br-cAMPS or RP-8-Br-cGMPS (both 2 $\mu \mathrm{g} / \mu \mathrm{l})$ was injected bilaterally over a time period of one minute through the infusion cannulae which were connected to two $10 \mu \mathrm{l}$ Hamilton syringes by polyethylene tubes. The injection needles were left in place for an additional minute to prevent reflux of infused drugs along the cannula track. Drug dosages and administration routes were based on previous studies (20, 43, 44). For electrophysiological experiments, vardenafil (10 nM), rolipram (100nM), Rp-8-Br-cGMPS $(10 \mu \mathrm{M})$ and Rp-8-Br-cAMPS $(20 \mu \mathrm{M})$ were diluted in artificial CSF (ACSF) immediately before use, and applied in the bath solution at different time points before or after the induction of LTP. The concentrations were based on previous literature $(22,29)$.

\section{Electrophysiology}

Electrophysiological recordings were performed as previously described (29). Briefly, transverse hippocampal slices $(400 \mu \mathrm{m})$ were cut and transferred to a 
recording chamber where they were maintained at $29^{\circ} \mathrm{C}$ and perfused with ACSF (flow rate $2 \mathrm{ml} / \mathrm{min}$ ) continuously bubbled with $95 \% \mathrm{O} 2$ and $5 \% \mathrm{CO} 2$. The ACSF composition was composed of the following (in $\mathrm{mM}$ ): $124.0 \mathrm{NaCl}$, $4.4 \mathrm{KCl}, 1.0 \mathrm{Na} 2 \mathrm{HPO} 4,25.0 \mathrm{NaHCO} 3,2.0 \mathrm{CaCl}$, 2.0 MgSO4, and 10.0 glucose. Field extracellular recordings were performed by stimulating the Schaeffer collateral fibers through a bipolar tungsten electrode and recording in CA1 stratum radiatum with a glass electrode filled with ACSF. A 15 min baseline was recorded every minute at an intensity that evoked a response approximately $35 \%$ of the maximum evoked response. Early-LTP was induced by a weak tetanus ( 4 pulses at $100 \mathrm{~Hz}$, with the bursts repeated at $5 \mathrm{~Hz}$ and one tetanus of 10-burst trains) $(29,45,46)$. Responses were recorded for $3 \mathrm{~h}$ after tetanization and measured as field excitatory post-synaptic potentials (f-EPSP) slope expressed as percentage of baseline. The results were expressed as mean \pm standard error mean.

\section{Statistical analysis}

A one-way ANOVA was performed to investigate effects of treatment on discrimination index for every type of PDE inhibitor separately. In case of significant between group effects, we used Fischer's LSD for post hoc comparisons. For LTP, statistical analysis was performed with 2-way ANOVA with repeated measures. For all analyses, significance level was set at 0.05 . 


\section{RESULTS}

\section{Object memory}

\section{Effect of cGMP-selective PDE5 inhibition is PKG-dependent and limited to early consolidation}

Memory performance was assessed in the ORT with a $24 \mathrm{~h}$ interval in rats. Differences were found in discrimination performance for the different PDE5 inhibition conditions $(F(4,93)=3.18 ; p<0.05)$, which are summarized in figure $1 \mathrm{~A}$. When compared to vehicle condition, vardenafil in combination with an intra-hippocampal saline injection enhanced memory when given immediately $(T+0 h)$ after the first trial $(p<0.05)$, but not when administered 3 $\mathrm{h}$ after the first trial (n.s.). Memory improvement after immediate vardenafil treatment remained when the administration of the PDE5 inhibitor was combined with an intra-hippocampal injection of PKA inhibitor (n.s.). However, when vardenafil was co-administered with PKG inhibition directly after learning, the memory enhancement tended to be reduced $(p=0.056)$.

\section{Effect of cAMP-selective PDE4 inhibition is PKA-dependent and limited}

\section{to late consolidation}

Differences were found on discrimination performance for the different PDE4 inhibition conditions $(F(4,94)=2.74 ; p<0.05)$, which are summarized in figure 1B. Rolipram improved memory when it was injected $3 \mathrm{~h}$ after the first trial, in combination with intra-hippocampal saline infusions $(p<0.05)$. However, this improvement was not present when drugs were administered immediately after learning (n.s.). The memory enhancement after delayed rolipram administration $(T+3 h)$ was unaffected when RP-8-Br-cGMPS was intra-hippocampally co-administered (n.s.), whereas RP-8-Br-cAMPS blocked the improvement $(p<0.05)$. 

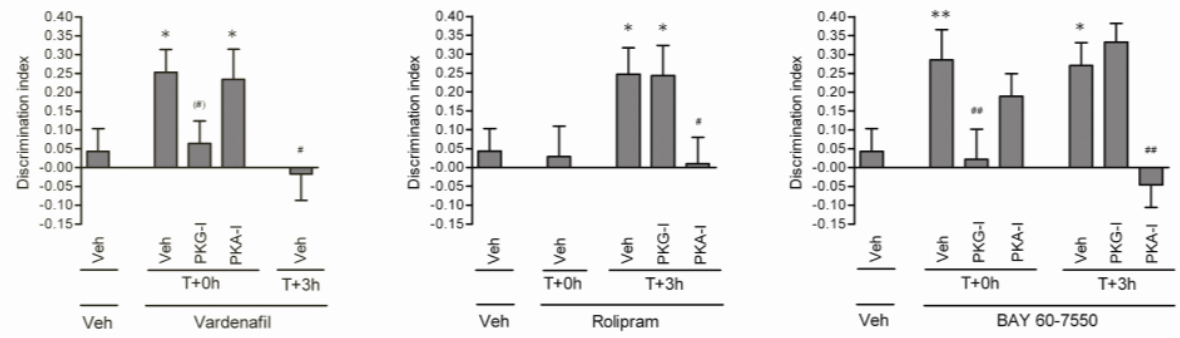

Figure 1. The effects of PDE inhibition treatment (A: PDE5 inhibition - Vardenafil $1 \mathrm{mg} / \mathrm{kg}$, p.o., $\mathrm{n}=26 / 18 / 18 / 18 / 18$; B: PDE4 inhibition - Rolipram $0.03 \mathrm{mg} / \mathrm{kg}$, i.p., $\mathrm{n}=26 / 18 / 18 / 19 / 18$; C: PDE2 inhibition - BAY $60-75503 \mathrm{mg} / \mathrm{kg}$, p.o., $\mathrm{n}=26 / 19 / 18 / 19 / 18 / 16 / 19)$ on discrimination performance (discrimination index; means + S.E.M.) in a $24-h$-delay object recognition task. PDE inhibition was administered immediately after $(T+0 h)$ or $3 \mathrm{~h}(T+3 h)$ after the first trial. When PDE inhibition combined with saline intra-hippocampal injections (veh) yielded significant improvement of discrimination, we subsequently combined PDE treatment with inhibitors of PKG (PKG-I; RP-8-Br-cGMPS $1 \mu \mathrm{g} / \mathrm{kg}$ ) or PKA (PKA-I; RP-8-Br-CAMPS $1 \mu \mathrm{g} / \mathrm{kg}$ ). Asterisks indicate significant differences $\left({ }^{*} p<0.05,{ }^{* *} p<0.01\right)$ of PDE inhibition treatment from vehicle condition. Hashes indicate a significant reversal of PDEinduced memory improvement $\left({ }^{(\#)} p=0.056,{ }^{\#} p<0.05\right.$, $\#$ \# $<0.01$ ).

\section{Effect of PDE2 inhibition involves both early and late consolidation and is PKG- and PKA-dependent.}

Differences were found on discrimination performance for the different PDE2 inhibition conditions $(F(6,128)=4.53 ; p<0.001)$, which are summarized in figure 1C. In comparison with the vehicle condition, BAY 60-7550 enhanced memory after both immediate $(p<0.01)$ and delayed administration $(p<0.05)$. The immediate improvement was fully prevented by co-administration of a PKG inhibitor $(p<0.01)$, but remained when PDE2 inhibition was combined with a PKA inhibitor (n.s.). When memory enhancement was induced by delayed injections of BAY 60-7550, these effects were blocked by intrahippocampal infusions of RP-8-Br-cAMPS $(p<0.01)$. In this case, however, coadministration of RP-8-Br-cGMPS could not block memory enhancement (n.s.). 

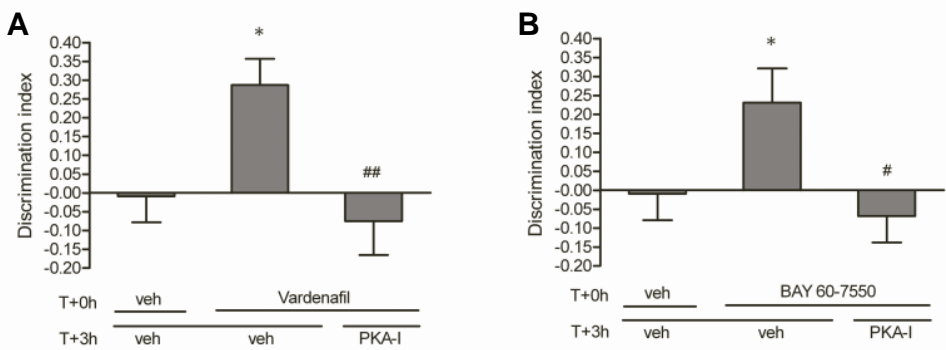

Figure 2. The effects of early CGMP-targeting PDE inhibition treatment (A: PDE5 inhibition Vardenafil $1 \mathrm{mg} / \mathrm{kg}, \mathrm{n}=28 / 13 / 14$; B: PDE2 inhibition - BAY 60-7550 $3 \mathrm{mg} / \mathrm{kg}, \mathrm{n}=28 / 12 / 13$ ) in combination with PKA inhibition (PKA-I; RP-8-Br-cAMPS; i.h.; $1 \mu \mathrm{g} / \mathrm{side}) 3 \mathrm{~h}(\mathrm{~T}+3 \mathrm{~h})$ after the first trial on discrimination performance (discrimination index; means + S.E.M.) in a 24-h-delay object recognition task. Asterisks indicate significant differences $\left({ }^{*} p<0.05\right)$ of PDE inhibition treatment from vehicle condition. Hashes indicate a significant reversal of PDEinduced memory improvement $\left(" \mathrm{p}<0.05,{ }^{\# \#} \mathrm{p}<0.01\right)$.

\section{Memory enhancing effects of cGMP-targeting PDEs are dependent on subsequent PKA activity.}

To investigate whether memory improvement after immediate treatment with cGMP-targeting PDE inhibitors relies on CAMP-PKA signaling during late consolidation, immediate vardenafil and BAY 60-7550 administration were combined with PKA inhibition 3 hours after learning. Results are summarized in figure 2. For vardenafil treatment, significant changes in discrimination performance were found $(F(2,38)=5.62 ; p<0.01$; fig. $2 A)$ with animals that received only vardenafil performing better than the vehicle group $(p<0.05)$, and a reversal to vehicle levels in combined treatment with vardenafil and $\mathrm{Rp}-8$-Br-cAMPS $(p<0.01)$. For BAY $60-7550$ treatment we found similar changes in memory performance $(F(2,36)=3,97 ; p<0.05$; fig. $2 B)$. That is, $B A Y$ 60-7550 enhanced discrimination $(p<0.05)$, whereas combining BAY $60-7550$ with delayed PKA inhibition reversed the improvement $(p<0.05)$. 

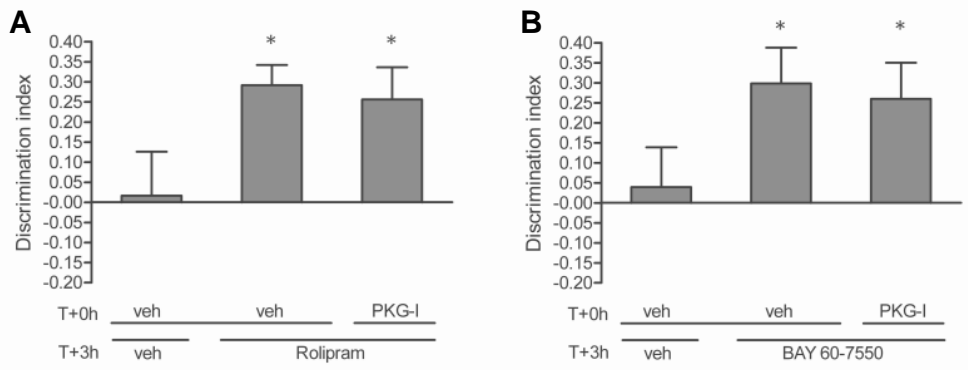

Figure 3. The effects of $C A M P$-targeting PDE inhibition treatment (A: PDE4 inhibition - Rolipram 0.03 mg/kg, n=10/14/12; B: PDE2 inhibition - BAY 60-7550 3 mg/kg, $\mathrm{n}=9 / 10 / 11$ ) administered $3 \mathrm{~h}$ after learning in combination with PKG inhibition (PKG-I; RP-8-Br-cGMPS; i.h.; $1 \mu \mathrm{g} / \mathrm{side}$ ) immediately after the first trial on discrimination performance (discrimination index; means + S.E.M.) in a 24-h-delay object recognition task. Asterisks indicate significant differences $\left({ }^{*} p<0.05\right)$ of PDE inhibition treatment from vehicle condition.

\section{Delayed CAMP stimulation enhances memory performance, regardless}

\section{of preceding blockage of cGMP signaling}

We evaluated the dependency of CAMP-mediated memory enhancement on preceding CGMP activity, by combining immediate intrahippocampal administration of Rp-8-Br-cGMPS with rolipram injected 3 hours after learning (fig. $3 \mathrm{~A}$ ). This resulted in significant changes in discrimination performance $(F(2,33)=3.38 ; p<0.05)$. Memory improving effects of rolipram could not be precluded with immediate Rp-8-Br-cGMPS injections $(p<0.05)$. In addition, we replicated these findings for memory enhancing effects after administration of BAY 60-7550 ( $F(2,27)=3.63 ; p<0.05$; fig. 3B). Again, Rp-8-BrcGMPS could not prevent improved discrimination performance caused by delayed BAY 60-7550 treatment $(p<0.05)$. 


\section{Effects of altered cyclic nucleotide-signaling on LTP}

Electrophysiological experiments were performed by using a weak tetanus to produce E-LTP, i.e. a transient potentiation, at Schaffer collateral-CA1 synapses in hippocampal slices. Similar to behavioral studies, the PDE5 inhibitor vardenafil $(10 \mathrm{nM})$ produced a longer-lasting potentiation when administered before $(F(1,14)=10.53, p<0.01$; fig. $4 A)$, but not when administered 90 minutes after tetanus $(F(1,13)=0.874$; n.s.). The effect of vardenafil administration 10 minutes after LTP induction did not differ from potentiation after vardenafil administration 10 minutes before induction $F(1,13)=0.210 ;$ n.s.). No effects on baseline transmission were observed (supplementary fig. 1). The effect of vardenafil was blocked by co-perfusion with the PKG inhibitor Rp-8-Br-cGMPS $(10 \mu \mathrm{M} ; \mathrm{F}(1,14)=0.01$; n.s. compared with vehicle; fig. 4A). The positive effect of vardenafil on LTP was also blocked by the PKA inhibitor Rp-8-Br-cAMPS $(20 \mu \mathrm{M}$ for 30 minutes; $F(1,13)=$ 0.04 , n.s.; $F(1,13)=8.86, p<0.05$; comparing vardenafil and vardenafil +Rp-8$\mathrm{Br}$-cAMPS before and after $\mathrm{Rp}-8$-Br-cAMPS administration respectively; fig. $4 \mathrm{~B})$, but only when administered 90 minutes after tetanus and not when administered together at time of induction $(F(1,13)=0.061 ;$ n.s.; Fig. $5 C)$. The time window at 90 minutes after induction was identified by applying Rp-8Br-CAMPS at various time points after vardenafil facilitated LTP induction (supplementary fig. $2 ; \mathrm{t}(8)=39.41, p<0.0001$ compared to vardenafil-treated slices).

We then tested whether inhibition of PDE4 affected LTP. Slices treated with the PDE4 inhibitor rolipram (100 nM) 90 minutes after a weak tetanus showed an enhancement of LTP $(F(1,12)=12.91 ; p<0.01$ compared with vehicle; fig. 5A). Bath application of rolipram before tetanus yielded in an enhanced LTP $(F(1,12)=5.659 ; p<0.05)$, while 10 minutes after tetanus rolipram did not affect $\operatorname{LTP}(F(1,13)=0.001 ; n . s ;$ fig. $5 D)$. The facilitation observed after rolipram administration at 90 minutes after tetanus could be blocked by co-perfusion with $\mathrm{Rp}-8$-Br-cAMPS. This blockage was partial as LTP was still enhanced compared to vehicle which might be a matter of dosing of rolipram, i.e. too high, and/or Rp-8-Br-CAMPS, i.e. too low. Importantly, the effect of rolipram was specific to LTP because it did not affect basal synaptic transmission $(F(2,12)=2.49$, n.s.; supplementary fig. 1$)$. 

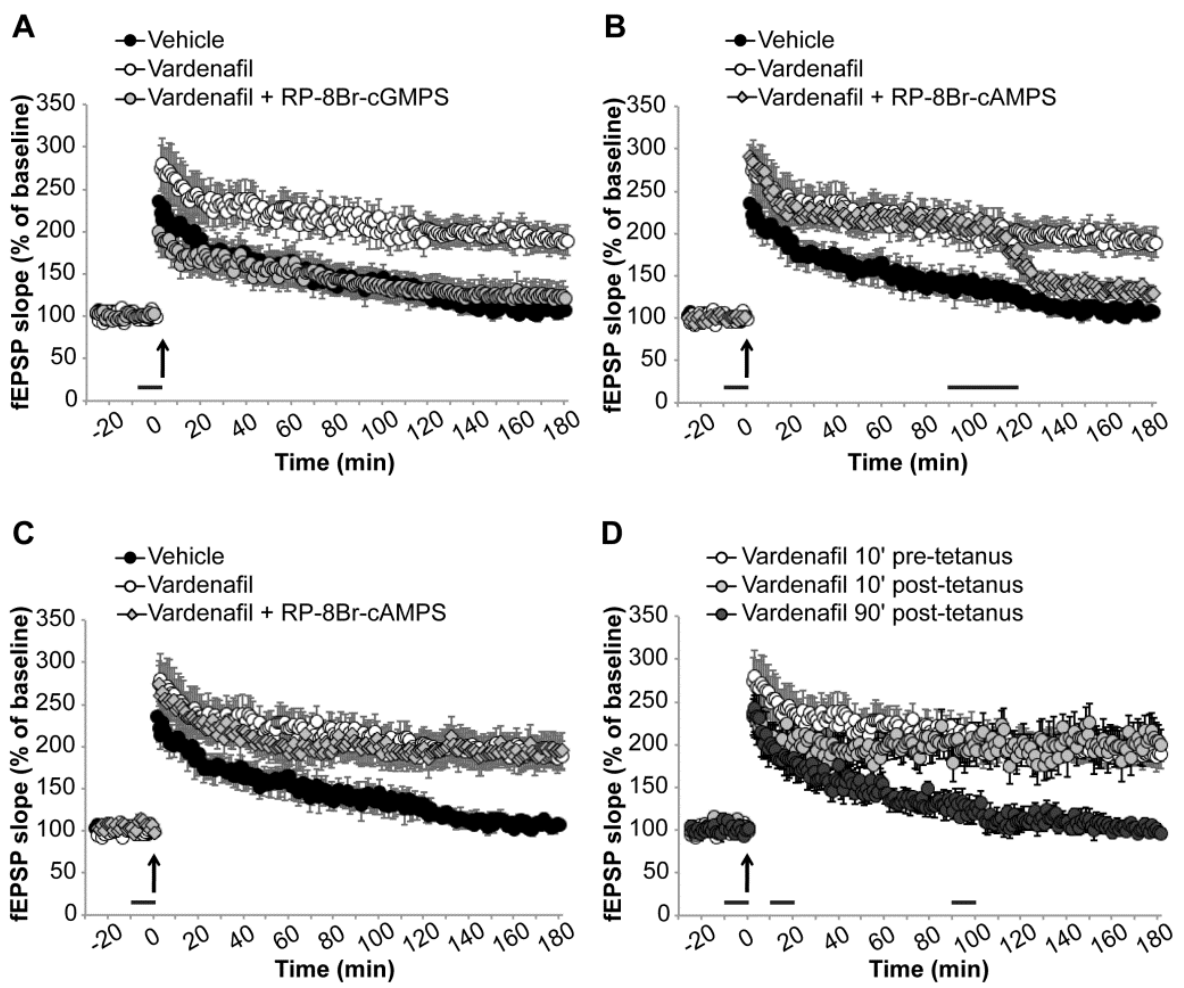

Figure 4. Effects of vardenafil and PKG/PKA inhibitors on hippocampal LTP.

A. Ten minutes perfusion of hippocampal slices with vardenafil $(10 \mathrm{nM})$ before tetanus increases levels of potentiation when compared to vehicle treated slices $(n=8 / 8)$; PKG inhibition by Rp-8Br-cGMPS $(10 \mu \mathrm{M})$ reverses the vardenafil-induced LTP improvement $(n=8)$. B. The increase of LTP induced by vardenafil before tetanus is blocked by a 30 minute perfusion with $\mathrm{Rp}-8-\mathrm{Br}$ cAMPS $(20 \mu \mathrm{M})$ administered at 90 minutes after tetanus $(n=7$; comparing vardenafil and vardenafil+Rp-8-Br-cAMPS before and after $\mathrm{Rp}-8$-Br-CAMPS administration). C. Perfusion with $\mathrm{Rp}$-8-Br-cAMPS concomitant to vardenafil ten minutes before tetanus does not affect the vardenafil-induced potentiation ( $\mathrm{n}=7$; comparing vardenafil and vardenafil+ $\mathrm{Rp}-8$ - $\mathrm{Br}$-CAMPS before tetanus). D. Vardenafil increases potentiation when administered 10 minutes before or after tetanus ( $n=7$; comparing vardenafil before and after tetanus), whereas it does not have any effect at 90 minutes after tetanus ( $n=7$; comparing vardenafil and vehicle). Arrow indicates tetanus delivery (one 10-burst stimulation - weak tetanus) and horizontal bars indicate the period during which drugs were added to the bath solution. 

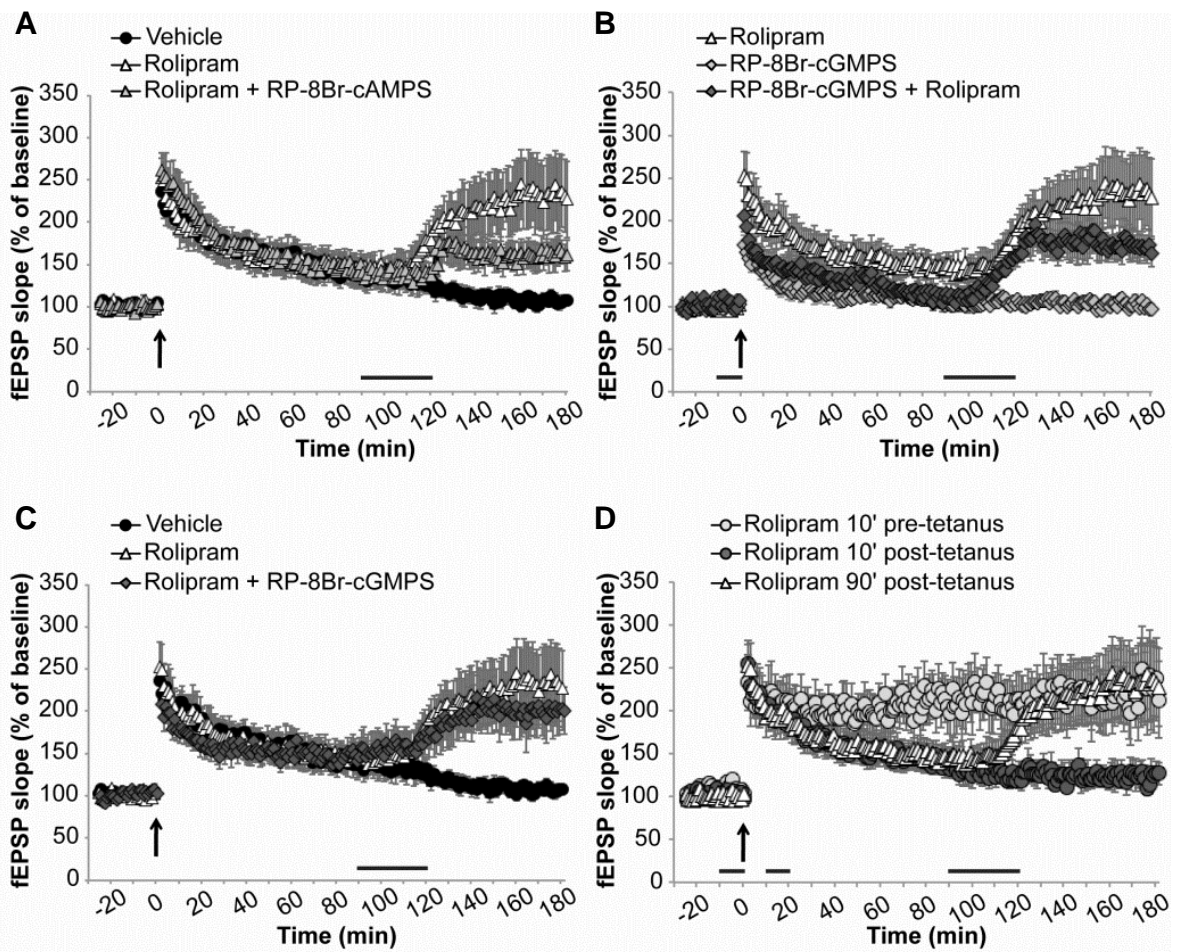

Figure 5. Effects of rolipram and PKG/PKA inhibitors on hippocampal LTP.

A. Perfusing hippocampal slices with rolipram (100 nM) 90 minutes after a weak tetanus boosts LTP in comparison to vehicle $(n=6 / 8)$. Co-perfusion with Rp-8-Br-CAMPS $(20 \mu \mathrm{M})$ induced a reduction of the effect of rolipram that, however, still shows an increased potentiation compared to vehicle $(n=5 / 8)$. B. Brief perfusion with Rp-8-Br-cGMPS $(10 \mu M)$ does not significantly decrease rolipram-induced improvement of LTP $(n=6 / 6)$. Yet Rp-8-Br-cGMPS alone decreases LTP (early-phase) compared to vehicle-treated slices $(n=8 / 8$; the latter conditions are shown in panel A). C. Treatment with Rp-8-Br-cGMPS concomitant with rolipram 90 minutes after tetanus does not affect rolipram-induced LTP ( $n=7$; comparing rolipram and rolipram $+\mathrm{Rp}-8-\mathrm{Br}-$ cGMPS). D. Rolipram increases potentiation when administered 10 minutes before tetanus ( $\mathrm{n}=$ 7; comparing rolipram with vehicle), whereas it does not have any effect at 10 minutes after tetanus ( $n=7$; comparing rolipram with vehicle). Arrow indicates tetanus delivery (one $\theta$-burst stimulation - weak tetanus) and horizontal bars indicate the period during which drugs were added to the bath solution. 
When Rp-8-Br-cGMPS (10 $\mu \mathrm{M})$ was applied alone before tetanus it led to significant decrease of E-LTP when compared to vehicle-treated slices $(F(1,14)=12.36 ; p<0.01)$. Importantly, however, the rolipram-induced improvement of LTP was not significantly changed $(F(1,10)=1.43$; n.s.; fig. 5B). Application of $\mathrm{Rp}-8-\mathrm{Br}-\mathrm{cGMPS}$ together with rolipram at 90 minutes after induction resulted in a similar level of enhanced LTP as with rolipram application alone $(F(1,11)=0.317$; n.s.; fig. $5 C)$.

\section{DISCUSSION}

The present study replicated our previous findings (11) by showing that inhibition of PDE2, 4 and 5 can prolong retention in an object recognition task, although these PDE subtypes act differentially on early and late stages of memory consolidation depending on their target cyclic nucleotide. That is, inhibition of PDE5 (by vardenafil), a cGMP-targeting PDE subtype, during early stages of consolidation and synaptic plasticity improved memory formation and as was now also shown LTP, i.e. it converted a E-LTP into a longer-lasting L-LTP-like signal. A CAMP-specific PDE4 inhibitor (by rolipram) showed a memory improving effect as well as the ability, as shown for the first time, to induce a longer-lasting LTP when applied during late consolidation and a later stage of synaptic plasticity, respectively. The fact that rolipram enhances synaptic plasticity when administered before, but not after LTP induction is line with previous literature (22), and might be explained by effects only on acquisition-like processes, which we also found to be independent of PKA signaling. Finally, inhibition of PDE2 (by BAY 607550), which regulates levels of both CAMP and CGMP, effectively enhanced memory performance when administered directly as well as $3 \mathrm{~h}$ after learning.

In addition, we demonstrated that it is possible to counteract the memoryenhancing effects of PDE inhibitors by intra-hippocampal co-administration of an inhibitor of PKA or PKG, two important effector proteins of CAMP and cGMP respectively. Specifically, memory enhancement as observed after early treatment with PDE5 or PDE2 inhibitors was successfully blocked only by co-administration of the PKG inhibitor RP-8-Br-cGMPS, while memory 


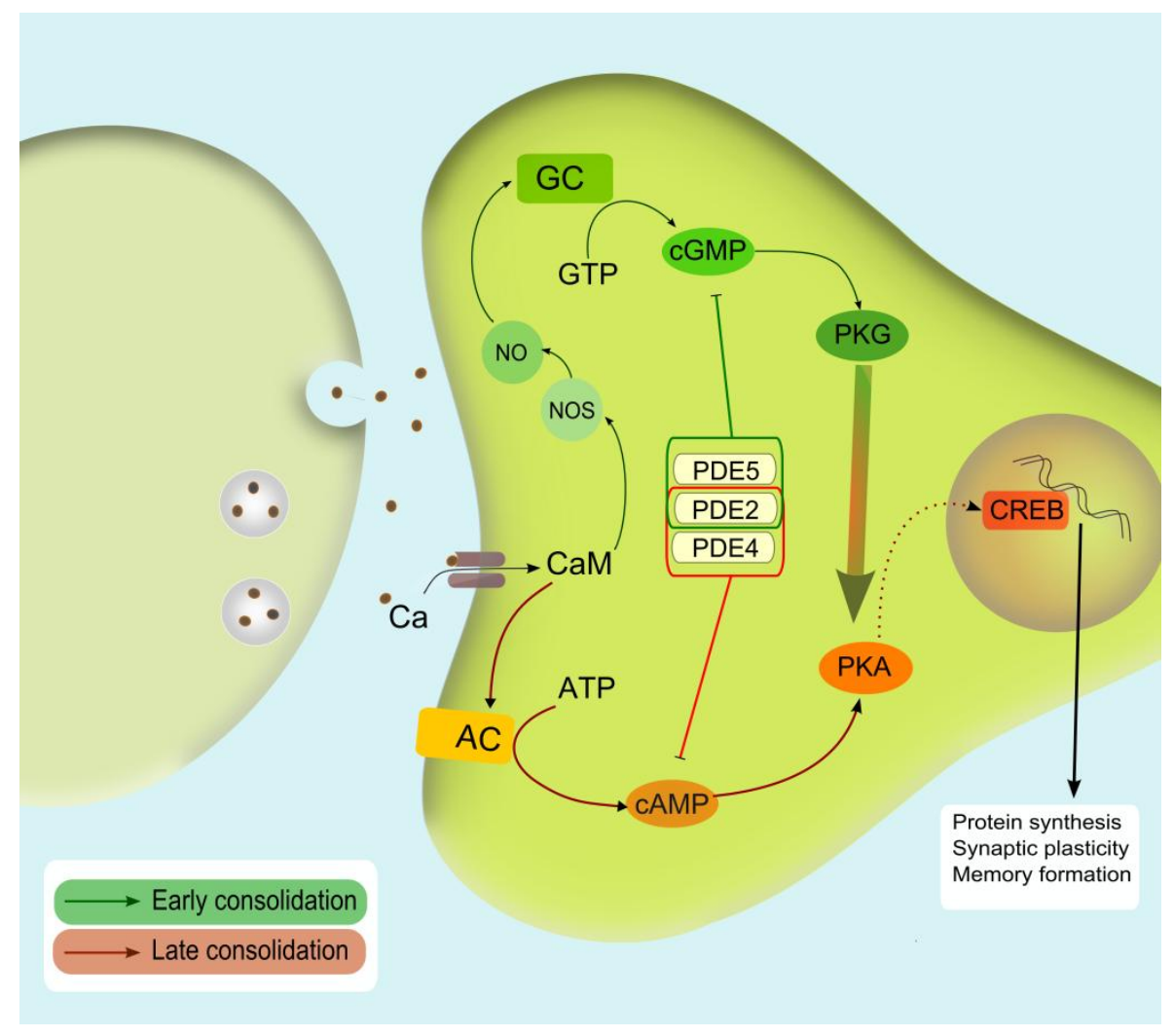

Figure 6. Hypothetical scheme of CGMP and CAMP-mediated pathways in hippocampal memory consolidation processes. Calcium $\left(\mathrm{Ca}^{2+}\right)$ influx through NMDA receptors activates calmodulin (CaM) which in an early phase mediates the activation of nitric oxide synthase and subsequent nitric oxide (NO). The latter binds to soluble guanylate cyclase (GC) which upon binding stimulates the conversion of guanosine triphosphate (GTP) to cyclic guanosine monophosphate (cGMP). cGMP then hydrolyzes protein kinase G (PKG). As a consequence of a persistent intracellular presence of $\mathrm{Ca}^{2+}$, adenylyl cyclase (AC) will eventually be triggered to convert adenosine triphosphate (ATP) into cyclic adenosine monophosphate. Consequently, CAMP will stimulate protein kinase $A$ (PKA) presumably to enhance CAMP responsive element binding protein (CREB)-mediated transcription and in that manner promote protein synthesis. Our data show that upregulation of the CGMP-PKG pathway in an early consolidation phase requires CAMP-mediated signaling in a later phase of consolidation. How this mechanistically takes place is not clear. It could be argued that CGMP and/or PKG lower the stimulation threshold for $\mathrm{Ca}^{2+}$ signals from other sources then through influx via the NMDA receptor, and therefore could enhance postsynaptic CAMP-signaling. 
improvement remained intact when combined with the PKA inhibitor RP-8Br-CAMPS. PDE4 or PDE2 inhibitors improved memory when administered during late consolidation processes and co-administration of a PKA inhibitor prevented this enhancement. However, co-administration of a PKG inhibitor did not hinder the memory improvement induced by PDE inhibitors that target cAMP. These findings were again replicated for PDE4 and PDE5 inhibition in in vitro LTP measurements in hippocampal slices. This has major implications for treatment with cognition enhancing drugs which improve specifically the CGMP and/or CAMP signaling cascades. That is, timing of treatment is essential to optimally influence memory consolidation processes after learning.

The results of this study show that the memory-enhancing effects of cGMPand CAMP-selective PDE inhibitors are mediated by CGMP-PKG and CAMPPKA signaling, respectively. Only a few studies have attempted to provide direct evidence for the contribution of these cascades in the behavioral effects induced by PDE inhibition. Devan and colleagues (23) blocked cGMPPKG signaling in vivo through upstream inhibition of NOS (nitric oxide synthase), and could attenuate subsequent memory impairment with a PDE5 inhibitor. In accordance with our present findings, Kroker et al. (24) were able to convert E-LTP into L-LTP by increasing CGMP via a PDE9 inhibitor, which was blocked by co-application with a PKG inhibitor. Moreover, our results now show that for CAMP as well as CGMP stimulation, the subsequent activation of their respective protein kinases is required for the memoryenhancing effects of PDE inhibition.

Improved memory formation due to enhancement of CGMP- and CAMPsignaling cascades is most likely attained through de novo protein synthesis caused by postsynaptic CREB-mediated transcription, although we do not provide direct evidence for this notion in this study. The critical role for CREB phosphorylation downstream of CGMP-PKG and CAMP-PKA signaling has been described in LTP studies (25-27). Furthermore, in the formation of several types of long-term memory, among which object recognition, the necessity of CRE-gene driven protein synthesis paradigms has been extensively reported. Previous studies demonstrated increased hippocampal levels of phosphorylated CREB after in vivo subchronic rolipram treatment 
(28), as well as after in vitro bath application of sildenafil on tetanized hippocampal slices in APP/PS1 mice (29) and aged mice (30). Although the transcriptional program of CREB phosphorylation is still largely unclear, it is known that the target genes of CREB are functionally heterogeneous, including channel subunits, other transcription factors and growth factors (31).

It has to be noted that vasodilation is one of the most evident effects of PDE inhibitors (32). The memory-enhancing effects of PDE inhibition could therefore also be attributed to an increased central blood flow and glucose metabolism. However, in a previous study we have demonstrated that the beneficial effects of systemically applied PDE inhibitors on memory in rats are independent of cerebrovascular effects (33). In addition, in the present study, synaptic plasticity in hippocampal slices was enhanced after in vitro bath application of vardenafil and rolipram. Because of this, it is rather implausible that changes in blood flow contribute significantly to memory enhancement after PDE inhibition, but is more likely attributable to alterations in synaptic plasticity in the hippocampus.

This is further supported by the fact that when upregulating cyclic nucleotides, and thus activating their respective pathways, timing is of the essence: only immediate elevation of cGMP levels or increased cAMP levels $3 \mathrm{~h}$ after learning resulted in prolonged memory. This suggests that at times, despite the elevated levels of cyclic nucleotides, synaptic plasticity is not enhanced. Moreover, we demonstrated that the memory improvement caused by administration of cGMP-targeting PDE inhibitors immediately after learning can be blocked by infusion of a PKA inhibitor $3 \mathrm{~h}$ after learning. This important finding shows that for memory improvement the enhancement of cGMP-PKG signaling in early consolidation phases requires PKA signaling in a later stage of consolidation. CAMP-PKA signaling on the other hand is not reliant on previous CGMP activity during consolidation. This seemingly contradicts earlier LTP work that suggested that CAMP-PKA and CGMP-PKG act in parallel to activate CREB (34). However in these studies a difference in time windows was not investigated, which explains the apparent discrepancy. A similar sequential relationship between CGMP and CAMP during long-term memory formation has been suggested based on work in crickets by 
Matsumoto and colleagues (35). Strikingly, our LTP data again supports our behavioral data as we observed that even though early PKG inhibition decreased E-LTP below vehicle levels, adding rolipram 90 minutes after induction still brought about enhanced synaptic plasticity, irrespective of the initial PKG inhibition. Thus, CAMP-PKA signaling acts independently of CGMP signaling to improve memory formation.

Our data indicate that CGMP and PKG may facilitate memory formation through mechanisms which eventually lead to reinforcement of postsynaptic CAMP-PKA-CREB signaling. CGMP-PKG signaling has been shown to act as an intrinsic modulatory system which regulates $\mathrm{Ca}^{2+}$ levels in the neuron, for example through activation of cyclic nucleotide gated channels (35) or via the release of $\mathrm{Ca}^{2+}$ from ryanodine stores (25). As such, elevated levels of cGMP and PKG can lower the stimulation threshold for $\mathrm{Ca}^{2+}$ signals from other sources, and therefore could enhance postsynaptic CAMP-signaling. Our study implies that long-term memory improvement due to cGMPtargeting PDE inhibitors should be regarded as the result of cGMP-mediated modulation of CAMP pathways. The necessity of late consolidation processes for long-term memory consolidation corresponds to the notion that during the early phase of memory consolidation synaptic changes are labile and require stabilization later on in the memory formation process (3). See fig. 6 for a hypothetical scheme illustrating how postsynaptic cGMP and CAMP signaling could be involved in memory formation.

In the present study we demonstrated that CAMP-targeting and CGMPtargeting PDE inhibitors improve memory through hippocampal CAMP-PKA signaling and CGMP-PKG signaling respectively. These signaling cascades take part in memory consolidation during two temporally separated phases after learning. CGMP-PKG signaling mediates early consolidation, while late consolidation requires activation of the CAMP-PKA cascade. These effects on memory were in line with the LTP studies, lending support to the notion that synaptic changes underlie the nootropic effects of PDE inhibitors. Importantly, we demonstrate for the first time that the early cGMP-pathway is unable to enhance consolidation or synaptic plasticity in absence of late CAMP-signaling, implying that CAMP signaling is the common pathway in long-term memory formation. 


\section{SUPPLEMENTARY INFORMATION}

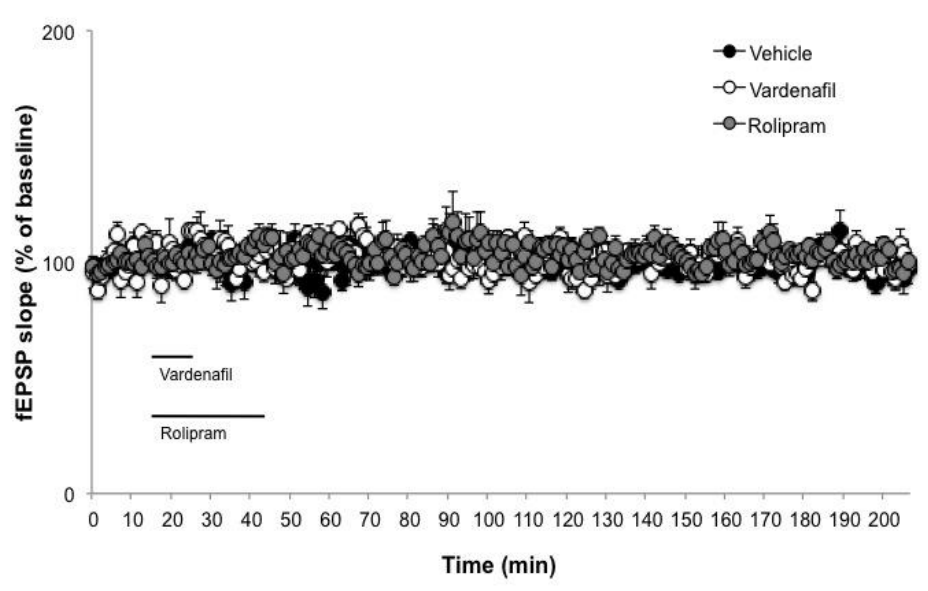

Supplementary figure S1. Neither rolipram (100 nM for 30 minutes) nor vardenafil (10 nM for 10 minutes) affect baseline transmission ( $n=5$ for each condition, $\left.F_{(2,12)}=2.494, p=0.124\right)$. Horizontal bars indicate the period during which drugs were added to the bath solution.

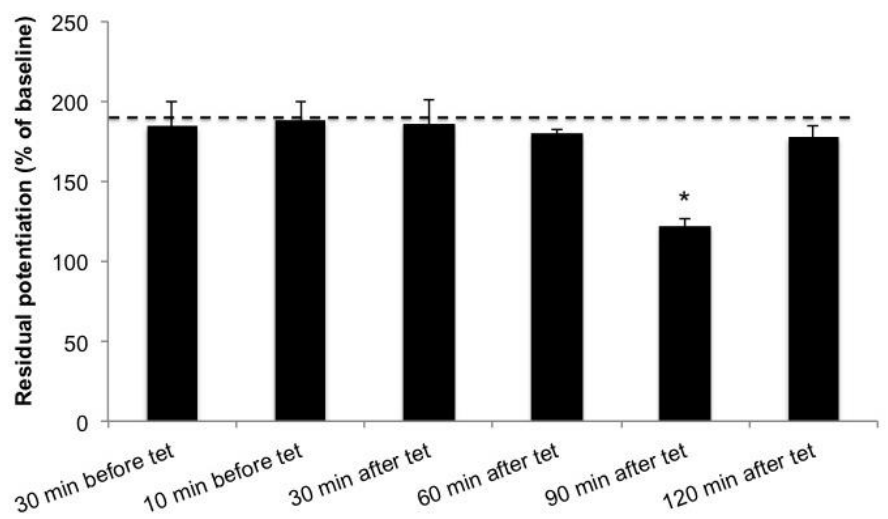

Supplementary figure S2. RP-8-Br-cAMPS $(20 \mu \mathrm{M})$ inhibits LTP induced by vardenafil $(10 \mathrm{nM})$ only when administered at 90 minutes after the weak tetanus. The dashed line represents the level of potentiation obtained after 10 minutes perfusion with vardenafil 10 minutes before tetanus. $\mathrm{N}=5$ for each condition. An asterisk depicts a significant difference when compared to vardenafil-treated slices: $p<0.05$ (Student t-test). 


\section{REFERENCES}

1. Izquierdo, I. \& Medina, J. H. (1997) Memory formation: the sequence of biochemical events in the hippocampus and its connection to activity in other brain structures. Neurobiol Learn Mem 68(3):285-316.

2. Izquierdo, I., Bevilaqua, L. R. M., Rossato, J. I., Bonini, J. S., Medina, J. H., et al. (2006) Different molecular cascades in different sites of the brain control memory consolidation. Trends in Neurosciences 29(9):496-505.

3. Kandel, E. R. (2001) The molecular biology of memory storage: a dialogue between genes and synapses. Science 294(5544):1030-1038.

4. Bach, M. E., Barad, M., Son, H., Zhuo, M., Lu, Y. F., et al. (1999) Age-related defects in spatial memory are correlated with defects in the late phase of hippocampal longterm potentiation in vitro and are attenuated by drugs that enhance the CAMP signaling pathway. P. Natl. Acad. Sci. U.S.A. 96(9):5280-5285.

5. Son, H., Lu, Y. F., Zhuo, M., Arancio, O., Kandel, E. R., et al. (1998) The specific role of cGMP in hippocampal LTP. Learning \& Memory 5(3):231-245.

6. Frey, U., Huang, Y. Y., \& Kandel, E. R. (1993) Effects of cAMP simulate a late stage of LTP in hippocampal CA1 neurons. Science 260(5114):1661-1664.

7. Lu, Y. F., Kandel, E. R., \& Hawkins, R. D. (1999) Nitric oxide signaling contributes to late-phase LTP and CREB phosphorylation in the hippocampus. J. Neurosci. 19(23):10250-10261.

8. Bernabeu, R., Schmitz, P., Faillace, M. P., Izquierdo, I., \& Medina, J. H. (1996) Hippocampal cGMP and CAMP are differentially involved in memory processing of inhibitory avoidance learning. Neuroreport 7(2):585-588.

9. Prickaerts, J., de Vente, J., Honig, W., Steinbusch, H. W., \& Blokland, A. (2002) CGMP, but not CAMP, in rat hippocampus is involved in early stages of object memory consolidation. Eur. J. Pharmacol. 436(1-2):83-87.

10. Bourtchouladze, R., Abel, T., Berman, N., Gordon, R., Lapidus, K., et al. (1998) Different training procedures recruit either one or two critical periods for contextual memory consolidation, each of which requires protein synthesis and PKA. Learning \& Memory 5(4-5):365-374.

11. Rutten, K., Prickaerts, J., Hendrix, M., van der Staay, F. J., Sik, A., et al. (2007) Timedependent involvement of CAMP and CGMP in consolidation of object memory: Studies using selective phosphodiesterase type 2, 4 and 5 inhibitors. Eur. J. Pharmacol. 558(1-3):107-112.

12. Izquierdo, I., Bevilaqua, L. R., Rossato, J. I., Bonini, J. S., Medina, J. H., et al. (2006) Different molecular cascades in different sites of the brain control memory consolidation. Trends Neurosci. 29(9):496-505.

13. Reneerkens, O., Rutten, K., Blokland, A., \& Prickaerts, J. (2009) Selective phosphodiesterase inhibitors: a promising target for cognition enhancement. Psychopharmacology 202(1-3):419-443. 
14. Barad, M., Bourtchouladze, R., Winder, D. G., Golan, H., \& Kandel, E. (1998) Rolipram, a type IV-specific phosphodiesterase inhibitor, facilitates the establishment of longlasting long-term potentiation and improves memory. P. Natl. Acad. Sci. U.S.A. 95(25):15020-15025.

15. Rose, G. M., Hopper, A., De Vivo, M., \& Tehim, A. (2005) Phosphodiesterase inhibitors for cognitive enhancement. Curr. Pharm. Design 11(26):3329-3334.

16. Zhang, H. T., Huang, Y., Suvarna, N. U., Deng, C., Crissman, A. M., et al. (2005) Effects of the novel PDE4 inhibitors MEM1018 and MEM1091 on memory in the radial-arm maze and inhibitory avoidance tests in rats. Psychopharmacology (Berl) 179(3):613-619.

17. Rutten, K., Lieben, C., Smits, L., \& Blokland, A. (2007) The PDE4 inhibitor rolipram reverses object memory impairment induced by acute tryptophan depletion in the rat. Psychopharmacology (Berl) 192(2):275-282.

18. Prickaerts, J., Sik, A., van Staveren, W. C., Koopmans, G., Steinbusch, H. W., et al. (2004) Phosphodiesterase type 5 inhibition improves early memory consolidation of object information. Neurochem. Int. 45(6):915-928.

19. Rutten, K., Vente, J. D., Sik, A., Ittersum, M. M., Prickaerts, J., et al. (2005) The selective PDE5 inhibitor, sildenafil, improves object memory in Swiss mice and increases cGMP levels in hippocampal slices. Behav. Brain Res. 164(1):11-16.

20. Boess, F. G., Hendrix, M., van der Staay, F. J., Erb, C., Schreiber, R., et al. (2004) Inhibition of phosphodiesterase 2 increases neuronal cGMP, synaptic plasticity and memory performance. Neuropharmacology 47(7):1081-1092.

21. Blokland, A., Schreiber, R., \& Prickaerts, J. (2006) Improving memory: a role for phosphodiesterases. Curr. Pharm. Des. 12(20):2511-2523.

22. Barad, M., Bourtchouladze, R., Winder, D. G., Golan, H., \& Kandel, E. (1998) Rolipram, a type IV-specific phosphodiesterase inhibitor, facilitates the establishment of longlasting long-term potentiation and improves memory. Proceedings of the National Academy of Sciences 95(25):15020-15025.

23. Devan, B. D., Pistell, P. J., Daffin, L. W., Jr., Nelson, C. M., Duffy, K. B., et al. (2007) Sildenafil citrate attenuates a complex maze impairment induced by intracerebroventricular infusion of the NOS inhibitor N(omega)-nitro-L-arginine methyl ester. Eur. J. Pharmacol. 563(1-3):134-140.

24. Kroker, K. S., Rast, G., Giovannini, R., Marti, A., Dorner-Ciossek, C., et al. (2012) Inhibition of acetylcholinesterase and phosphodiesterase-9A has differential effects on hippocampal early and late LTP. Neuropharmacology 62(5-6):1964-1974.

25. Lu, Y. F. \& Hawkins, R. D. (2002) Ryanodine receptors contribute to cGMP-induced late-phase LTP and CREB phosphorylation in the hippocampus. J. Neurophysiol. 88(3):1270-1278.

26. Navakkode, S., Sajikumar, S., \& Frey, J. U. (2004) The type IV-specific phosphodiesterase inhibitor rolipram and its effect on hippocampal long-term potentiation and synaptic tagging. J. Neurosci. 24(35):7740-7744.

27. Taqatqeh, F., Mergia, E., Neitz, A., Eysel, U. T., Koesling, D., et al. (2009) More than a retrograde messenger: nitric oxide needs two CGMP pathways to induce hippocampal long-term potentiation. J Neurosci 29(29):9344-9350. 
28. Monti, B., Berteotti, C., \& Contestabile, A. (2006) Subchronic Rolipram Delivery Activates Hippocampal CREB and Arc, Enhances Retention and Slows Down Extinction of Conditioned Fear. Neuropsychopharmacology 31(2):278-286.

29. Puzzo, D., Staniszewski, A., Deng, S. X., Privitera, L., Leznik, E., et al. (2009) Phosphodiesterase 5 inhibition improves synaptic function, memory, and amyloidbeta load in an Alzheimer's disease mouse model. J Neurosci 29(25):8075-8086.

30. Palmeri, A., Privitera, L., Giunta, S., Loreto, C., \& Puzzo, D. (2013) Inhibition of phosphodiesterase-5 rescues age-related impairment of synaptic plasticity and memory. Behav Brain Res 240:11-20.

31. Sakamoto, K., Karelina, K., \& Obrietan, K. (2011) CREB: a multifaceted regulator of neuronal plasticity and protection. J Neurochem 116(1):1-9.

32. Paterno, R., Faraci, F. M., \& Heistad, D. D. (1996) Role of $\mathrm{Ca}(2+)$-dependent K+ channels in cerebral vasodilatation induced by increases in cyclic GMP and cyclic AMP in the rat. Stroke 27(9):1603-1607; discussion 1607-1608.

33. Rutten, K., Van Donkelaar, E. L., Ferrington, L., Blokland, A., Bollen, E., et al. (2009) Phosphodiesterase inhibitors enhance object memory independent of cerebral blood flow and glucose utilization in rats. Neuropsychopharmacology 34(8):1914-1925.

34. Lu, Y.-F. \& Hawkins, R. D. (2002) Ryanodine Receptors Contribute to cGMP-Induced Late-Phase LTP and CREB Phosphorylation in the Hippocampus. Journal of Neurophysiology 88(3):1270-1278.

35. Matsumoto, Y., Unoki, S., Aonuma, H., \& Mizunami, M. (2006) Critical role of nitric oxide-cGMP cascade in the formation of CAMP-dependent long-term memory. Learning and Memory 13(1):35-44.

36. Ennaceur, A. \& Delacour, J. (1988) A new one-trial test for neurobiological studies of memory in rats. 1: Behavioral data. Behav. Brain Res. 31(1):47-59.

37. Prickaerts, J., Steinbusch, H. W., Smits, J. F., \& de Vente, J. (1997) Possible role of nitric oxide-cyclic GMP pathway in object recognition memory: effects of 7-nitroindazole and zaprinast. Eur. J. Pharmacol. 337(2-3):125-136.

38. Akkerman, S., Blokland, A., Reneerkens, O., van Goethem, N. P., Bollen, E., et al. (2012) Object recognition testing: methodological considerations on exploration and discrimination measures. Behav Brain Res 232(2):335-347.

39. Paxinos, G. \& Watson, C. (1998) The Rat Brain in Stereotaxic Coordinates Academic Press, London) fourth Ed.

40. Krause, W. \& Kuhne, G. (1988) Pharmacokinetics of rolipram in the rhesus and cynomolgus monkeys, the rat and the rabbit. Studies on species differences. Xenobiotica 18(5):561-571.

41. Reneerkens, O. A., Rutten, K., Akkerman, S., Blokland, A., Shaffer, C. L., et al. (2012) Phosphodiesterase type 5 (PDE5) inhibition improves object recognition memory: indications for central and peripheral mechanisms. Neurobiol Learn Mem 97(4):370379.

42. Reneerkens, O. A., Rutten, K., Bollen, E., Hage, T., Blokland, A., et al. (2013) Inhibition of phoshodiesterase type 2 or type 10 reverses object memory deficits induced by scopolamine or MK-801. Behav Brain Res 236(1):16-22.

43. Prickaerts, J., van Staveren, W. C., Sik, A., Markerink-van Ittersum, M., Niewohner, U., et al. (2002) Effects of two selective phosphodiesterase type 5 inhibitors, sildenafil and 
vardenafil, on object recognition memory and hippocampal cyclic GMP levels in the rat. Neuroscience 113(2):351-361.

44. Rutten, K., Prickaerts, J., \& Blokland, A. (2006) Rolipram reverses scopolamine-induced and time-dependent memory deficits in object recognition by different mechanisms of action. Neurobiol. Learn. Mem. 85(2):132-138.

45. Chapman, P. F., White, G. L., Jones, M. W., Cooper-Blacketer, D., Marshall, V. J., et al. (1999) Impaired synaptic plasticity and learning in aged amyloid precursor protein transgenic mice. Nat Neurosci 2(3):271-276.

46. Zakharenko, S. S., Patterson, S. L., Dragatsis, I., Zeitlin, S. O., Siegelbaum, S. A., et al. (2003) Presynaptic BDNF required for a presynaptic but not postsynaptic component of LTP at hippocampal CA1-CA3 synapses. Neuron 39(6):975-990. 



\title{
CHAPTER 5
}

\section{OBJECT MEMORY ENHANCEMENT BY COMBINING}

\author{
SUB-EFFICACIOUS DOSES OF SPECIFIC
}

PHOSPHODIESTERASE INHIBITORS

E Bollen ${ }^{*}$, S Akkerman ${ }^{*}$, D Puzzo, A Palmeri, R D'Hooge, D Balschun, HWM Steinbusch, A Blokland, J Prickaerts.

*Both authors contributed equally to the manuscript

Submitted 


\section{ABSTRACT}

The second messengers CGMP and CAMP have a vital role in synaptic plasticity and memory processes. As such, phosphodiesterases inhibitors (PDEi's), which prevent the breakdown of these cyclic nucleotides, represent a potential treatment strategy in memory decline. Recently it has been demonstrated that CGMP and CAMP signaling act in sequence during memory consolidation, with early CGMP signaling requiring subsequent cAMP signaling. Here, we sought to confirm this relationship, and to evaluate its therapeutic implications. Combining sub-efficacious doses of the CGMPspecific PDE type 5 inhibitor vardenafil $(0.1 \mathrm{mg} / \mathrm{kg})$ and CAMP-specific PDE type 4 inhibitor rolipram $(0.01 \mathrm{mg} / \mathrm{kg})$ during the early and late memory consolidation phase, respectively, led to improved memory performance in a $24 \mathrm{~h}$ interval object recognition task. Similarly, such a sub-efficacious combination treatment enhanced the transition of early-phase long-term potentiation (LTP) to late-phase LTP in the hippocampal slices. In addition, object memory was improved after administration of two sub-efficacious doses of the dual substrate PDE type 2 inhibitor BAY60 $7550(0.3 \mathrm{mg} / \mathrm{kg})$ at the early- and late consolidation phase, respectively. Taken together, combinations of sub-efficacious doses of CAMP- and CGMP-specific PDEi's have an additive effect on long-term memory formation and might prove a superior alternative to single PDEi treatment. 


\section{INTRODUCTION}

Cognitive decline is a hallmark symptom in a wide range of disorders including Alzheimer's disease, Parkinson's disease, and schizophrenia. However, to date no satisfactory treatment has been found for alleviating this symptom in patients. Therefore, the search for more efficacious nootropic drugs is ever increasing. Over the last years, phopshodiesterase inhibitors (PDEi's) have been repeatedly reported to demonstrate cognition enhancing effects in preclinical studies $(1,2)$. Positive effects of PDE inhibition were reported on memory formation, executive functioning, information processing and attention. Phosphodiesterases (PDE) are enzymes that are responsible for the breakdown of cyclic nucleotides cyclic adenosine monophosphate (CAMP) and cyclic guanosine monophosphate (cGMP) into their respective inactive forms. These cyclic nucleotides are ubiquitous second messenger molecules. Among other functions, they have a key role in relaying incoming signals at the neurons to downstream effectors which enhance synaptic plasticity (3-9). It has been demonstrated that enhancing cAMP or cGMP levels augments hippocampal long-term potentiation (LTP) (10-13), a physiological phenomenon which is generally considered to be the neuronal correlate of memory $(14,15)$. The importance of cyclic nucleotides in neuronal signaling has consequently led to an increasing amount of studies evaluating the cognition enhancing effects of inhibiting different PDEs.

An interesting feature of the PDE family is that 11 different subfamilies (PDE1-PDE11) have been identified, each with their specific function, regulation and localization pattern (16). An important distinction can be made based on the target cyclic nucleotide. PDEs are CAMP-specific, (PDEs $4,7,8$ ), cGMP-specific (PDEs 5,6,9) or have dual substrate properties (i.e. cAMP and CGMP-targeting; PDEs 1,2,3,10,11). Memory enhancing effects have been reported for all three types of PDEi's (17-19). Furthermore, our group has recently shown that, although CGMP and CAMP signaling are both important for consolidation of information into long-term memory, they are involved in different phases of the consolidation process. cGMP signaling is important immediately after acquisition, while cAMP signaling is critically involved at a 
late consolidation phase which is associated with the implementation of de novo transcribed proteins $(10,19)$. The relationship of cGMP signaling and CAMP signaling has shown to be sequential, with activation of the CAMP signaling pathway during the late consolidation phase being a prerequisite for CGMP-mediated cognition enhancement (10).

Cyclic nucleotides and most PDEs are abundantly present throughout the body and the brain (20). Therefore, PDEi's are likely to instigate adverse sideeffects through elevations of cyclic nucleotide levels in non-targeted areas. A well-known example is the prototypical cAMP-specific PDE type 4 (PDE4) inhibitor rolipram, which showed promising antidepressant effects in clinical trials, but the development was eventually stopped because of the severe emetic effects (21).

Given these findings, the aim of the present study is to evaluate whether our knowledge regarding the sequential relationship of CGMP and CAMP signaling can be translated into a superior treatment option by combining different types of PDEi's. Specifically, we hypothesize that a sub-efficacious dose of a cGMP-targeting PDEi can facilitate the effects of a sub-efficacious dose of CAMP-targeting PDEi. This could have a substantial advantage over normal singular PDE treatment as it will lead to less unwanted side-effects. In this study we will combine a sub-efficacious dose of rolipram (late consolidation phase) with the cGMP-specific PDE type 5 (PDE5) inhibitor vardenafil (early consolidation phase) to increase memory performance as measured in the object recognition task (ORT). Additionally, we assessed the effects of administration of two likewise temporally separated sub-efficacious doses of the dual substrate PDE type 2 (PDE2) inhibitor BAY 60-7550 on object recognition. Finally, we verified if the effects of our sub-efficacious treatments on memory performance can be attributed to changes in synaptic plasticity by measuring LTP in response to the combined PDEi's treatment at sub-efficacious concentrations. 


\section{METHODS}

\section{Subjects}

The experimental procedures described in this study were approved by the local ethical committee for animal experiments of Maastricht University or of the University of Catania and were in agreement with the respective governmental guidelines.

For behavioral experiments, 3 to 4-months old male Wistar rats (Harlan, Horst, the Netherlands) were used. Rats were individually housed in standard type 3 Makrolon cages on sawdust bedding. The animals were held in an airconditioned room (approximately $21{ }^{\circ} \mathrm{C}$ ) and had free access to food and water. A soft-playing radio provided background noise. A reversed light-dark cycle was applied in the room (lights on between 7.00 PM and 7.00 AM) in order to test the animals during their naturally active period.

For electrophysiological studies C57BL/6J 3-months old male mice were obtained from a breeding colony housed in the animal facility of the University of Catania. Housing conditions of the mice were the same as for rats, except that they were housed socially with 5 animals per cage.

\section{Object recognition}

Apparatus. Animals were subjected to the object recognition task (ORT) (10, 22). This task was performed in a circular arena with a diameter of $83 \mathrm{~cm}$ and walls of $40 \mathrm{~cm}$ high. The backside half of the arena wall was made of grey polyvinyl chloride, and the front half of transparent polyvinyl chloride. The objects consisted of four sets including 1) a cone made of brass, 2) a transparent glass bottle, 3) a solid metal beam with two holes and 4) a massive aluminum cube with a tapered top. The animals were unable to displace the objects. All objects were present in three-fold and were cleaned thoroughly after each trial to remove all olfactory traces. 
Procedure. ORT procedures were adapted from previous literature (23), with modifications as stated elsewhere $(10,24)$. During a first trial, rats were put in a circular apparatus, in which two identical objects were placed. $24 \mathrm{~h}$ later, the procedure was repeated with one of the objects from the initial trial replaced by another object. During both trials, exploration times were manually scored using a personal computer by the experimenter, who was unaware of the treatment condition tested. Exploration was defined as directing the nose to the object, with a maximal distance between nose and object of $2 \mathrm{~cm}$. Leaning or sitting on the object was not considered exploratory behavior. A relative measure of discrimination was calculated, which was corrected for total exploration time. The resulting discrimination index (exploration time new object - exploration time old object)/(exploration time new object + exploration time old object) reflects recognition memory independent of normal exploratory behavior (22). In addition, total time spent exploring objects during trial 1 and 2 (e1 and e2 respectively) was calculated to ascertain that treatment did not affect exploration in general. Animals that did not show normal exploration ( $\mathrm{T} 1<6$ $\mathrm{sec}$ or $\mathrm{T} 2<9 \mathrm{sec}$ ) were excluded from analysis. Testing sessions were between $9.00 \mathrm{AM}$ and $17.00 \mathrm{PM}$, and were performed under red light conditions while the test room was dimly lit by a lamp ( $25 \mathrm{~W}$ ), located in the corner of the room.

\section{Treatment}

PDE2i BAY 60-7550 (kindly donated by BAYER AG, Wuppertal, Germany), the PDE4i rolipram (Sigma Aldrich, Zwijndrecht, Netherlands) and the PDE5i vardenafil (kindly donated by BAYER AG) were freshly dissolved on the day of testing. Drug administration of the PDEi's was done either orally (BAY 60$75500.3 \mathrm{mg} / \mathrm{kg}$ and vardenafil $0.1 \mathrm{mg} / \mathrm{kg}$ ) or intraperitoneally (rolipram 0.01 $\mathrm{mg} / \mathrm{kg}$ ). All PDEi's were dissolved in the same vehicle (98\% methyl cellulose [tylose] solution ( $0.5 \%$ ) and $2 \%$ Tween 80 ) and administered in a volume of 2 $\mathrm{ml} / \mathrm{kg}$. To target early and late phases of memory consolidation, the drugs were administrated immediately $(\mathrm{T} 1+0 \mathrm{~h})$ or $3 \mathrm{~h}$ after the learning trial $(\mathrm{T} 1+3 \mathrm{~h})$. Of note, all treatments were based on previously established subefficacious doses and concentrations $(10,19,25)$. 


\section{Electrophysiology}

Electrophysiological recordings were performed as previously described [11]. Briefly, transverse hippocampal slices $(400 \mu \mathrm{m})$ were cut and transferred to a recording chamber where they were maintained at $29^{\circ} \mathrm{C}$ and perfused with ACSF continuously bubbled with $95 \%$ O2 and $5 \%$ CO2. The ACSF composition was composed of the following (in $\mathrm{mM}$ ): $124.0 \mathrm{NaCl}, 4.4 \mathrm{KCl}, 1.0$ $\mathrm{Na} 2 \mathrm{HPO} 4,25.0 \mathrm{NaHCO}$, 2.0 $\mathrm{CaCl} 2,2.0 \mathrm{MgCl} 2$, and 10.0 glucose. Field extracellular recordings were performed by stimulating the Schaeffer collateral fibers through a bipolar tungsten electrode and recording in CA1 stratum radiatum with a glass electrode filled with ACSF. A 15 min baseline was recorded at an intensity that evoked a response approximately $35 \%$ of the maximum evoked response. LTP was induced using one 10-burst train (weak tetanus). Responses were recorded for $3 \mathrm{~h}$ after tetanization and measured as field excitatory post-synaptic potentials (f-EPSP) slope expressed as percentage of baseline. For electrophysiological experiments, vardenafil $(0.3 \mathrm{nM})$ and rolipram $(1 \mathrm{nM})$ were diluted in artificial CSF (ACSF) immediately before use, and applied in the bath solution at different time points before or after the induction of LTP.

\section{Statistical analysis}

According to statistical guidelines for ORT analysis [26], we compared all experimental conditions with a fictive group (discrimination index $=0 \pm 0.65$ ) using two-sided student $t$-tests to evaluate whether animals discriminated between objects. Furthermore, a one-way ANOVA was performed, after which individual comparisons were assessed using the Fishers' LSD test for multiple comparisons. LTP data were analyzed with 2-way repeated measures ANOVAs. Significance level was for all analyses set at 0.05 . 


\section{RESULTS}

\section{Object memory}

Rats that received vehicle injections or a single, sub-efficacious, vardenafil $(\mathrm{T} 1+0 \mathrm{~h})$ or rolipram $(\mathrm{T} 1+3 \mathrm{~h})$ PDEi's dose did not show significant object discrimination $24 \mathrm{~h}$ after the learning trial (respectively: $\mathrm{t}(45)=0.09$, n.s.; $\mathrm{t}(44)=0.17$, n.s.; $\mathrm{t}(45)=0.18$, n.s.). When both sub-efficacious doses were combined, animals showed a preference towards the new object $(t(45)=2.89$; $p<0.01$ ) (See Fig. 1A). In addition, between group comparisons revealed that rats receiving combination treatment of vardenafil and rolipram showed a significantly better discrimination performance when compared to animals in all other treatment conditions $(F(3,80)=3,75 ; p<0.05)$.

Sub-efficacious administrations of the PDE2i BAY 60-7550 showed a similar pattern of results (Fig. 1B). Single PDE-2I administration, i.e. at $\mathrm{T}+\mathrm{Oh}$ or $\mathrm{T}+3 \mathrm{~h}$, did not produce a preference of rats towards the novel object (respectively: $\mathrm{t}(44)=0.15$, n.s.; $\mathrm{t}(44)=0.52$, n.s.), while combination treatment with the two time-separated injections of BAY 60-7550 led to a significant increase in discrimination performance $(t(45)=2.65, p<0.05)$. When comparing between treatment conditions, we found that animals receiving double PDE2i treatment had a significantly better discrimination performance than in all three other conditions $(F(3,85)=3.56, p<0.05)$.

\section{Electrophysiology}

Perfusion of hippocampal slices with a low concentration of vardenafil before tetanus, or rolipram 90 min after tetanus did not alter synaptic transmission (Vehicle: $112.03 \pm 5.50 \%$ of baseline slope 180 min after tetanus; Vardenafil: $130.53 \pm 17.21 \%$ of baseline slope, $F(1,10)=0.911, p=0.362$; Rolipram: $125.13 \pm 10.35 \%$ of baseline slope, $F(1,10)=2.951, p=0.117$ compared to vehicle; Fig. 2A). When combining both perfusions, we observed an increase in hippocampal synaptic transmission starting from around 120 min after tetanus, which is the end time of rolipram perfusion; Fig. 2B). This increase was stable and lasted untill the end of the experiment $(183.83 \pm 13.51 \%$ of 
A

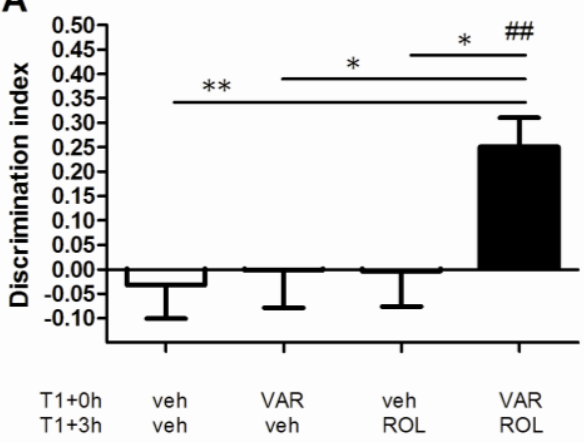

B

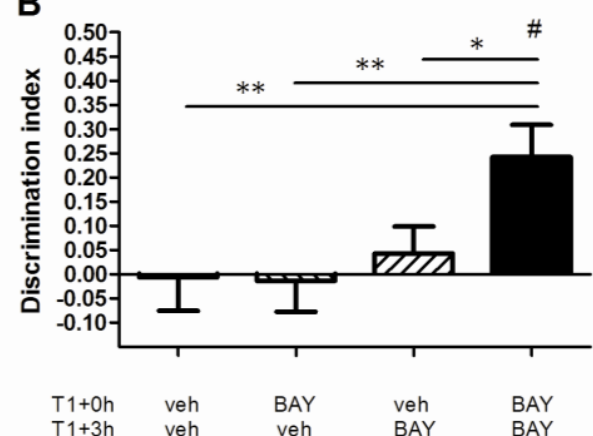

Figure 1. Discrimination performance in an object recognition task after a single or combined sub-efficacious PDEi administration. A) Sub-efficacious dose of vardenafil (VAR; $0.1 \mathrm{mg} / \mathrm{kg}$ ) at $\mathrm{T} 1+0 \mathrm{~h}$ and/or rolipram at $\mathrm{T} 1+3 \mathrm{~h}(\mathrm{ROL} ; 0.01 \mathrm{mg} / \mathrm{kg}), \mathrm{n}=20-21-21-22$. B) Sub-efficacious dose of BAY 60-7550 (BAY; $0.3 \mathrm{mg} / \mathrm{kg}$ ) at $\mathrm{T} 1+0 \mathrm{~h}$ and/or at $\mathrm{T} 1+3 \mathrm{~h} ; \mathrm{n}=21-22-23-23$. Bars represent means \pm S.E.M. Hashes indicate significant object discrimination (two-sided t-test; \#p $<0.05$, \#\# $p<0.01$ ) and asterisks represent significant differences between conditions (post-hoc Fishers' LSD test; ${ }^{*} p<0.05,{ }^{* *} p<0.01$ ).

A

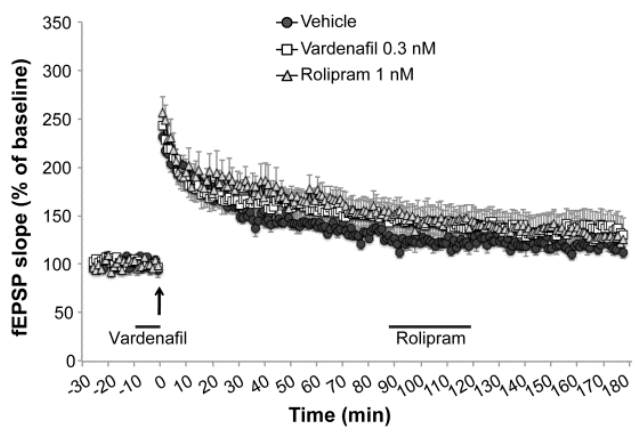

B

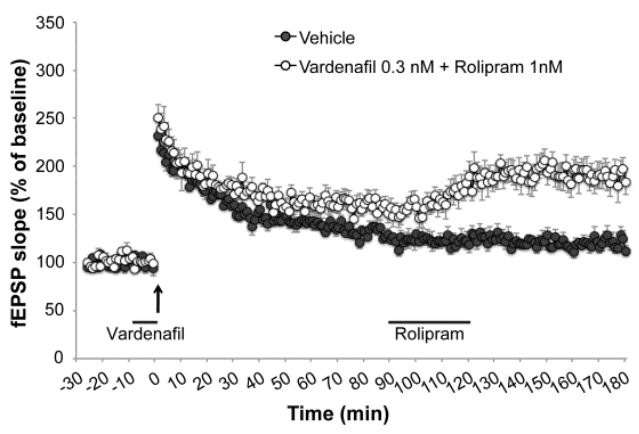

Figure 2: Effects of sub-efficacious PDEi's perfusion on hippocampal LTP. A. Perfusion of hippocampal slices with vardenafil $(0.3 \mathrm{nM} ; 10$ minutes) before tetanus or rolipram ( $1 \mathrm{nM}$; 30 minutes) 90 minutes after tetanus does not increase levels of potentiation when compared to vehicle treated slices ( $n=6$ for each condition) B. Perfusion of slices with both vardenafil $(0.3 \mathrm{nM})$ before tetanus and rolipram $(1 \mathrm{nM})(\mathrm{n}=8) 90$ minutes after tetanus increases hippocampal LTP when compared to controls. Arrow indicates tetanus delivery (one 10-burst stimulation - weak tetanus) and horizontal bars indicate the period during which drugs were added to the bath solution. 
baseline slope $180 \mathrm{~min}$ after tetanus at $180 \mathrm{~min}$ after tetanus, $F(1,12)=$ 27.720, $p<0.0001$ compared to vehicle). This suggests that combining vardenafil and rolipram triggers a conversion of a transient E-LTP into a stable long-lasting L-LTP.

\section{DISCUSSION}

In this study, we confirmed the memory enhancing properties of three types of PDEi's, i.e. CAMP-specific PDE4i rolipram, CGMP-specific PDE5i vardenafil and PDE2i BAY 60-7550, which influences both CAMP and cGMP levels. Their cognition enhancing effects have been described in a vast number of studies, showing beneficial effects on different cognitive functions and paradigms (for a review, see $1,2,27$ ). The origin of the enhanced cognitive performances has been a matter of discussion. Because PDE inhibition is known to cause vasodilation, some have argued that PDE induced cognition enhancement is likely the result of an increased blood flow in cognitionrelated brain areas (28). However, we have demonstrated that the doses of vardenafil and rolipram which were effective in enhancing memory performance did not increase blood flow or glucose metabolism in brain structures vital for memory formation such as the hippocampus (29). In addition, selective inhibition of PDE2, PDE4 as well as PDE5 has been shown to increase synaptic plasticity as measured with $\operatorname{LTP}(11,17,30)$. Ever since the discovery of LTP, these synaptic plasticity changes have been linked to neuronal memory formation $(14,15)$. Thus, the effects of PDEi's are most likely attributable to changes in neuronal CAMP and CGMP-related signaling.

A recent study of our group demonstrated the sequential relationship of CGMP and CAMP in memory consolidation. During an early phase in the consolidation process, memory performance can be altered by applying cGMP-targeting drugs, while in a later phase during consolidation CAMP is essential for memory formation and synaptic plasticity, i.e. LTP (10). In the present study, we confirm this relationship and suggest that these findings may have therapeutical implications. We observed an enhancement in memory performance and synaptic plasticity when an early sub-efficaciously dose of the CGMP-targeting PDE5i vardenafil was combined with a delayed 
sub-efficacious dose of the CAMP-targeting PDE4i rolipram. This implies that upon weak stimulation of the CGMP pathway, the effects of CAMP stimulation are facilitated. The precise mechanism by which cGMP exerts its effect on CAMP signaling is not fully understood. Memory improvement of cGMP-targeting PDEi's is dependent on subsequent protein kinase G (PKG) signaling $(10,31,32)$. It can be speculated that cGMP-PKG signaling affects CAMP signaling via calcium $\left(\mathrm{Ca}^{2+}\right)$ influx through cyclic nucleotide gated receptors or via $\mathrm{Ca}^{2+}$ release from the intracellular $\mathrm{Ca}^{2+}$ stores through activation of ryanodine receptors $(33,34)$. This would further depolarize the synapse and create beneficial circumstances for cAMP elevation. Once cAMP levels are upregulated, protein kinase $A$ is recruited to phosphorylate CAMP responsive element binding protein (CREB), a transcription factor responsible for de novo synthesis of many plasticity related proteins (35). The implementation of these new proteins in the synapse is thought to underlie the long-term plasticity changes observed in LTP and memory formation (36).

Our findings may have important implications for future therapeutic use of PDEi's, in particular as an acute treatment. The therapeutic effects of rolipram, the prototypic PDE4 inhibitor, have been extensively studied for a wide array of disorders. The usage of selective PDE4 inhibitors such as rolipram in a therapeutic setting has been limited by its adverse side effects. The strong, dose-dependent emetic properties of rolipram are without any doubt the most problematic $(21,37)$. The rolipram-induced emesis has been attributed to the presence of high levels PDE4 in the area postrema, which is known to be a major chemoreceptor trigger zone for vomiting $(38,39)$. Recently, a second generation PDE4 inhibitor roflumilast (Daxas) has been approved for the treatment of chronic obstructive pulmonary disorder. Roflumilast has less severe emetic side effects, although nausea is still reported by $5 \%$ of the patients (40). The selective PDE5i's vardenafil, sildenafil and tadalafil have been approved by the FDA for the treatment of erectile dysfunction and are currently on the market under the trade names Levitra, Viagra and Cialis, respectively. However, vardenafil and other selective PDE5 inhibitors also show a number of common, dose-dependent side effects - although less invasive as compared to rolipram-induced emesis - , such as headache, flushing, dyspepsia and rhinitis $(41,42)$. Although the 
pro-cognitive effects are well established in pre-clinical studies, these sideeffects might represent a major obstacle for replication of these nootropic effects in clinical trials (43). Therefore, combining very low doses of PDE4 and PDE5 inhibitors could be an interesting clinical approach to maximize cognition-enhancing effects while minimizing potential side-effects. Our study demonstrates for the first time that low-dose combination treatment of different types of PDEi's may prove effective in treating memory dysfunction.

It is important to note that our study does not provide direct pharmacological evidence for a synergistic interaction of rolipram and vardenafil. To determine such a relationship, a quantitative analysis of dosedependent potency is mandatory (44), which was beyond the scope of this article. However, one can interpret these findings as a therapeutic synergy, as the observed potency of the combination treatment for cognition enhancement is higher than what would be expected from simply adding up the effects of the singular sub-efficacious doses of the respective PDEi's.

We also showed that two combined non-efficacious doses of BAY 607550 , directly after learning and at $3 \mathrm{~h}$ after learning, effectively improved object memory. These findings are in line with the dual-substrate properties of PDE2 and existing literature which demonstrated that memory improving effects of PDE2i's can be either CGMP- or CAMP-mediated, dependent on the timing of treatment $(10,19)$. That is, when applied during the early consolidation phase, the enhanced long-term memory performance is the result of enhanced cGMP-mediated signaling, while during late consolidation the improvement is attributable to enhanced CAMP-signaling. This adds further weight to the notion that PDE2i's are attractive candidates for cognition enhancement. Along similar lines, our findings suggest that a constant low-level presence of PDE2i's could represent a novel strategy for treating cognitive disorders. Of note, in preclinical research, chronic treatment with BAY 60-7550 has not only shown to enhance memory consolidation, but has also demonstrated beneficial effects on other cognitive functions, depressive-like behavior and memory performance in a mouse model of Alzheimer's disease $(17,45,46)$. 
Taken together, this study provides further evidence for the potential use of PDEi's for memory improvement. Furthermore, our results emphasize the feasibility of combined treatment with CAMP-specific and CGMP-specific PDEi's and of repeated administration of dual substrate PDEi's, all at subefficacious doses. We suggest that these low-dose treatment strategies might prove to be a superior option over singular PDE inhibition treatment. In future research, attempts should be made to translate these findings into the clinical setting. 


\section{REFERENCES}

1. Blokland, A., Menniti, F. S., \& Prickaerts, J. (2012) PDE inhibition and cognition enhancement. Expert Opin Ther Pat 22(4):349-354.

2. Reneerkens, O. A., Rutten, K., Steinbusch, H. W., Blokland, A., \& Prickaerts, J. (2009) Selective phosphodiesterase inhibitors: a promising target for cognition enhancement. Psychopharmacology (Berl) 202(1-3):419-443.

3. Bach, M. E., Barad, M., Son, H., Zhuo, M., Lu, Y. F., et al. (1999) Age-related defects in spatial memory are correlated with defects in the late phase of hippocampal long-term potentiation in vitro and are attenuated by drugs that enhance the CAMP signaling pathway. P. Natl. Acad. Sci. U.S.A. 96(9):5280-5285.

4. Son, H., Lu, Y. F., Zhuo, M., Arancio, O., Kandel, E. R., et al. (1998) The specific role of cGMP in hippocampal LTP. Learning \& Memory 5(3):231-245.

5. Frey, U., Huang, Y. Y., \& Kandel, E. R. (1993) Effects of cAMP simulate a late stage of LTP in hippocampal CA1 neurons. Science 260(5114):1661-1664.

6. Lu, Y. F., Kandel, E. R., \& Hawkins, R. D. (1999) Nitric oxide signaling contributes to latephase LTP and CREB phosphorylation in the hippocampus. J. Neurosci. 19(23):1025010261.

7. Bernabeu, R., Schmitz, P., Faillace, M. P., Izquierdo, I., \& Medina, J. H. (1996) Hippocampal CGMP and CAMP are differentially involved in memory processing of inhibitory avoidance learning. Neuroreport 7(2):585-588.

8. Prickaerts, J., de Vente, J., Honig, W., Steinbusch, H. W., \& Blokland, A. (2002) cGMP, but not cAMP, in rat hippocampus is involved in early stages of object memory consolidation. Eur. J. Pharmacol. 436(1-2):83-87.

9. Bourtchouladze, R., Abel, T., Berman, N., Gordon, R., Lapidus, K., et al. (1998) Different training procedures recruit either one or two critical periods for contextual memory consolidation, each of which requires protein synthesis and PKA. Learning \& Memory 5(45):365-374.

10. Bollen, E., Puzzo, D., Rutten, K., Privitera, L., De Vry, J., et al. (Improved Long-Term Memory via Enhancing CGMP-PKG Signaling Requires CAMP-PKA Signaling. Neuropsychopharmacology:Epub ahead of publication: DOI 10.1038/npp.2014.1106.

11. Puzzo, D., Staniszewski, A., Deng, S. X., Privitera, L., Leznik, E., et al. (2009) Phosphodiesterase 5 inhibition improves synaptic function, memory, and amyloid-beta load in an Alzheimer's disease mouse model. J Neurosci 29(25):8075-8086.

12. Vitolo, O. V., Sant'Angelo, A., Costanzo, V., Battaglia, F., Arancio, O., et al. (2002) Amyloid beta -peptide inhibition of the PKA/CREB pathway and long-term potentiation: reversibility by drugs that enhance CAMP signaling. Proc Natl Acad Sci U S A 99(20):1321713221.

13. Palmeri, A., Privitera, L., Giunta, S., Loreto, C., \& Puzzo, D. (2013) Inhibition of phosphodiesterase-5 rescues age-related impairment of synaptic plasticity and memory. Behav Brain Res 240:11-20.

14. Bliss, T. V. \& Lomo, T. (1973) Long-lasting potentiation of synaptic transmission in the dentate area of the anaesthetized rabbit following stimulation of the perforant path. $J$ Physiol 232(2):331-356. 
15. Lynch, M. A. (2004) Long-term potentiation and memory. Physiol Rev 84(1):87-136.

16. Bender, A. T. \& Beavo, J. A. (2006) Cyclic nucleotide phosphodiesterases: molecular regulation to clinical use. Pharmacol Rev 58(3):488-520.

17. Boess, F. G., Hendrix, M., van der Staay, F. J., Erb, C., Schreiber, R., et al. (2004) Inhibition of phosphodiesterase 2 increases neuronal CGMP, synaptic plasticity and memory performance. Neuropharmacology 47(7):1081-1092.

18. Prickaerts, J., Sik, A., van Staveren, W. C., Koopmans, G., Steinbusch, H. W., et al. (2004) Phosphodiesterase type 5 inhibition improves early memory consolidation of object information. Neurochem Int 45(6):915-928.

19. Rutten, K., Prickaerts, J., Hendrix, M., van der Staay, F. J., Sik, A., et al. (2007) Timedependent involvement of CAMP and CGMP in consolidation of object memory: studies using selective phosphodiesterase type 2, 4 and 5 inhibitors. Eur J Pharmacol 558(13):107-112.

20. Lakics, V., Karran, E. H., \& Boess, F. G. (2010) Quantitative comparison of phosphodiesterase mRNA distribution in human brain and peripheral tissues. Neuropharmacology 59(6):367-374.

21. Hebenstreit, G. F., Fellerer, K., Fichte, K., Fischer, G., Geyer, N., et al. (1989) Rolipram in major depressive disorder: results of a double-blind comparative study with imipramine. Pharmacopsychiatry 22(4):156-160.

22. Akkerman, S., Blokland, A., Reneerkens, O., van Goethem, N. P., Bollen, E., et al. (2012) Object recognition testing: methodological considerations on exploration and discrimination measures. Behav Brain Res 232(2):335-347.

23. Ennaceur, A. \& Delacour, J. (1988) A new one-trial test for neurobiological studies of memory in rats. 1: Behavioral data. Behav. Brain Res. 31(1):47-59.

24. Prickaerts, J., Steinbusch, H. W., Smits, J. F., \& de Vente, J. (1997) Possible role of nitric oxide-cyclic GMP pathway in object recognition memory: effects of 7-nitroindazole and zaprinast. Eur. J. Pharmacol. 337(2-3):125-136.

25. Rutten, K., Prickaerts, J., \& Blokland, A. (2006) Rolipram reverses scopolamine-induced and time-dependent memory deficits in object recognition by different mechanisms of action. Neurobiol Learn Mem 85(2):132-138.

26. Akkerman, S., Prickaerts, J., Steinbusch, H. W., \& Blokland, A. (2012) Object recognition testing: statistical considerations. Behav Brain Res 232(2):317-322.

27. Puzzo, D., Sapienza, S., Arancio, O., \& Palmeri, A. (2008) Role of phosphodiesterase 5 in synaptic plasticity and memory. Neuropsychiatr Dis Treat 4(2):371-387.

28. Paterno, R., Faraci, F. M., \& Heistad, D. D. (1996) Role of $\mathrm{Ca}(2+)$-dependent K+ channels in cerebral vasodilatation induced by increases in cyclic GMP and cyclic AMP in the rat. Stroke 27(9):1603-1607; discussion 1607-1608.

29. Rutten, K., Van Donkelaar, E. L., Ferrington, L., Blokland, A., Bollen, E., et al. (2009) Phosphodiesterase inhibitors enhance object memory independent of cerebral blood flow and glucose utilization in rats. Neuropsychopharmacology 34(8):1914-1925.

30. Gong, B., Vitolo, O. V., Trinchese, F., Liu, S., Shelanski, M., et al. (2004) Persistent improvement in synaptic and cognitive functions in an Alzheimer mouse model after rolipram treatment. J Clin Invest 114(11):1624-1634.

31. Hosseini-Sharifabad, A., Ghahremani, M. H., Sabzevari, O., Naghdi, N., Abdollahi, M., et al. (2012) Effects of protein kinase $A$ and $G$ inhibitors on hippocampal cholinergic markers 
expressions in rolipram- and sildenafil-induced spatial memory improvement. Pharmacol Biochem Behav 101(3):311-319.

32. Zhuo, M., Hu, Y., Schultz, C., Kandel, E. R., \& Hawkins, R. D. (1994) Role of guanylyl cyclase and CGMP-dependent protein kinase in long-term potentiation. Nature 368(6472):635639.

33. Matsumoto, Y., Unoki, S., Aonuma, H., \& Mizunami, M. (2006) Critical role of nitric oxidecGMP cascade in the formation of cAMP-dependent long-term memory. Learn Mem 13(1):35-44.

34. Lu, Y. F. \& Hawkins, R. D. (2002) Ryanodine receptors contribute to cGMP-induced latephase LTP and CREB phosphorylation in the hippocampus. J Neurophysiol 88(3):12701278.

35. Kandel, E. R. (2012) The molecular biology of memory: CAMP, PKA, CRE, CREB-1, CREB-2, and CPEB. Mol Brain 5:14.

36. Silva, A. J., Kogan, J. H., Frankland, P. W., \& Kida, S. (1998) CREB and memory. Annu Rev Neurosci 21:127-148.

37. Robichaud, A., Tattersall, F. D., Choudhury, I., \& Rodger, I. W. (1999) Emesis induced by inhibitors of type IV cyclic nucleotide phosphodiesterase (PDE IV) in the ferret. Neuropharmacology 38(2):289-297.

38. Miller, A. D. \& Leslie, R. A. (1994) The area postrema and vomiting. Front Neuroendocrinol 15(4):301-320.

39. Mori, F., Perez-Torres, S., De Caro, R., Porzionato, A., Macchi, V., et al. (2010) The human area postrema and other nuclei related to the emetic reflex express CAMP phosphodiesterases 4B and 4D. J Chem Neuroanat 40(1):36-42.

40. Rabe, K. F. (2011) Update on roflumilast, a phosphodiesterase 4 inhibitor for the treatment of chronic obstructive pulmonary disease. BrJ Pharmacol 163(1):53-67.

41. Bischoff, E. (2004) Vardenafil preclinical trial data: potency, pharmacodynamics, pharmacokinetics, and adverse events. Int J Impot Res 16 Suppl 1:S34-37.

42. Hellstrom, W. J., Gittelman, M., Karlin, G., Segerson, T., Thibonnier, M., et al. (2002) Vardenafil for treatment of men with erectile dysfunction: efficacy and safety in a randomized, double-blind, placebo-controlled trial. J Androl 23(6):763-771.

43. Richter, W., Menniti, F. S., Zhang, H. T., \& Conti, M. (PDE4 as a target for cognition enhancement. Expert Opin Ther Targets 17(9):1011-1027.

44. Tallarida, R. J. (2012) Quantitative methods for assessing drug synergism. Genes Cancer 2(11):1003-1008.

45. Sierksma, A. S., Rutten, K., Sydlik, S., Rostamian, S., Steinbusch, H. W., et al. (2012) Chronic phosphodiesterase type 2 inhibition improves memory in the APPswe/PS1dE9 mouse model of Alzheimer's disease. Neuropharmacology 64:124-136.

46. Xu, Y., Pan, J., Chen, L., Zhang, C., Sun, J., et al. (2012) Phosphodiesterase-2 inhibitor reverses corticosterone-induced neurotoxicity and related behavioural changes via cGMP/PKG dependent pathway. Int J Neuropsychopharmacol 16(4):835-847. 


\section{CHAPTER 6}

\section{7,8-DIHYDROXYFLAVONE IMPROVES MEMORY CONSOLIDATION PROCESSES IN RATS AND MICE}

E Bollen, T Vanmierlo, S Akkerman, C Wouters, H.M.W. Steinbusch, J Prickaerts.

Behavioural Brain Research, 2012, 257: 8-12 


\section{ABSTRACT}

Brain-derived neurotrophic factor (BDNF) is a crucial regulator of neuronal survival and neuroplasticity in the central nervous system (CNS). As a result, there has been a growing interest in the role of BDNF in neuropsychiatric disorders associated with neurodegeneration, including depression and dementia. However, until now, BDNF-targeting therapies have yielded disappointing results. BDNF is thought to exert its beneficial effects on synaptic and neuronal plasticity mainly through binding to the tyrosine kinase B (TrkB) receptor. Recently, 7,8-dihydroxyflavone (7,8-DHF) was identified as the first selective TrkB agonist. In the present study the effectiveness of 7,8-DHF on memory formation was evaluated. In healthy rats, 7,8-DHF improved object memory formation in the object recognition task when administered both immediately and 3 hours after learning. In a transgenic mouse model for Alzheimer's disease, i.e. APPswe/PS1dE9 mice, spatial memory as measured in the object location task was improved after administration of 7,8-DHF in a similar manner as wild-type littermates at 7months of age in which neuropathology and hippocampal dysfunction are known to be present. The acute beneficial effects in healthy animals suggest that effects might be symptomatic rather than curing. Nevertheless, this study suggests that 7,8-DHF might be a promising therapeutic target in dementia. 


\section{INTRODUCTION}

Brain derived neurotrophic factor (BDNF) is a neurotrophin which has emerged as one of the most important regulators of differentiation and survival of neurons in the central nervous system (CNS). It instigates diverse and region specific effects. BDNF plays an important role in neuronal survival and pruning throughout the development of the brain and is involved in physiological proliferation during embryonic development, and cortical and hippocampal health (1). In the adult CNS, BDNF is shown to be highly implicated in mechanisms of synaptic plasticity and neurogenesis (2). Interestingly, one specific form of plasticity, i.e. hippocampal long-term potentiation (LTP) has been reported to be reliant on $\operatorname{BDNF}(3,4)$. LTP is generally considered as the cellular correlate of memory formation. The dependence of LTP on BDNF implies a critical role for BDNF in the formation of learning and memory. Indeed, evidence for the involvement of BDNF in learning and memory is substantial. BDNF expression has been reported to increase following learning experiences in various tasks and animals (see $(5$, 6)). Although genetic modeling of BDNF is complex because of its crucial role in neurodevelopment, serious memory deficits are apparent in in vivo models when lowering or prohibiting expression of BNDF through conditional knockouts or viral approaches (7-9). Furthermore, there is an association between lower levels of BDNF and cognitive decline as is obvious in aging, depression, schizophrenia and Rett's syndrome (10). In Alzheimer's disease (AD) in which memory decline is a core symptom, BDNF activity is decreased. Expression of mature BDNF (mBDNF) as well as forms of proBDNF, precursors of BDNF, are reduced in hippocampal and cortical areas, and this decline is present in preclinical stages of $A D(11)$.

Therefore, targeting BDNF is considered a very attractive treatment strategy for disorders such as AD. However, up until now, efforts to establish direct BDNF-based therapeutic interventions have yielded disappointing effects in preclinical studies (12). There are multiple reasons why BDNF-targeting therapies are inadequate. BDNF has a poor pharmacokinetic profile, as it undergoes little diffusion, does not readily cross the blood-brain barrier and has a short half-life in vivo. Furthermore, due to the inability of recombinant 
BDNF to significantly cross the blood-brain barrier, proposed administration techniques were mostly too invasive to apply on a large scale in patients.

BDNF binds to two receptors, Tyrosine kinase $B$ (TrkB) receptor and $p 75$. Whereas p75 binds mostly proBDNF, a precursor of BDNF, and all other neurotrophins with low-affinity, TrkB binds specifically mature BDNF (mBDNF) with high affinity (13). Generally, it is understood that p75 is closely associated with apoptotic processes, while TrkB is linked to processes of neuronal growth and survival (13).

Recently 7,8-dihydroxyflavone (7,8-DHF) was identified as a selective TrkB agonist. This small and potent molecule mimics the effects of BDNF on TrkB binding and consequent activation of neuroprotective molecular pathways (14-16). Furthermore, since 7,8-DHF selectively activates TrkB receptors and not p75 receptors, potential apoptotic processes that are associated with BDNF signaling are avoided. Therefore, 7,8-DHF is an interesting new option for therapeutic interventions in memory decline. In this study, we aimed at a profound evaluation the memory-enhancing effects of 7,8-DHF. We assessed episodic-like memory in rodents, in particular object memory in healthy rats and spatial, i.e. object location, memory in a genetic mouse model for $A D$, i.e. APPswe/PS1dE9 mice.

\section{METHODS}

All experiments were designed to minimize the potential discomfort of the animals during the behavioral experiments and all experimental procedures were approved by the local ethical committee for animal experiments according to governmental guidelines.

\section{Animals}

In the current study, both rats and mice were tested. Animals were separately caged in individually ventilated cages in a reversed light/dark cycle (lights on from 19.00h-07.00h). During the entire experiment animals had free access to food and water. They were tested during their active phase (the dark 
phase) in red light conditions. Animals were housed in the same room where testing procedures took place. A radio played continuously to provide background noise.

Three-month-old male Wistar rats and seven-month old male APPswe/PS1dE9 transgenic mice and wild type (WT) littermates, that were purchased from Charles River (Sulzfeld, Germany and L'Arbresle, France, respectively) were used in this study. The APPswe/PS1dE9 mice express mouse/human chimeric APP695 harbouring the Swedish K694M/N595L mutation and the PS1 gene with a deletion of exon 9 (PS1 $\Delta$ E9) under the mouse prion protein promoter (17). The animals were backcrossed to a C57BL/6 background for at least 8 generations.

\section{Behavioral Procedures}

\section{Object Recognition Task (ORT)}

The object recognition task was performed in Wistar rats as described elsewhere (18). The ORT is a one trial learning task. In the first (learning) trial the rat was put into an arena in which two identical objects are placed. After a certain delay, the animal is given a second trial. In this second trial the animals are again placed in the same arena but now one of the objects has been replaced by a novel object. Time spent exploring both objects was recorded using a personal computer. 24 hours after the learning trial, memory performance was assessed by replacing one of the previously presented objects by a new object. Exploration of both objects was again recorded. The interval in between the learning and retrieval trial was set at 24 hours. Under normal circumstances rats have forgotten the objects after 24 hours, i.e. they are unable to discriminate between the new and old object (19).

Before actual testing, rats were handled and habituated to the ORT setting and oral drug administration (p.o.) procedures. All experimental conditions were tested in 15 Wistar rats. This number is based on previous experience in ORT, and results in a statistical power of $89 \%(\delta=3.20 ; \alpha=0.05)$. To avoid bias, we excluded animals that had less than seven seconds exploration during a 
trial (19). Throughout the experiment, 23 observations did not meet this criterion and were discarded from further analysis. Conditions were tested in random order. Within one testing session, multiple treatment conditions were tested. The experimenter scoring the animals was unaware of the treatment condition being tested.

\section{Object Location Task (OLT)}

Using this one-trial learning task spatial memory of WT and APPswe/PS1dE9 mice was assessed (20). In the first (learning) trial mice were put into an arena for four minutes in which two identical objects are placed. After a certain delay, the animal is given a second trial. In this second trial the animals were again placed in the same arena with the same objects, but one of the objects had been moved to a different position within the area. On a personal computer the time the mice explore the two objects is manually scored. Mice show a good spatial memory performance when a one-hour delay is interposed between the first and second trial. However, when a twenty-four hour delay is used they do not discriminate between the moved and the stationary object in the second trial, indicating that they do not remember the object's location, which was presented in the first trial (21). We opted for the 24 delay in order to evaluate the potential of 7,8-DHF to prolong the recollection of the object locations in wild-type animals as well as in animals with existing AD pathology. In total, 67 animals (34 WT and 33 APPswe/PS1dE9) were repeatedly tested in the different treatment conditions, which resulted in a power of $83 \%(\delta=0.5 ; \alpha=0.05)$. A minimum of four seconds exploration was set as an inclusion criterion. Rats and mice differ in their exploration rates, with mice being more neophobic. Therefore, the time in the arena and inclusion criteria are adjusted accordingly. We had to remove a total of 42 observations (18 WT and 24 APPswe/PS1dE9) from the dataset. The experimenter was unaware of the genotype of the animals and condition tested. 


\section{Treatment}

TrkB agonist dihydroxyflavone (7,8-DHF; TCI Europe, Zwijndrecht, Belgium) was prepared fresh at day of testing and was dissolved for administration in mice or rats in $2 \%$ or $4 \%$ tween 80 (Sigma Aldrich, Zwijndrecht, The Netherlands) and $98 \%$ or $96 \%$ tylose $(0.5 \%)$ respectively, given that we apply a 30 -fold higher dosage in rats in comparison to mice.

Different dosages $(0.1 \mathrm{mg} / \mathrm{kg}, 0.3 \mathrm{mg} / \mathrm{kg}, 1 \mathrm{mg} / \mathrm{kg}$ and $3 \mathrm{mg} / \mathrm{kg}$ ) were tested to obtain a dose-response curve. In rats, the compound was dissolved in vehicle to the desired concentration in a volume of $2 \mathrm{ml} / \mathrm{kg}$. Rats were injected immediately or 3 hours after $\mathrm{T} 1$ to affect early or late memory consolidation processes. In mice, 7,8-DHF was administered i.p., at a volume of $6.67 \mathrm{ml} / \mathrm{kg}$ and at a dosage of $0.1 \mathrm{mg} / \mathrm{kg}$ based on previous experiences in extrapolating doses from rats to mice. Injections in mice were given three hours after learning based on the findings in rats. The order of testing of the different treatment conditions was randomized, and every testing day two different conditions were tested. Every animal was subjected once to every treatment condition.

\section{Statistical analysis}

Results of ORT and OLT are based on the measures of times spent by rats in exploring an object during $\mathrm{T} 1$ and $\mathrm{T} 2$. The reported discrimination index is a relative measure representing discrimination between the new and old object or position, corrected for explorative activity ((time spent exploring new location)/time spent exploring old)/total time spent exploring). Explorative activity during the first (e1) and second (e2) trial is also taken into account as measure, to verify normal activity during the task.

Data of the rat study were analyzed in two ways. Firstly, the ability to discriminate between the new and old was separately assessed object for every condition using a one-sample t-test to test for a difference from zero, with zero representing no discrimination. Second, we analyzed group differences for memory performance and explorative activity using a oneway ANOVA with Dunnett's multiple comparison corrections. To assess memory performance and explorative activity in the mice study a two-way ANOVA was applied with treatment and genotype as factors. 


\section{RESULTS}

\section{Effects of 7,8-DHF on object recognition memory in healthy rats}

First, we determined the effective dose of the TrkB agonist 7,8-DHF in rats. Thus, different dosages of 7,8-DHF $(0.3 \mathrm{mg} / \mathrm{kg} ; 1 \mathrm{mg} / \mathrm{kg}$ and $3 \mathrm{mg} / \mathrm{kg})$ were tested at a $24 \mathrm{~h}$ interval. Animals were treated immediately or $3 \mathrm{~h}$ after the learning trial. In general, we did not observe any significant change over treatment conditions in exploration during the first $(e 1 ; F(8,106)=1.80 ; n$.s. $)$ or second trial $(e 2 ; F(8,106)=1.24 ;$ n.s. $)$ in the ORT.

Memory performance in the ORT with different dosages of 7,8-DHF administrated immediately after learning are represented in Figure $1 \mathrm{~A}$. Whereas vehicle $(t(11)=0.79$, n.s.) and $0.3 \mathrm{mg} / \mathrm{kg}$ treated animals were unable to discriminate between new and old objects $(t(9)=0.20$, n.s.) after 24 hours, animals which had been given $1 \mathrm{mg} / \mathrm{kg}(t(8)=4.88, p<0.01)$ and $3 \mathrm{mg} / \mathrm{kg}$ $(t(12)=5.68, p<0.001)$ favored the new object. A one-way ANOVA showed that the discrimination indices differed across the three dosages $(F(3,41)=10.33 ; p<0.001)$. Post hoc Dunnett's Multiple Comparison Test revealed similar results as the t-tests: Vehicle treated animals differed from animals treated with $1 \mathrm{mg} / \mathrm{kg}(p<0.05)$ and $3 \mathrm{mg} / \mathrm{kg}(p<0.01)$. There was no significant difference found between the lowest dose, i.e. $0.3 \mathrm{mg} / \mathrm{kg}$, and the vehicle group (n.s.).

Effects of different dosages of 7,8-DHF given 3 hours after learning are depicted in Figure 1B. A preference for the new object was observed 24 hours after learning in the $0.3 \mathrm{mg} / \mathrm{kg}(t(13)=3.10, p<0.05), 1 \mathrm{mg} / \mathrm{kg}$ $(t(11)=3.27 ; p<0.05)$ as well as the $3 \mathrm{mg} / \mathrm{kg}(t(13)=6.81, p<0.001)$ treatment condition. After detection of memory improvement at a $0.3 \mathrm{mg} / \mathrm{kg}$, an extra dosing condition $(0.1 \mathrm{mg} / \mathrm{kg})$ was added, which did not yield significant discrimination $(t(12)=0.71$, n.s.). A one-way ANOVA revealed a treatment effect $(F(4,63)=6.13, p<0.001)$. Further post-hoc analyses showed differences between vehicle and $0.3 \mathrm{mg} / \mathrm{kg}(p<0.05)$ and $3 \mathrm{mg} / \mathrm{kg}(p<0.01)$ treated animals. 


\section{Effects of 7,8-DHF on object location memory in WT and AD mice}

No significant differences in exploratory activity were observed between genotypes or treatment conditions during the first exploration trial and there was no interaction effect $\left(\mathrm{F}^{\prime} \mathrm{s}(1,86)<2.68\right.$, n.s.) Also during the second trial of the OLT, exploratory activity was similar across conditions $\left(F^{\prime} s(1,86)<2.49\right.$, n.s.). We found a memory improving effect of treatment effect 7,8-DHF $(F(1,88)=25.87, \quad p<0.001)$. Animals that were treated showed a better discrimination performance. No significant influence of genotype was observed. Indeed, untreated WT $(t(24)=0.522$, n.s.) and APPswe/PS1dE9 $(t(20)=0.786$, n.s.) mice did not discriminate between objects. After administration of $7,8 \mathrm{DHF}, \mathrm{WT}(t(24)=4.31 ; p<0.001)$ and APPswe/PS1dE9 mice $(t(20)=5,86 ; p<0.001)$ significantly discriminated between the new and old object.
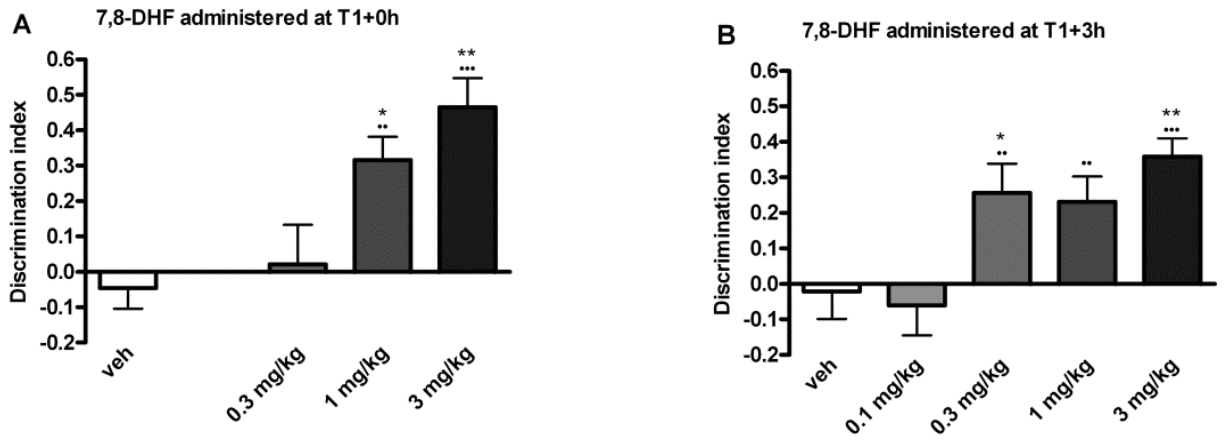

Figure 1: Discrimination in a 24 hour interval object recognition task after administration of different dosages of 7,8-DHF immediately $(\mathrm{T} 1+0 \mathrm{~h} ; \mathrm{A})$ or 3 hours after learning (T1+3h; B). A: $\mathrm{n}=$ $12,10,9,13 ; \mathrm{B}: \mathrm{n}=15,13,14,12,14 .{ }^{*} p<0.05 ;{ }^{* *} p<0.01 ;{ }^{* * *} p<0.001$ with a Dunnett's post-hoc test; $\bullet p<0.05 ; \bullet p<0.01 ; \bullet \bullet<0.001$ with a one sample t-test: comparison with zero.

\section{DISCUSSION AND CONCLUSION}

The aim of the current study was to evaluate the cognition enhancing properties of 7,8-DHF. Beneficial effects of 7,8-DHF were already reported in 
previous studies. Thus far, most studies have focused on depressive-like behavior and stress-related memory performance because of the wellestablished link between depression and BDNF (22). When enhancing BDNF/TrkB-signaling via 7,8-DHF administration, potent antidepressant effects are evident (23-25). Furthermore, it enhances fear learning, and when assessing it in preclinical models of post-traumatic stress disorder (PTSD), in which fear conditioning is disturbed, 7,8-DHF is able to reverse emotional learning and extinction deficits (26-28).

In this study, episodic-like object and spatial memory were assessed. Whereas preceding studies mostly reported the ability of 7,8-DHF to reverse of deficits due to age, stress or genetic background, we report memory enhancement in young healthy rats. The dosages used were lower (p.o. $0.1-$ $3 \mathrm{mg} / \mathrm{kg}$ ) than those used in previous studies (i.p. $5 \mathrm{mg} / \mathrm{kg}$ ) (16, 29-31), yet they generated potent memory improving effects. These findings strengthen the notion postulated in existing literature that BDNF has an important role in memory formation. BDNF mRNA and protein expression as well as TrkB phosphorylation have been reported to increase in memory-related brain structures following learning (32). Intra-hippocampal BDNF administration

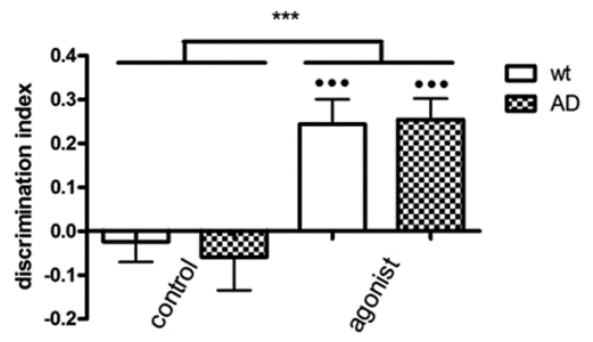

Figure 2: Discrimination in a 24 hour interval object location task in APPswe/PS1dE9 mice (AD) and wild-type littermates (WT). Animals were injected with $0.1 \mathrm{mg} / \mathrm{kg} 7,8-\mathrm{DHF}$ three hours after the learning trial. $\mathrm{n}=25,21,25,21 .{ }^{* *} p<0.001$ with an ANOVA; $\bullet p<0.01 ; \bullet \bullet \bullet<0.001$ with a one sample t-test: comparison with zero. 
improves memory performance while intracerebroventricular infusion of antisense BDNF oligonucleotides causes memory deficits $(33,34)$. This study specifically shows the importance BDNF/TrkB-signaling in memory consolidation.

However, memory is not a unitary process; different stages in memory formation require activation of different molecular pathways. In memory consolidation, a differentiation can be made between an early, proteinsynthesis independent phase in which temporary changes in the synapse and a late $(<3 h)$ protein-synthesis-dependent phase with enduring structural synaptic changes. We applied the TrkB agonist immediately or 3 hours after the learning experience to assess at which phase in the consolidation process TrkB activation would facilitate the formation of the memory trace. BDNF activity has been mostly associated with later consolidation phases. A crucial transcription factor for de novo protein synthesis is CAMP responsive element binding factor (CREB), which is an important regulator of BDNF expression (35). Therefore we expected to find a more prominent effect of 7,8-DHF in later phases of memory consolidation. Along similar lines, recently it has been shown that hippocampal BDNF protein levels are highest in the late phase of consolidation (32). Surprisingly, 7,8-DHF could boost memory performance both during the early as well as the later consolidation phase. Two explanations can be given for this finding. On the one hand, it may be that administration of 7,8-DHF immediately after learning directly enhances synaptic transmission via glutamate release and altering NMDA receptor signaling, whereas a delayed administration stabilizes the memory trace by promoting long-term synaptic changes (36-38). On the other hand, one could also argue that that the effects of administration during early consolidation might be explained by residual activity of 7,8-DHF in the brain 3 hours after learning given the pharmacokinetic profile of 7,8-DHF. Our finding that the lowest effective dose was lower, i.e. $0.3 \mathrm{mg} / \mathrm{kg}$, when 7,8 DHF was administered during the late consolidation phase compared to 1 $\mathrm{mg} / \mathrm{kg}$ during early consolidation, supports this notion and might suggest a stronger involvement of BDNF/TrkB signaling in late memory consolidation.

Furthermore, effects of 7,8-DHF on spatial memory in mice were evaluated. We showed memory enhancing effects in a 24 interval, which were equally 
pronounced in wild-type and in AD mice. In the used APPswe/PS1dE9 mouse model of $A D, A \beta$ plaques are reported to be present from about 4 months of age and from 7 months of age hippocampal functional deficits are evident $(17,39-41)$. One may reason that the acute memory improvement of 7,8-DHF is probably symptomatic rather than addressing the cause of $A D$ itself. Interestingly, one study already assessed the effectiveness of 7,8-DHF in an AD mouse model. In 5XFAD mice, Devi and Ohno (30) reported full restoration of a working memory deficit after systemic 7,8-DHF application (5 $\mathrm{mg} / \mathrm{kg}$ ) during 10 consecutive days together with normalized BDNF-TrkB functioning and reductions in BACE1 levels. They observed a downregulation of baseline levels of $\beta$-secretase enzyme that initiates amyloid- $\beta$ generation after 7,8-DHF treatment. Thus this suggests that BDNF-TrkB dysfunction might be contributing to amyloid- $\beta$ accumulation in 5XFAD mice. We show that acute administration of 7,8-DHF in a fifty-fold lower dosage is also capable of showing beneficial effects on cognition in animals with amyloid$\beta$-induced neurotoxicity and synaptic dysfunction.

The beneficial effects of 7,8-DHF can be explained by its selective binding to the TrkB receptor at the same binding site as BDNF, which causes dimerization and autophosphorylation of the receptor and instigates downstream signaling cascades both in vivo and in vitro, leading to higher levels of phosphorylation of Akt, Erk and CaMKII (14, 16, 30, 31). Furthermore, the TrkB agonist protects neurons from apoptosis, increases spine density in the hippocampus and induces epigenetic changes by increasing levels of histone acetylation (16).

In contrast to recombinant $\mathrm{BDNF}, 7,8-\mathrm{DHF}$ readily passes the blood-brain barrier, has a beneficial pharmacokinetic profile, and is effective in low doses $(14,25,42)$. Furthermore, selectively targeting TrkB receptors has a number of advantages over directly increasing BDNF levels. Overexpression of BDNF has been shown to actually have detrimental effects on memory performance (43). This negative outcome might be linked to the proapoptotic p75 receptor to which BDNF binds with low affinity. This could be circumvented by applying an agonist of TrkB. In addition, activation of BDNF/TrkB signaling cascades seemingly instigates a positive feedback loop, possibly via Erk phosphorylation and consequent histone acetylation (16). In 
case of lowered BDNF levels, application of 7,8-DHF has been reported not only to activate BDNF/TrkB-related cascades, but also to restore BDNF expression to normal levels.

Although the role of BDNF in the pathogenesis of $A D$ is not fully understood, 7,8-DHF could be at least considered a symptomatic approach to treat ADrelated cognitive dysfunction, that is by improving memory and synaptic function to slow down the process of functional decline without dealing with the cause of the disease. In that regard, 7,8-DHF might be a superior option over current symptomatic therapeutic interventions, that have limited efficacy. Dysfunction of BDNF/TrkB-signaling is already present in preclinical stages of $A D$ and even more importantly, these changes are preceding the cholinergic dysfunctions on which most treatment options are currently based (11). However, the clinical potential of 7,8-DHF is not limited to AD. There are indications that it may serve to be an interesting tool to treat agerelated memory decline, Parkinson's disease, Rett's syndrome, depression and PTSD $(14,24,30,31,44,45)$. Overall, it can be concluded 7,8-DHF is a very appealing candidate for treating several neurodegenerative disorders including age-related memory decline and AD. 


\section{REFERENCES}

1. Chapleau, C. A. \& Pozzo-Miller, L. (Divergent roles of p75NTR and Trk receptors in BDNF's effects on dendritic spine density and morphology. Neural Plast 2012:578057.

2. Bramham, C. R. \& Messaoudi, E. (2005) BDNF function in adult synaptic plasticity: the synaptic consolidation hypothesis. Prog Neurobiol 76(2):99-125.

3. Messaoudi, E., Ying, S. W., Kanhema, T., Croll, S. D., \& Bramham, C. R. (2002) Brainderived neurotrophic factor triggers transcription-dependent, late phase long-term potentiation in vivo. J Neurosci 22(17):7453-7461.

4. Pang, P. T., Teng, H. K., Zaitsev, E., Woo, N. T., Sakata, K., et al. (2004) Cleavage of proBDNF by tPA/plasmin is essential for long-term hippocampal plasticity. Science 306(5695):487-491.

5. Cunha, C., Brambilla, R., \& Thomas, K. L. (2010) A simple role for BDNF in learning and memory? Front Mol Neurosci 3:1.

6. Bekinschtein, P., Cammarota, M., \& Medina, J. H. (2013) BDNF and memory processing. Neuropharmacology http://dx.doi.org/10.1016/j.neuropharm.2013.04.024.

7. Linnarsson, S., Bjorklund, A., \& Ernfors, P. (1997) Learning deficit in BDNF mutant mice. Eur J Neurosci 9(12):2581-2587.

8. Heldt, S. A., Stanek, L., Chhatwal, J. P., \& Ressler, K. J. (2007) Hippocampus-specific deletion of BDNF in adult mice impairs spatial memory and extinction of aversive memories. Mol Psychiatry 12(7):656-670.

9. Gorski, J. A., Balogh, S. A., Wehner, J. M., \& Jones, K. R. (2003) Learning deficits in forebrain-restricted brain-derived neurotrophic factor mutant mice. Neuroscience 121(2):341-354.

10. Autry, A. E. \& Monteggia, L. M. (2012) Brain-derived neurotrophic factor and neuropsychiatric disorders. Pharmacol Rev 64(2):238-258.

11. Peng, S., Wuu, J., Mufson, E. J., \& Fahnestock, M. (2005) Precursor form of brainderived neurotrophic factor and mature brain-derived neurotrophic factor are decreased in the pre-clinical stages of Alzheimer's disease. J Neurochem 93(6):14121421.

12. Thoenen, H. \& Sendtner, M. (2002) Neurotrophins: from enthusiastic expectations through sobering experiences to rational therapeutic approaches. Nat Neurosci 5 Suppl:1046-1050.

13. Lu, B., Pang, P. T., \& Woo, N. H. (2005) The yin and yang of neurotrophin action. Nat Rev Neurosci 6(8):603-614.

14. Jang, S. W., Liu, X., Yepes, M., Shepherd, K. R., Miller, G. W., et al. (2010) A selective TrkB agonist with potent neurotrophic activities by 7,8-dihydroxyflavone. Proc Natl Acad Sci U S A 107(6):2687-2692.

15. Mendelsohn, A. R. \& Larrick, J. W. (2012) Epigenetic-mediated decline in synaptic plasticity during aging. Rejuvenation Res 15(1):98-101.

16. Zeng, Y., Tan, M., Kohyama, J., Sneddon, M., Watson, J. B., et al. (2011) Epigenetic enhancement of BDNF signaling rescues synaptic plasticity in aging. J Neurosci 31(49):17800-17810. 
17. Sierksma, A. S., Rutten, K., Sydlik, S., Rostamian, S., Steinbusch, H. W., et al. (2012) Chronic phosphodiesterase type 2 inhibition improves memory in the APPswe/PS1dE9 mouse model of Alzheimer's disease. Neuropharmacology 64:124-136.

18. van Goethem, N. P., Rutten, K., van der Staay, F. J., Jans, L. A., Akkerman, S., et al. (2012) Object recognition testing: rodent species, strains, housing conditions, and estrous cycle. Behav Brain Res 232(2):323-334.

19. Akkerman, S., Blokland, A., Reneerkens, O., van Goethem, N. P., Bollen, E., et al. (Object recognition testing: methodological considerations on exploration and discrimination measures. Behav Brain Res 232(2):335-347.

20. Vanmierlo, T., Rutten, K., Dederen, J., Bloks, V. W., van Vark-van der Zee, L. C., et al. (2011) Liver $X$ receptor activation restores memory in aged AD mice without reducing amyloid. Neurobiol Aging 32(7):1262-1272.

21. Bruno, O., Fedele, E., Prickaerts, J., Parker, L. A., Canepa, E., et al. (2011) GEBR-7b, a novel PDE4D selective inhibitor that improves memory in rodents at non-emetic doses. Br J Pharmacol 164(8):2054-2063.

22. Castren, E., Voikar, V., \& Rantamaki, T. (2007) Role of neurotrophic factors in depression. Curr Opin Pharmacol 7(1):18-21.

23. Liu, X., Chan, C. B., Jang, S. W., Pradoldej, S., Huang, J., et al. (2010) A Synthetic 7,8Dihydroxyflavone Derivative Promotes Neurogenesis and Exhibits Potent Antidepressant Effect. J Med Chem 53:8274-8286.

24. Blugeot, A., Rivat, C., Bouvier, E., Molet, J., Mouchard, A., et al. (2011) Vulnerability to depression: from brain neuroplasticity to identification of biomarkers. J Neurosci 31(36):12889-12899.

25. Liu, X., Qi, Q., Xiao, G., Li, J., Luo, H. R., et al. (2013) O-Methylated Metabolite of 7,8Dihydroxyflavone Activates TrkB Receptor and Displays Antidepressant Activity. Pharmacology 91(3-4):185-200.

26. Andero, R., Heldt, S. A., Ye, K., Liu, X., Armario, A., et al. (2011) Effect of 7,8dihydroxyflavone, a small-molecule TrkB agonist, on emotional learning. Am J Psychiatry 168(2):163-172.

27. Andero, R., Daviu, N., Escorihuela, R. M., Nadal, R., \& Armario, A. (2012) 7,8dihydroxyflavone, a TrkB receptor agonist, blocks long-term spatial memory impairment caused by immobilization stress in rats. Hippocampus 22(3):399-408.

28. Choi, D. C., Gourley, S. L., \& Ressler, K. J. (2012) Prelimbic BDNF and TrkB signaling regulates consolidation of both appetitive and aversive emotional learning. Transl Psychiatry 2:e205.

29. Andero, R., Daviu, N., Escorihuela, R. M., Nadal, R., \& Armario, A. (2010) 7,8dihydroxyflavone, a TrkB receptor agonist, blocks long-term spatial memory impairment caused by immobilization stress in rats. Hippocampus.

30. Devi, L. \& Ohno, M. (2011) 7,8-Dihydroxyflavone, a Small-Molecule TrkB Agonist, Reverses Memory Deficits and BACE1 Elevation in a Mouse Model of Alzheimer's Disease. Neuropsychopharmacology.

31. Zeng, Y., Liu, Y., Wu, M., Liu, J., \& Hu, Q. (2012) Activation of TrkB by 7,8dihydroxyflavone prevents fear memory defects and facilitates amygdalar synaptic plasticity in aging. J Alzheimers Dis 31(4):765-778. 
32. Callaghan, C. K. \& Kelly, A. M. (2013) Neurotrophins play differential roles in short and long-term recognition memory. Neurobiol Learn Mem 104C:39-48.

33. Mizuno, M., Yamada, K., Olariu, A., Nawa, H., \& Nabeshima, T. (2000) Involvement of brain-derived neurotrophic factor in spatial memory formation and maintenance in a radial arm maze test in rats. J Neurosci 20(18):7116-7121.

34. Cirulli, F., Berry, A., Chiarotti, F., \& Alleva, E. (2004) Intrahippocampal administration of BDNF in adult rats affects short-term behavioral plasticity in the Morris water maze and performance in the elevated plus-maze. Hippocampus 14(7):802-807.

35. Shieh, P. B. \& Ghosh, A. (1999) Molecular mechanisms underlying activity-dependent regulation of BDNF expression. J Neurobiol 41(1):127-134.

36. Tyler, W. J., Zhang, X. L., Hartman, K., Winterer, J., Muller, W., et al. (2006) BDNF increases release probability and the size of a rapidly recycling vesicle pool within rat hippocampal excitatory synapses. J Physiol 574(Pt 3):787-803.

37. Rose, C. R., Blum, R., Kafitz, K. W., Kovalchuk, Y., \& Konnerth, A. (2004) From modulator to mediator: rapid effects of BDNF on ion channels. Bioessays 26(11):1185-1194.

38. Jovanovic, J. N., Czernik, A. J., Fienberg, A. A., Greengard, P., \& Sihra, T. S. (2000) Synapsins as mediators of BDNF-enhanced neurotransmitter release. Nat Neurosci 3(4):323-329.

39. Garcia-Alloza, M., Robbins, E. M., Zhang-Nunes, S. X., Purcell, S. M., Betensky, R. A., et al. (2006) Characterization of amyloid deposition in the APPswe/PS1dE9 mouse model of Alzheimer disease. Neurobiol Dis 24(3):516-524.

40. O'Leary, T. P. \& Brown, R. E. (2009) Visuo-spatial learning and memory deficits on the Barnes maze in the 16-month-old APPswe/PS1dE9 mouse model of Alzheimer's disease. Behav Brain Res 201(1):120-127.

41. Reiserer, R. S., Harrison, F. E., Syverud, D. C., \& McDonald, M. P. (2007) Impaired spatial learning in the APPSwe + PSEN1DeltaE9 bigenic mouse model of Alzheimer's disease. Genes Brain Behav 6(1):54-65.

42. Pardridge, W. M., Kang, Y. S., \& Buciak, J. L. (1994) Transport of human recombinant brain-derived neurotrophic factor (BDNF) through the rat blood-brain barrier in vivo using vector-mediated peptide drug delivery. Pharm Res 11(5):738-746.

43. Cunha, C., Angelucci, A., D'Antoni, A., Dobrossy, M. D., Dunnett, S. B., et al. (2009) Brain-derived neurotrophic factor (BDNF) overexpression in the forebrain results in learning and memory impairments. Neurobiol Dis 33(3):358-368.

44. Andero, R. \& Ressler, K. J. (2012) Fear extinction and BDNF: translating animal models of PTSD to the clinic. Genes Brain Behav 11(5):503-512.

45. Johnson, R. A., Lam, M., Punzo, A. M., Li, H., Lin, B. R., et al. (2012) 7,8-dihydroxyflavone exhibits therapeutic efficacy in a mouse model of Rett syndrome. J Appl Physiol 112(5):704-710. 


\section{CHAPTER 7}

\section{DISSOCIATIVE EFFECTS OF REPEATED ROLIPRAM}

ADMINISTRATION IN THE HIPPOCAMPUS AND NUCLEUS ACCUMBENS ON ANHEDONIA IN RATS.

E Bollen, J De Vry, T Vanmierlo, HWM Steinbusch, J Prickaerts. 


\section{ABSTRACT}

Phosphodiesterase (PDE) 4 inhibitors are known to exert antidepressant effects, which are attributed to increased phosphorylation of the transcription factor CAMP responsive element binding protein (CREB). However, previous work has demonstrated pro- and antidepressant effects when enhancing CREB expression specifically in the nucleus accumbens and hippocampus, respectively. In the present study, we evaluated whether a similar dissociation could be found after repeated administration of the PDE4 inhibitor rolipram directly to the CA1 of the dorsal hippocampus or to the core of the nucleus accumbens in healthy rats. Along this line we found that anhedonia, as measured by sucrose intake, was increased in animals in which we administered rolipram in the nucleus accumbens, while anhedonia was decreased in hippocampal-treated animals. Behavioral despair measures in the forced swim test and CREB activation in the hippocampus and nucleus accumbens remained unaltered after chronic local rolipram treatment. Since behavior and CREB activation were assessed at least 15 hours after a repeated rolipram injection, it may be suggested that rolipram does not induce tonic changes in CAMP-CREB signaling, though the temporary molecular changes might be long enough to alter synaptic plasticity and affective behavior. 


\section{INTRODUCTION}

Cyclic adenosine monophosphate (CAMP) is a second messenger that has been linked to the pathophysiology of depression. Whereas the targets of existing antidepressants are diverse, many have cAMP in common as an important downstream effector and numerous studies have demonstrated a downregulation of CAMP signaling in depression (1). These findings increased interest in the potential development of antidepressant drugs that directly target CAMP levels. Of special interest in this regard are phosphodiesterase inhibitors (PDEi). Phosphodiesterases (PDE) are a family of proteins that degrade cyclic nucleotides among which CAMP and as such, they decrease levels of CAMP. Phosphodiesterase inhibitors, and specifically inhibitors of the PDE4 subtype that selectively enhance CAMP signaling, exhibit antidepressant effects (2-6). These effects are attributed to the upregulation of gene transcription and subsequent neurotropic actions via the transcription factor CREB, an important downstream effector of the cAMP-cascade (7-9).

Interestingly, CREB has been reported to exert pro- and antidepressant effects in the ventral tegmental area-nucleus accumbens (VTA-NAc) and hippocampus, respectively. Rats with diminished CREB function in the NAc by

viral-mediated knockdown of CREB or overexpression of a dominant/negative form of CREB display less depressive-like behavior (10, 11). CREB overexpression in the NAc increases immobility in the forced swim test (11), while overexpression of CREB in the hippocampus decreases immobility time in this behavioral assay (12). In addition, antidepressants increase CREB levels in the hippocampus (13) while they reduce CREB phosphorylation in the NAC (14).

In this study, we want to confirm the antidepressant and prodepressant properties of CAMP/CREB signaling in the dorsal hippocampus and NAc core, respectively. Confirmation of this hypothesis would further identify CREB as a mediating factor in the proposed region-specific neurotrophic actions with regard to depressive-like behavior (9). This was done by infusing male Wistar rats with rolipram, a PDE4 inhibitor, for 14 consecutive days into the NAC 
core or CA1 region of the hippocampus. Depressive- and anxiety-like behavior was assessed in the sucrose intake test (SIT), the forced swim test (FST) and the zero-maze (ZM). Locomotor activity was measured in the open field (OF) test. After behavioral testing, hippocampal and NAc tissue was collected for biochemical analysis of CREB phosphorylation. We hypothesize that rolipram exerts antidepressant effects in the hippocampus and prodepressant effects in the NAc by increasing CAMP/PKA/CREB signaling.

\section{METHODS}

\section{Subjects}

All experimental procedures were approved by the local ethical committee for animal experiments of Maastricht University and were in agreement with local governmental guidelines. For behavioral experiments, 3- to 4-months old male Wistar rats were used (Charles River, Sulzfeld, Germany).

Rats were individually housed in standard type 3 Makrolon cages on sawdust bedding. The animals were held in an air-conditioned room (approximately $21^{\circ} \mathrm{C}$ ) and had free access to food and water. A softly playing radio provided constant background noise. A reversed light-dark cycle was applied in the room (lights on between 7.00 PM and 7.00 AM) in order to test the animals during their naturally active period. Animals were randomly tested between 9.00 AM and 4.00 PM.

\section{Drug administration}

Cannulae placement. Rats underwent stereotaxic surgery for cannulae implantation. Animals were fixed in a stereotaxic frame after induction of full anesthesia with a mixture of isoflurane and air (induction: $5 \%$; maintenance: $2 \%$ ). Cannulae (IDEE, Maastricht, The Netherlands) were placed bilaterally in hand drilled holes above the nucleus accumbens or hippocampus at the following coordinates: $-3.6 \mathrm{~mm}$ anterior, $\pm 3.0 \mathrm{~mm}$ lateral and $3.0 \mathrm{~mm}$ ventral from bregma for the CA1 region of the hippocampus and $1.59 \mathrm{~mm}$ anterior, 
$\pm 1.70 \mathrm{~mm}$ lateral and $7.80 \mathrm{~mm}$ ventral from bregma for the nucleus accumbens (Paxinos and Watson, 1998). When cannulae were in place, they were fixed to the skull using acrylic dental cement (Paladur ${ }^{\circledR}$, Heraeus Kulzer, Hanau, Germany) and small screws. Animals were allowed to recover from surgery for two weeks before the testing procedures started.

The injection location was verified by macroscopical examination of the injection track when dissecting the hippocampus or nucleus accumbens. The total number of animals taken into account in the analysis was 15 in the nucleus accumbens group (vehicle $n=7$, rolipram $n=8$ ) and 20 in the hippocampus group (vehicle $n=10$, rolipram $n=10$ ).

Treatment. The nucleus accumbens group and the hippocampus group were tested in two separate studies. Animals were treated daily for 14 consecutive days with the PDE4 inhibitor rolipram (Sigma Aldrich, Zwijndrecht, Netherlands) or vehicle. Animals were randomly assigned to a treatment condition. The experimenter was blinded to injection and behavioral testing conditions to avoid bias.

The vehicle solution contained $99.9 \%$ saline $(0.9 \% \mathrm{NaCl})$ and $0.1 \%$ dimethylsulfoxide (DMSO). We infused $0.5 \mu \mathrm{l}$ of the vehicle solution, or the vehicle solution containing rolipram $(0.0275 \mu \mathrm{g} / \mu \mathrm{l}$, i.e. $100 \mu \mathrm{M})$ bilaterally using two $10 \mu \mathrm{l}$ Hamilton syringes connected to a micropump with polyethylene tubes. Drug dosage was based on previous studies (15). The injection volume was infused over one minute after which the injection needles were left in place for an additional minute to prevent reflux of infused drugs along the cannula track. Rolipram was stored at $-20^{\circ} \mathrm{C}$ at a concentration of $0.0275 \mathrm{mg} / \mu \mathrm{l}$ in $100 \%$ DMSO. The injection solutions were freshly prepared on the day of administration. In order to avoid acute effects of the drug on the behavioral tests, administration of the drug was done daily between 4.00 P.M. and 7.00 P.M., i.e. after behavioral testing.

\section{Behavioral procedures}

Sucrose Intake Test: Anhedonia was assessed using the SIT. First, rats were allowed to drink a $1 \%$ sucrose solution for 24 hours. Next, animals received 
$24 \mathrm{~h}$ of normal drinking water. The consumption of water during these 24 hours was recorded for each rat by weighing the drinking bottles before and after the given period. Finally, rats were deprived from food and water for 6 hours, starting at 7.30 A.M., after which the consumption of $1 \%$ sucrose solution was measured for one hour. Water intake over 24 hours was used to correct for individual drinking behavior (16).

Locomotor activity: An OF was used to assess potential locomotor activity changes as these may interfere with other behavioral tasks relying on locomotion (17). The test was conducted in a square Plexiglas base $(100 \times 100$ $\mathrm{cm}$ ) with a black floor and $40 \mathrm{~cm}$ high transparent Plexiglas ${ }^{\circledR}$ walls, which was divided into 4 equal arenas $(50 \times 50 \mathrm{~cm}$ each) separated by $40 \mathrm{~cm}$ high black walls. Four rats were placed in the center of each open field and able to freely move around for $30 \mathrm{~min}$. The illumination of the room was reduced to 20 lux on the floor of the apparatus. The total distance moved (in $\mathrm{cm}$ ) was measured via a video camera connected to a video tracking system (Ethovision Pro, Noldus, Wageningen, The Netherlands).

Zero Maze: The ZM, as originally described by Shepherd (18) was used to assess anxiety. The apparatus consisted of a circular runway $(100 \mathrm{~cm}$ in diameter, $10 \mathrm{~cm}$ path width, $70 \mathrm{~cm}$ above floor level) made of black plastic, which is divided equally into two opposite open parts and two opposite parts enclosed with $40 \mathrm{~cm}$ high side walls. A $5 \mathrm{~mm}$ high rim surrounded the open parts to prevent falls. A rat was placed into one of the open parts facing a closed part and allowed to explore the maze for $5 \mathrm{~min}$. Total and relative duration and distance traveled in the open and enclosed parts were measured under low light conditions (1-2 lux) via an infrared video camera connected to a video tracking system (Ethovision Pro, Noldus).

Forced Swim Test: Animals were tested in the modified FST according to Detke (19). For this test, four cylindrical glass tanks $(40 \mathrm{~cm}$ length $\times 19 \mathrm{~cm}$ diameter) were used, filled to a depth of $30 \mathrm{~cm}$ with $25^{\circ} \mathrm{C}$ water. All animals initially underwent a session in which each animal was placed in the water for 12 min (day 1 ). On the following day, the animals were tested again by placing them in the water for 6 min (day 2). Immobility was scored manually by an experimenter who was blinded for the treatment condition being tested. Immobility was defined as follows: making no movements (floating) 
or only making those movements that are necessary to keep the nose above the water. Video tracking was not possible due to the inability of the animals to float in the water in a normal way, which was most likely due to the cannulated cap on their heads.

\section{Western Blot}

Two days after the testing procedures, and one day ( $24 \mathrm{~h})$ after the last infusion, animals were sacrificed by decapitation and their brains were rapidly removed. In the hippocampus treated animals, the whole hippocampal tissue was dissected immediately after sacrificing and was snap frozen in liquid nitrogen. In the nucleus accumbens treated animals, brains were snapfrozen upon decapitation. Later, brains were slightly defrosted and we dissected the nucleus accumbens section rapidly by cutting a coronal slice from $+2.0 \mathrm{~mm}$ to $+0.7 \mathrm{~mm}$ to bregma. Guided by the lateral ventricles and olfactory tubercles, the nucleus accumbens area was taken and again frozen to $-80 \mathrm{C}$. All tissues were stored in a $-80^{\circ} \mathrm{C}$ freezer.

Tissue was homogenized in $1.5 \mathrm{ml}$ of ice-cold extraction buffer containing PBS, $1 \mathrm{mM}$ EGTA, $1 \mathrm{mM}$ EDTA, 0.01\% SDS, and $1 \mathrm{mM}$ PMSF. Protein concentrations were determined using a Bradford assay (Bio-Rad, Veenendaal, the Netherlands) with bovine serum albumin as the standard. Equivalent amounts of protein $(50 \mu \mathrm{g})$ for each sample were resolved in $7.5 \%$ SDS-PAGE. After electrophoresis, proteins were transferred to polyvinylidene difluoride membranes. Membranes were incubated in 50\% Odyssey blocking buffer (Li-Cor, Wateringen, the Netherlands) and 50\% PBS with 1\% Tween 20 (PBS-T) for $1 \mathrm{hr}$ at room temperature to block nonspecific binding. The blots were incubated with primary antibodies against pCREB and CREB overnight at $4^{\circ} \mathrm{C}$. After washing in PBS-T, blots were incubated with secondary antibody in PBS-T for $1 \mathrm{hr}$. Membranes were then washed three times with PBS-T. The primary antibodies used were mouse anti-CREB (Cell Signaling Technology, Lake Placid, NY, \#9104, 1:1000) and rabbit anti-pCREB (phosphorylated at Ser-133; \#9198, 1:500; Cell Signaling). The secondary antibodies used were 1:5000 goat anti-rabbit IRDye 800 (\#926-32211, Li-Cor) and 1:5000 donkey anti-mouse IRDye 680 (\#926-32222, Li-Cor). Densitometric analysis was conducted to quantify the immunoreactivity with an Odyssey Infrared 
Imaging System (Li-Cor) and ImageJ software. The CREB and pCREB bands were detected at $43 \mathrm{kDa}$, and the $\mathrm{pCREB} / \mathrm{CREB}$ ratio was calculated for each sample and analyzed across conditions.

\section{Statistical analysis}

All data are represented as means and standard error of the mean (S.E.M.). Unpaired student's t-tests were performed to investigate effects of rolipram treatment on the behavioral outcome within the hippocampus and nucleus accumbens groups separately. Statistical significance was set at an alpha level of 0.05 .

Hippocampus

a

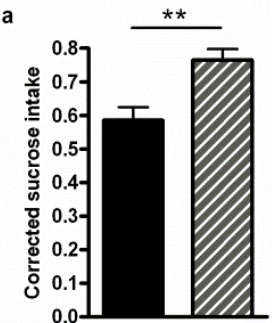

c

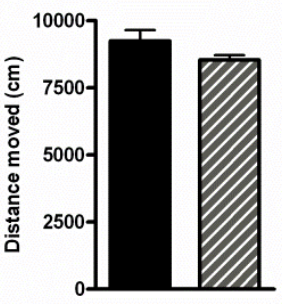

b

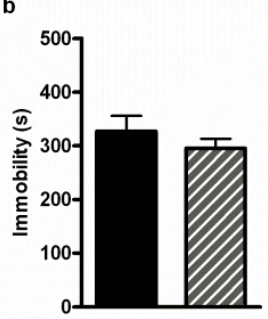

d

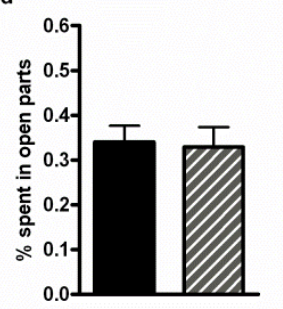

Nucleus Accumbens

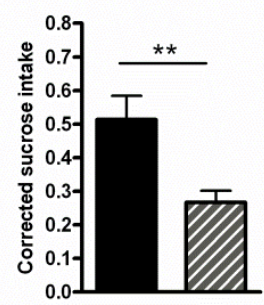

g

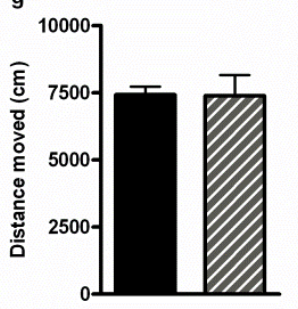

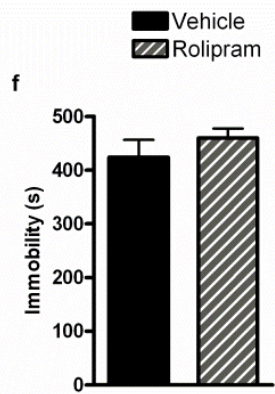

h

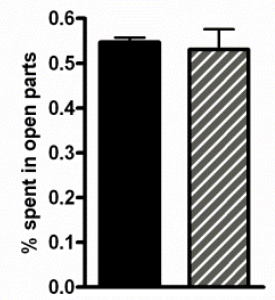

Figure 1. Behavioral assessment of affective behavior in animals chronically treated with rolipram in the hippocampus ( $a-d ; n=10-10$ ) or nucleus accumbens (e-h; $n=7-8)$. a, e: Amount of sucrose consumed in one hour corrected for $24 \mathrm{~h}$ water consumption. b, f: Immobility time in the forced swim task (day 1). c, g: Distance moved in the open field. $d$, h: Percentage of total time spent in the open parts of the zero maze. Bars represent means and S.E.M. ${ }^{* *}$ indicate significant differences between groups, with $p<0.01$. 


\section{RESULTS}

\section{Hippocampus}

Daily drug administration into the hippocampus changed affective behavior as sucrose intake was increased after chronic administration of rolipram $(t(18)=3.58 ; p<0.01$; fig. 1 a). Measures of locomotor activity (OF: $t(18)=1.61$; n.s.; fig. 1 c), anxiety (ZM: $t(18)=0.20 ; n . s ;$ fig. $1 \mathrm{~d}$ ) and immobility (FST day 1 : immobility $\mathrm{t}(18)=0.95$; n.s.; data not shown: day 1 latency to immobility: $\mathrm{t}(18)=0.98$; n.s., fig. 1 b; FST day 2: immobility $\mathrm{t}(18)=0.72$; n.s.; day 2 latency to immobility: $\mathrm{t}(18)=1.38$; n.s., data not shown) were not affected by drug administration.

\section{Nucleus Accumbens}

The behavioral effects of PDE4 inhibition in the NAc are depicted in figure 1 (e-h). We assessed affective behavior after chronic treatment with rolipram directly in the NAc. Drug administration decreased sucrose consumption in the SIT ( $t(13)=3.26 ; p<0.01 ;$ fig. 1 e). Rolipram treatment did not result in differences on locomotor activity in the $\mathrm{OF}(\mathrm{t}(13)=0.04$; n.s.; fig. $1 \mathrm{~g}$ ), anxiety in the $\mathrm{ZM}(\mathrm{t}(13)=0.32$; n.s.; fig. $1 \mathrm{~h}$ ) or immobility in the FST (day 1 : $t(13)=1.03$; n.s, fig. 1 ; day 1 latency to immobility: $t(13)=0.15$; n.s.; day 2 immobility $\mathrm{t}(13)=0.78$; n.s.; day 2 latency to immobility: $\mathrm{t}(13)=0.67$; $\mathrm{n} . \mathrm{s}$, data not shown).

\section{CREB phosphorylation}

Activation of the transcription factor CREB was measured in hippocampal or NAc tissue of animals that were treated repeatedly with rolipram in the respective brain structure. Using Western Blot, the levels of CREB and its activated form phosphorylated CREB (pCREB) were quantified. pCREB/CREB ratios were unaltered by rolipram in hippocampal tissue of hippocampal treated animals ( $\mathrm{t}(18)=1.03$; n.s.; fig 2 a) or in the NAc of NAc treated rats $(t(13)=1.13$; n.s.; fig 2 b). 

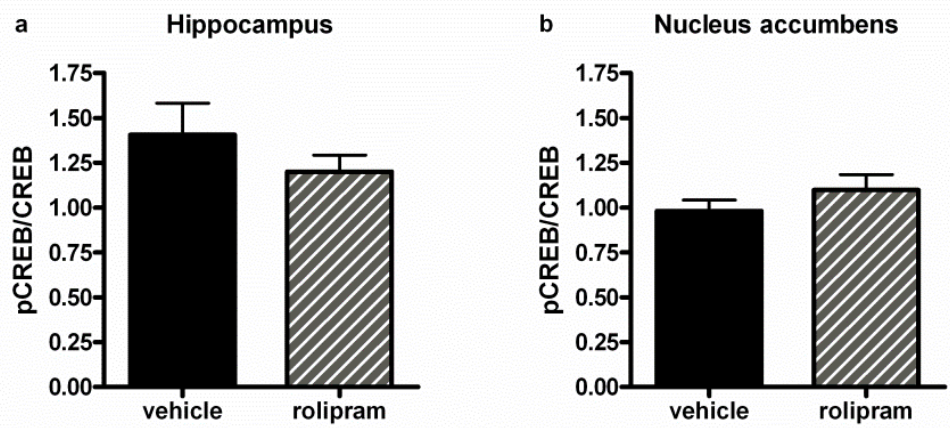

Figure 2. Levels of phosphorylated $c A M P$-responsive element binding protein ( $p C R E B$ ) relative to unphosphorylated CREB in the hippocampus $(a, n=10-10)$ and nucleus accumbens $(b, n=7-8)$ after repeated rolipram administration to the hippocampus or nucleus accumbens respectively. Levels of PCREB and CREB were determined by Western blot analysis. Bars represent means and S.E.M.

\section{DISCUSSION}

In this study we investigated if depressive-like behavior can be differently altered by CREB activation in a brain-structure dependent manner after chronic treatment with the PDE4 inhibitor rolipram in the hippocampus or nucleus accumbens in healthy rats (11).

In line with our hypothesis, we found contrasting behavioral effects of PDE4 inhibition depending on the targeted brain structure. Whereas chronic delivery of rolipram to the hippocampus led to hedonic outcomes, infusions in the NAc yielded anhedonic effects, while leaving anxiety and motor activity measures unaffected. Anhedonic behavior is one of the most prominent hallmarks of depression. Our results thus provide evidence for the notion that administration of plasticity enhancing drugs in the NAc and hippocampus leads to opposite effects on depressive-like behavior.

Similar diverging effects were reported in studies altering CREB activation levels in the hippocampus and NAC (10-14). The clear discrepancy in CREB action in the NAc versus the hippocampus could be attributed to different target genes being regulated by CREB. Dynorphin is a $\mathrm{K}$-opioid receptor 
ligand, which is expressed in the NAc following activation of CREB $(14,20)$. Upon binding to the $\mathrm{k}$-opoid receptor, dynorphin decreases excitability of dopaminergic neurons innervating the NAc, resulting in decreased mesolimbic dopamine release into the NAc (21). This decreased dopaminergic state in the NAc is thought to explain drug withdrawal states and may explain dysphoria, aversion and anhedonia in major depression (2124). On the other hand, CREB phosphorylation in the hippocampus causes an upregulation of BDNF. Given the neurotrophic properties of BDNF, this could explain why activation of CREB in this brain structure increases cellular and synaptic plasticity and exerts antidepressant effects. $(25,26)$.

However, surprisingly we did not observe an enhancement of CREB phosphorylation in the specific rolipram treated brain structures. This finding is in conflict with earlier findings suggesting an upregulation of PCREB following acute or chronic rolipram treatment $(13,27)$. Methodological differences that might explain the apparent discrepancy include the time between the last rolipram treatment and tissue collection which in our case was 24 hours, compared to a few hours in most other studies, and quantification technique (immunostaining versus immunoblotting). Chronic treatment with rolipram has been reported to increase the amount of pCREB immunopositive cells in the granule cell layer of the hippocampus $(13,27))$. In contrast, we targeted the CA1 region of the hippocampus, as our main interest was not neurogenesis but synaptic plasticity. Also, we have quantified the PCREB expression relative to CREB in the total hippocampus using Western blotting which might have diluted any possible signal. Nevertheless, there are also other studies that, like us, were unable to demonstrate elevated PCREB levels after chronic PDE4 inhibition in healthy animals $(28,29)$. Gong and his colleagues (2004) found that in dysfunctional animals with $A D$ pathology chronic PDE4 inhibitor treatment increased CREB phosphorylation, but it did not in healthy animals. Furthermore, antidepressant effects of acute and chronic rolipram administration (all peripherally given, i.e. oral, i.p or s.c.) have been widely documented $(6,8,30$, $31)$, but to our knowledge most of the chronic preclinical studies have administered the animals with rolipram shortly before the testing procedures and/or used relatively high dosages of rolipram $(6,8,31)$. Thus, one could argue that these studies' effects were actually produced by acute elevations 
of CAMP. This raises the question whether chronic treatment leads to chronic elevated levels of cAMP or rather to temporary increases in CAMP levels that coincide with the daily injections of PDE4i. In the present study, no changes were observed in anxiolytic and behavioral despair measures after treatment with rolipram regardless of the targeted brain structure, which could be in favor of this notion, given that behavioral testing was done at least 15 hours after the last rolipram administration. Nevertheless, we did find effects 15 hours later on anhedonia. This supports the idea that although chronic rolipram treatment does not chronically increase CREB phosphorylation, it does result in long-lasting changes in cellular functioning. Acute increases of de novo protein synthesis via CREB are possibly involved, but this remains speculative. Future studies should further investigate the acute versus chronic effects of rolipram.

In summary, the present study describes the dissociative roles of CAMP signaling in the hippocampus and nucleus accumbens on anhedonia. We did not observe effects on anxiolytic and despair measures nor did we find evidence for the involvement of CREB. Whereas our behavioral findings suggest that plastic changes have occurred in response to chronic rolipram treatment, these changes are not caused by a chronic increase in CREB activation. Rather, they may be the result of transient elevations of CREB phosphorylation after each administration of rolipram. 


\section{REFERENCES}

1. Tardito, D., Perez, J., Tiraboschi, E., Musazzi, L., Racagni, G., et al. (2006) Signaling pathways regulating gene expression, neuroplasticity, and neurotrophic mechanisms in the action of antidepressants: a critical overview. Pharmacol Rev 58(1):115-134.

2. O'Donnell, J. M. (1993) Antidepressant-like effects of rolipram and other inhibitors of cyclic adenosine monophosphate phosphodiesterase on behavior maintained by differential reinforcement of low response rate. J Pharmacol Exp Ther 264(3):11681178.

3. O'Donnell, J. M. \& Zhang, H. T. (2004) Antidepressant effects of inhibitors of cAMP phosphodiesterase (PDE4). Trends Pharmacol Sci 25(3):158-163.

4. Wachtel, H. \& Loschmann, P. A. (1986) Effects of forskolin and cyclic nucleotides in animal models predictive of antidepressant activity: interactions with rolipram. Psychopharmacology (Berl) 90(4):430-435.

5. Wachtel, H. \& Schneider, H. H. (1986) Rolipram, a novel antidepressant drug, reverses the hypothermia and hypokinesia of monoamine-depleted mice by an action beyond postsynaptic monoamine receptors. Neuropharmacology 25(10):1119-1126.

6. Xiao, L., O'Callaghan, J. P., \& O'Donnell, J. M. (2011) Effects of repeated treatment with phosphodiesterase-4 inhibitors on cAMP signaling, hippocampal cell proliferation, and behavior in the forced-swim test. J Pharmacol Exp Ther 338(2):641-647.

7. Duman, R. S., Heninger, G. R., \& Nestler, E. J. (1997) A molecular and cellular theory of depression. Arch Gen Psychiatry 54(7):597-606.

8. Li, Y. F., Huang, Y., Amsdell, S. L., Xiao, L., O'Donnell, J. M., et al. (2009) Antidepressantand anxiolytic-like effects of the phosphodiesterase-4 inhibitor rolipram on behavior depend on cyclic AMP response element binding protein-mediated neurogenesis in the hippocampus. Neuropsychopharmacology 34(11):2404-2419.

9. Finkbeiner, S., Tavazoie, S. F., Maloratsky, A., Jacobs, K. M., Harris, K. M., et al. (1997) CREB: a major mediator of neuronal neurotrophin responses. Neuron 19(5):1031-1047.

10. Green, T. A., Alibhai, I. N., Roybal, C. N., Winstanley, C. A., Theobald, D. E., et al. (2010) Environmental enrichment produces a behavioral phenotype mediated by low cyclic adenosine monophosphate response element binding (CREB) activity in the nucleus accumbens. Biol Psychiatry 67(1):28-35.

11. Pliakas, A. M., Carlson, R. R., Neve, R. L., Konradi, C., Nestler, E. J., et al. (2001) Altered responsiveness to cocaine and increased immobility in the forced swim test associated with elevated CAMP response element-binding protein expression in nucleus accumbens. J Neurosci 21(18):7397-7403.

12. Chen, A. C., Shirayama, Y., Shin, K. H., Neve, R. L., \& Duman, R. S. (2001) Expression of the cAMP response element binding protein (CREB) in hippocampus produces an antidepressant effect. Biol. Psychiatry 49(9):753-762.

13. Nibuya, M., Nestler, E. J., \& Duman, R. S. (1996) Chronic antidepressant administration increases the expression of CAMP response element binding protein (CREB) in rat hippocampus. J Neurosci 16(7):2365-2372. 
14. Chartoff, E. H., Papadopoulou, M., MacDonald, M. L., Parsegian, A., Potter, D., et al. (2009) Desipramine reduces stress-activated dynorphin expression and CREB phosphorylation in NAc tissue. Mol. Pharmacol. 75(3):704-712.

15. Bruno, O., Fedele, E., Prickaerts, J., Parker, L. A., Canepa, E., et al. (2011) GEBR-7b, a novel PDE4D selective inhibitor that improves memory in rodents at non-emetic doses. Br J Pharmacol 164(8):2054-2063.

16. Blizard, D. A. \& McClearn, G. E. (2000) Association between ethanol and sucrose intake in the laboratory mouse: exploration via congenic strains and conditioned taste aversion. Alcohol Clin Exp Res 24(3):253-258.

17. Prickaerts, J., Raaijmakers, W., \& Blokland, A. (1996) Effects of myocardial infarction and captopril therapy on anxiety-related behaviors in the rat. Physiol Behav 60(1):4350.

18. Shepherd, J. K., Grewal, S. S., Fletcher, A., Bill, D. J., \& Dourish, C. T. (1994) Behavioural and pharmacological characterisation of the elevated "zero-maze" as an animal model of anxiety. Psychopharmacology (Berl) 116(1):56-64.

19. Detke, M. J., Johnson, J., \& Lucki, I. (1997) Acute and chronic antidepressant drug treatment in the rat forced swimming test model of depression. Exp Clin Psychopharmacol 5(2):107-112.

20. Carlezon, W. A., Jr., Thome, J., Olson, V. G., Lane-Ladd, S. B., Brodkin, E. S., et al. (1998) Regulation of cocaine reward by CREB. Science 282(5397):2272-2275.

21. Shirayama, Y. \& Chaki, S. (2006) Neurochemistry of the nucleus accumbens and its relevance to depression and antidepressant action in rodents. Current neuropharmacology 4(4):277-291.

22. Nestler, E. J., Barrot, M., DiLeone, R. J., Eisch, A. J., Gold, S. J., et al. (2002) Neurobiology of depression. Neuron 34(1):13-25.

23. Wise, R. A. (2004) Dopamine, learning and motivation. Nat. Rev. Neurosci. 5(6):483494.

24. Harris, G. C. \& Aston-Jones, G. (1994) Involvement of D2 dopamine receptors in the nucleus accumbens in the opiate withdrawal syndrome. Nature 371(6493):155-157.

25. Nair, A., Vadodaria, K. C., Banerjee, S. B., Benekareddy, M., Dias, B. G., et al. (2007) Stressor-specific regulation of distinct brain-derived neurotrophic factor transcripts and cyclic AMP response element-binding protein expression in the postnatal and adult rat hippocampus. Neuropsychopharmacology 32(7):1504-1519.

26. Vaidya, V. A. \& Duman, R. S. (2001) Depresssion--emerging insights from neurobiology. Br. Med. Bull. 57:61-79.

27. Nakagawa, S., Kim, J. E., Lee, R., Malberg, J. E., Chen, J., et al. (2002) Regulation of neurogenesis in adult mouse hippocampus by CAMP and the CAMP response element-binding protein. J Neurosci 22(9):3673-3682.

28. Gong, B., Vitolo, O. V., Trinchese, F., Liu, S., Shelanski, M., et al. (2004) Persistent improvement in synaptic and cognitive functions in an Alzheimer mouse model after rolipram treatment. J Clin Invest 114(11):1624-1634.

29. Sierksma, A. S., van den Hove, D. L., Pfau, F., Philippens, M., Bruno, O., et al. (2013) Improvement of spatial memory function in APPswe/PS1dE9 mice after chronic inhibition of phosphodiesterase type 4D. Neuropharmacology 77C:120-130. 
30. Laux, G., Becker, T., Kuhne, G., Lesch, K. P., Riederer, P., et al. (1988) Clinical and biochemical effects of the selective phosphodiesterase inhibitor rolipram in depressed inpatients controlled by determination of plasma level. Pharmacopsychiatry 21(6):378379.

31. Itoh, T., Tokumura, M., \& Abe, K. (2004) Effects of rolipram, a phosphodiesterase 4 inhibitor, in combination with imipramine on depressive behavior, CRE-binding activity and BDNF level in learned helplessness rats. Eur J Pharmacol 498(1-3):135-142. 



\section{CHAPTER 8}

GENERAL SUMMARY AND DISCUSSION 


\section{AIM OF THIS THESIS}

The aim of this thesis was to assess the role of cyclic nucleotide signaling in behavioral processes reliant on synaptic plasticity changes, and to evaluate the feasibility of therapeutic interventions aimed at enhancing cyclic nucleotide signaling and synaptic plasticity. To answer our research questions, we have applied behavioral pharmacological studies, have measured synaptic plasticity in vitro in hippocampal tissue and performed biochemical analysis of brain tissue.

\section{CYCLIC NUCLEOTIDE SIGNALING}

\section{Cyclic nucleotides, memory and synaptic plasticity}

As second messenger molecules, cyclic nucleotides are thought to be involved in a multitude of cellular processes. In the last decennia, evidence points to a vital role of neuronal cyclic nucleotide signaling in memory formation $(1,2)$. Memory formation in the hippocampus is the brain process most commonly associated with synaptic plasticity, although direct in vivo evidence linking synaptic plasticity and memory has only emerged relatively recently $(3,4)$. In chapter 4 and 5 we broadened the current knowledge of how cyclic nucleotide pathways interact to facilitate in particular memory consolidation processes and synaptic plasticity. We found a sequential relationship of the CGMP-PKG and CAMP-PKA pathway, in discriminate time windows within the memory consolidation process. Immediately after learning CGMP signaling can alter memory formation, while $3 \mathrm{~h}$ after the learning experience CAMP signaling is essential for memory formation. In line with the notion of sequential activation of the pathways, CGMP-signaling depends on CAMP-signaling to attain enhanced memory formation. The parallel finding in behavioral memory paradigms and LTP added further weight to the notion that synaptic plasticity changes underlie memory enhancement by alterations in cyclic nucleotide signaling. 


\section{Regional effects of cyclic nucleotides}

In depression, synaptic plasticity is thought to be dysfunctional as well (5). Therefore, we investigated the role of the CAMP pathway in depressive-like behavior in chapter 5 . In that study we observed a discrepancy in the outcome of PDE4i treatment depending on where exactly in the brain CAMPsignaling was enhanced. Accumbal injections of the PDE4i rolipram led to a decrease in hedonic behavior, while hippocampal injections had the opposite effects. This apparent discrepancy can be explained by regional differences in targeted genes by CREB. This emphasizes that it is not only important to look at neuronal processes influenced by cyclic nucleotides, but also at the bigger picture, i.e. which role these particular neurons play in the large network. On the other hand, zooming in on the intraneuronal processes also reveals another level of cyclic nucleotide signaling. It is now clear that individual PDE subtypes are responsible for compartmentalized regulation of cyclic nucleotide signaling (6). That is, specific PDE isozymes are recruited in different macromolecular complexes consisting of several signaling-relevant proteins, or signalosomes which have specialized functions within specific cellular compartments.

\section{Critical considerations}

Our research has solely focused on memory enhancing and antidepressant effects of selective inhibitors of three specific subtypes, i.e. PDE2 (CAMP/cGMP), PDE4 (cAMP), and PDE5 (cGMP), after mostly systemic injections. However, we realize that we have applied simplified hypotheses, limiting our studies to the CAMP-PKA-CREB and CGMP-PKG-CREB pathway, given the overwhelming complexity of the cyclic nucleotide signaling. Studies into the several other targets of cyclic nucleotide signaling, such as cyclic nucleotide channels and CAMP-specific exchange factors (EPAC) should be performed, as well into isozyme-specific differences, distinct signalosomes and compartmentalization within the cell, since they could significantly add to our knowledge about specific characteristics of cyclic nucleotide signaling in memory formation and depressive-like states. Another critique may be raised on account of chapter 7, where we reported that there was no increase in CREB phosphorylation in chronically rolipramtreated brain regions, which was unexpected. However, as we have argued in 
that chapter, this could be due to the fact that we did not measure the acute effects after rolipram treatment, i.e. we waited too long to find the effect. Nevertheless, we are aware that this thesis does not present evidence for the direct link between cyclic nucleotides signaling and upregulation of plasticity-related proteins, such as CREB and BDNF, although a multitude of studies have reported such a link $(7,8)$.

\section{NOVEL THERAPEUTIC STRATEGIES}

\section{Phosphodiesterase inhibition}

Because cyclic nucleotide pathways are involved in many physiological processes, PDEs, as their main regulators, have been identified as interesting targets for treatment of a multitude of disorders. As an example, in chapter 2 , an overview was given of preclinical and clinical studies that applied PDE5i in central nervous system (CNS) disorders. However, many of the clinical studies performed at the moment are not related to the CNS. For example, PDE5i's are currently receiving a lot of attention regarding their promise as therapeutics in heart failure, while PDE4i's are considered as novel antiinflammatory agents (6). In the experimental studies presented in this thesis, our primary focus was on the effects of PDEi on plasticity-associated behavioral processes. In specific, we focused on cognition and moodprocesses. Preclinical evidence of the cognition-enhancing effects of PDEi has been accumulating over the years (9). In chapter 4 and 5 we have confirmed the memory-enhancing properties of the PDE4i rolipram, PDE5i vardenafil and PDE2i BAY60 7550. In chapter 7, we confirmed the antidepressant properties of rolipram, although only when administered into the hippocampus and not into the nucleus accumbens. The interest in targeting cyclic nucleotide signaling via PDEi remains strong, although there have been some setbacks as the ubiquitous nature of CAMP and CGMP resulted in unwanted side-effects. For instance, emetic effects are associated with PDE4i's $(10,11)$. Also, researchers have had little success in demonstrating similar pro-cognitive effects in humans (for instance PDE5i's; see 12,13 , but also see 14 ). 
However, recent advances in our understanding of cyclic nucleotide signaling have reignited the attention towards PDE inhibitors (6). In chapter 4, we have demonstrated that the sequential relationship of CGMP and CAMP signaling could be translated into a therapeutical strategy by combining treatment of CAMP-selective and CGMP-selective PDEi's to enhance memory at low doses that are not effective when given separately. Thus, combining several PDEi's could produce more effective treatments, while reducing the unwanted sideeffects. Another strategy is to develop isozyme-specific PDEi. For example, it is now known that isozyme PDE4B is dysfunctional in schizophrenia, while PDE4D related to cognitive function $(15,16)$. The rationale behind this strategy is that targeting specific isozymes and thus specific compartments will have more precise effects on dysfunctional signalosomes in the signaling pathways, without affecting other functional members of its PDE family (6).

\section{TrkB agonism}

We assume that cyclic nucleotide activates CREB, which is an important regulator of transcription of the BDNF gene. BDNF is a well-known neurotropic growth factor. One may argue that using a different approach, such as targeting the BDNF-TrkB pathway with small-molecules TrkB agonists, synaptic changes may be produced even more specifically. Advantages of such an approach include the selective activation of the TrkB pathways, leaving the pro-apoptotic p75-pathway unaffected. In chapter 6 we tested the effects of selective TrkB agonist 7,8-dihydroxyflavone (7,8DHF) on memory consolidation. Memory formation was ameliorated by stimulation of the pro-plasticity TrkB pathways. Research into this particular compound and its derivates is currently booming, as 7,8-DHF was the first small molecule identified as a selective TrkB agonist (17). This discovery was a important breakthrough in BDNF-based therapeutic strategies and has resulted in a surge of evidence showing beneficial effects of 7,8-DHF in many disorders, including schizophrenia, depression and Huntington's disease (1820). 


\section{Neurodegeneration and synaptic repair}

In chapter 5, we showed that acute TrkB agonism not only improves memory function in healthy animals, but also enhances memory performance in a mouse model of Alzheimer's disease. Synaptic degeneration is a pathophysiological hallmark in several neurodegenerative disorders, including AD, Parkinson's disease and Huntington's disease (21). In chapter 3, evidence of PDE dysfunction in neurodegenerative diseases was reviewed. A major conclusion of this chapter was that although PDE expression is altered in several neurodegenerative disorders, PDEs do not seem to be involved in the pathogenesis, but are likely secondary changes in response to neuronal dysfunction and damage (with the exception of autosomal-dominant striatal degeneration, see chapter 3 ). Targeting synaptic plasticity via PDEi's, may still prove to be an effective treatment strategy in these disorders. Given the limited clinical success of targeting pathogenic processes, together with the challenges of an early diagnosis, a disease-modifying therapy might be the more practical approach (22). Whereas neuronal loss is considered permanent, synaptic damage is more likely to be reversible. Therefore, chronic synaptic repair therapies, including PDE inhibition and TrkB agonism, could induce long-term functional and structural changes and could slow or halt disease progression $(21,23)$.

\section{CONCLUSION}

In this thesis, we have demonstrated that CGMP and CAMP act sequential to affect memory and synaptic plasticity. We translated this into a combinatory therapeutic approach, which may be a novel approach to treating memory decline and neurodegenerative disorders, alongside BDNF-targeting approaches. Although very promising, future research will have to point out if these findings will be able to withstand the ultimate test in clinical studies. 


\section{REFERENCES}

1. Chien, W. L., Liang, K. C., Teng, C. M., Kuo, S. C., Lee, F. Y., et al. (2003) Enhancement of long-term potentiation by a potent nitric oxide-guanylyl cyclase activator, 3-(5hydroxymethyl-2-furyl)-1-benzyl-indazole. Mol Pharmacol 63(6):1322-1328.

2. Frey, U., Huang, Y. Y., \& Kandel, E. R. (1993) Effects of cAMP simulate a late stage of LTP in hippocampal CA1 neurons. Science 260(5114):1661-1664.

3. Bliss, T. V. \& Lomo, T. (1973) Long-lasting potentiation of synaptic transmission in the dentate area of the anaesthetized rabbit following stimulation of the perforant path. $J$ Physiol 232(2):331-356.

4. Whitlock, J. R., Heynen, A. J., Shuler, M. G., \& Bear, M. F. (2006) Learning induces longterm potentiation in the hippocampus. Science 313(5790):1093-1097.

5. Marsden, W. N. (2013) Synaptic plasticity in depression: molecular, cellular and functional correlates. Prog Neuropsychopharmacol Biol Psychiatry 43:168-184.

6. Maurice, D. H., Ke, H., Ahmad, F., Wang, Y., Chung, J., et al. (2014) Advances in targeting cyclic nucleotide phosphodiesterases. Nat Rev Drug Discov 13(4):290-314.

7. Puzzo, D., Loreto, C., Giunta, S., Musumeci, G., Frasca, G., et al. (2014) Effect of phosphodiesterase-5 inhibition on apoptosis and beta amyloid load in aged mice. Neurobiol Aging 35(3):520-531.

8. Wang, C., Zhang, J., Lu, Y., Lin, P., Pan, T., et al. (2014) Antidepressant-like effects of the phosphodiesterase-4 inhibitor etazolate and phosphodiesterase-5 inhibitor sildenafil via cyclic AMP or cyclic GMP signaling in mice. Metab Brain Dis.

9. Reneerkens, O. A., Rutten, K., Steinbusch, H. W., Blokland, A., \& Prickaerts, J. (2009) Selective phosphodiesterase inhibitors: a promising target for cognition enhancement. Psychopharmacology (Berl) 202(1-3):419-443.

10. Robichaud, A., Tattersall, F. D., Choudhury, I., \& Rodger, I. W. (1999) Emesis induced by inhibitors of type IV cyclic nucleotide phosphodiesterase (PDE IV) in the ferret. Neuropharmacology 38(2):289-297.

11. Hebenstreit, G. F., Fellerer, K., Fichte, K., Fischer, G., Geyer, N., et al. (1989) Rolipram in major depressive disorder: results of a double-blind comparative study with imipramine. Pharmacopsychiatry 22(4):156-160.

12. Goff, D. C., Cather, C., Freudenreich, O., Henderson, D. C., Evins, A. E., et al. (2009) A placebo-controlled study of sildenafil effects on cognition in schizophrenia. Psychopharmacology (Berl) 202(1-3):411-417.

13. Reneerkens, O. A., Sambeth, A., Ramaekers, J. G., Steinbusch, H. W., Blokland, A., et al. (2013) The effects of the phosphodiesterase type 5 inhibitor vardenafil on cognitive performance in healthy adults: a behavioral-electroencephalography study. J Psychopharmacol 27(7):600-608.

14. Shim, Y. S., Pae, C. U., Cho, K. J., Kim, S. W., Kim, J. C., et al. (2014) Effects of daily lowdose treatment with phosphodiesterase type 5 inhibitor on cognition, depression, somatization and erectile function in patients with erectile dysfunction: a doubleblind, placebo-controlled study. Int J Impot Res 26(2):76-80. 
15. Bruno, O., Fedele, E., Prickaerts, J., Parker, L. A., Canepa, E., et al. (2011) GEBR-7b, a novel PDE4D selective inhibitor that improves memory in rodents at non-emetic doses. Br J Pharmacol 164(8):2054-2063.

16. Millar, J. K., Mackie, S., Clapcote, S. J., Murdoch, H., Pickard, B. S., et al. (2007) Disrupted in schizophrenia 1 and phosphodiesterase 4B: towards an understanding of psychiatric illness. J Physiol 584(Pt 2):401-405.

17. Jang, S. W., Liu, X., Yepes, M., Shepherd, K. R., Miller, G. W., et al. (2010) A selective TrkB agonist with potent neurotrophic activities by 7,8-dihydroxyflavone. Proc Natl Acad Sci U S A 107(6):2687-2692.

18. Jiang, M., Peng, Q., Liu, X., Jin, J., Hou, Z., et al. (2013) Small-molecule TrkB receptor agonists improve motor function and extend survival in a mouse model of Huntington's disease. Hum Mol Genet 22(12):2462-2470.

19. Liu, X., Qi, Q., Xiao, G., Li, J., Luo, H. R., et al. (2013) O-methylated metabolite of 7,8dihydroxyflavone activates TrkB receptor and displays antidepressant activity. Pharmacology 91(3-4):185-200.

20. Yang, Y. J., Li, Y. K., Wang, W., Wan, J. G., Yu, B., et al. (2014) Small-molecule TrkB agonist 7,8-dihydroxyflavone reverses cognitive and synaptic plasticity deficits in a rat model of schizophrenia. Pharmacol Biochem Behav 122:30-36.

21. Lu, B., Nagappan, G., Guan, X., Nathan, P. J., \& Wren, P. (2013) BDNF-based synaptic repair as a disease-modifying strategy for neurodegenerative diseases. Nat Rev Neurosci 14(6):401-416.

22. Lewis, D. A. \& Sweet, R. A. (2009) Schizophrenia from a neural circuitry perspective: advancing toward rational pharmacological therapies. J Clin Invest 119(4):706-716.

23. Castello, N. A., Nguyen, M. H., Tran, J. D., Cheng, D., Green, K. N., et al. (2014) 7,8Dihydroxyflavone, a small molecule TrkB agonist, improves spatial memory and increases thin spine density in a mouse model of Alzheimer disease-like neuronal loss. PLoS One 9(3): 91453. 


\section{VALORISATION}



Our brain is without any doubt the most complex organ of our body. This complexity is also the major reason why most disorders of the central nervous system are still relatively poorly understood, despite the significant increase in efforts invested in neuroscience research in the last decades. As an obvious result of this lack of understanding, we are confronted with a general lack of effective therapies to prevent, treat or cure the majority of common neurological and psychiatric disorders, many of which are characterized by a specific level of cognitive dysfunction. In this respect, the best known example is Alzheimer's disease, in which severe memory loss is one of the core symptoms. According to an estimation of Alzheimer Europe, Alzheimer's disease currently affects approximately 11 million people in Europe, and this number is expected to rise significantly in the near future. This huge number represents a group of patients who are in need of chronic care, which results in an immense impact on the lives of the patient and its immediate surroundings, and thus in a vast financial burden for European societies, summing up to a cost of illness of approximately 200 billion euro in 2015. Importantly, in other common neurological and psychiatric disorders cognition is affected as well, including schizophrenia, autism, major depressive disorder, multiple sclerosis and Parkinson's disease, though the changes in cognition may be more subtle. However, these dysfunctions can be particularly disabling as they often represent a major factor in preventing the patient to be (re)integrated in society. At the moment, only five drugs are commercially available to attenuate cognitive symptoms, of which four are acetylcholinesterase inhibitors. However, these drugs are only approved for Alzheimer's disease and have limited efficacy, while also having side effects. Thus, there is a large interest in finding effective drug targets for treatment of cognitive impairment.

In this thesis, we have added knowledge of the underlying processes of memory formation. Comprehension of this basic process is a vital step to discover interventions which might repair dysfunctional pathways, and how the process could be reshaped to compensate for liabilities elsewhere in the system. Specifically, we have described how the intracellular signaling molecules CGMP and CAMP interact during subsequent phases of memory consolidation. This will give the scientific community new insights into the 
process of memory consolidation and in possible ways to specifically enhance memory formation.

Furthermore, we have put forward the idea of combining different low-dosed phosphodiesterase inhibitors (PDE-Is), which specifically increase cGMP and/or cAMP levels in the brain, as an optimization of their potential memory-enhancing effects. The cognition enhancing properties of PDE-Is were already well characterized in preclinical research. However, the research in clinical trials has encountered some setbacks due to side-effects including emesis related to CAMP signalling. The combination treatment may provide us with a means to benefit from the pro-cognitive profile of PDE-Is with minimal or even without side-effects.

We have also investigated the potential of the first specific tyrosine kinase $B$ (TrkB) receptor agonist to enhance memory. The identification of 7,8dihydroxyflavone as a specific TrkB agonist has been a breakthrough for BNDF-based treatment strategies. Our preclinical work has added to the recognition of 7,8-DHF as a potential novel treatment for cognitive impairment, possibly even in relation to Alzheimer's disease.

Although we are aware that the translation of rodent data to humans is often difficult, animal research in general is indispensable to establish a first proofof-principle, as well as to evaluate safety and the dosing regimen to test in patients. Along these lines, the value of the preclinical studies described in this thesis lies in the fact that they will help researchers to formulate new hypotheses for preclinical and clinical research into cognitive functions and in particular memory functioning, which thus may bring us one step closer to effective treatment of cognitive impairments. 
CURRICULUM VITAE 
Eva Bollen werd op 26 juli 1985 geboren in Tongeren. Ze voltooide in 2003 haar middelbare opleiding Latijn-wetenschappen aan het Heilig Graf instituut te Bilzen. Datzelfde jaar startte ze een Bachelor in de psychologie aan de Universiteit Maastricht en nam deel aan het facultaire Honours programma. Ze werd vervolgens toegelaten tot de opleiding Neuropsychology binnen het Research Master programma. In het kader van haar master thesis, startte ze met het onderzoek naar de betrokkenheid van cyclisch nucleotiden in geheugenvorming onder supervisie van Dr. Rutten en Dr. Prickaerts. In 2008 voltooide ze haar master opleiding cum laude, en later dat jaar werd haar een Kootstra Talent Fellowship voor talentvolle aspirant promovendi toegekend. In 2009 startte ze haar promotietraject onder begeleiding van Dr. Prickaerts en Prof. Steinbusch, waarin ze de onderzoekslijn van haar master thesis verder zette. Een significant deel van haar tijd als PhD student, bracht ze door aan de KU Leuven in het Laboratorium voor Biologische Psychologie onder begeleiding van Prof. D'Hooge, waar ze zich verdiepte in vitro electrofysiologie. Aangezien dit project ook financieel gesteund werd door zowel de Universiteit Maastricht als de KU Leuven, verkrijgt Eva een gezamelijk doctoraatsdiploma van beide universiteiten. De resultaten van haar promotie onderzoek staan beschreven in dit proefschrift. 
Eva Bollen was born July 26th 1985 in Tongeren. She completed her secondary education at the Heilig Graf institute in Bilzen in 2003. In the same year, she started her Bachelor in Psychology at Maastricht University and took part in the Honours program of the faculty. She was admitted to the Research Master program in the track Neuropsychology. In the context of her master thesis, she started researching the involvement of cyclic nucleotides in memory consolidation under the guidance of Dr. Rutten and Dr. Prickaerts. In 2008, she obtained her master degree cum laude. She was granted a Kootstra Talent Fellowship later that year, which enabled her to start her PhD-project at the School for Mental Health and Neuroscience under supervision of Dr. Prickaerts and Dr. Steinbusch, during which she continued research into cyclic nucleotide signaling and its involvement in behavior caused by synaptic plasticity changes. A significant part of PhDperiod was spent at the KU Leuven at the Laboratory of Biological Psychology under supervision of Prof. D'Hooge, where she familiarized herself with in vitro electrophysiology. This project was also financially supported by both universities, and therefore Eva will receive a joint doctoral diploma of Maastricht University and the KU Leuven. The results of her research performed during her $\mathrm{PhD}$ project are described in this thesis. 

Publications 


\section{Publications in international journals}

E Bollen, D Puzzo, K Rutten, L Privitera, J De Vry, T Vanmierlo, G Kenis, A Palmeri, R D'Hooge, D Balschun, H W M Steinbusch, A Blokland, J Prickaerts. Improved Long-Term Memory via Enhancing CGMP-PKG Signaling Requires CAMP-PKA Signaling. Neuropsychopharmacology, 2014; 39, 2497-2505.

E Bollen, T Vanmierlo, S Akkerman, C Wouters, H M W Steinbusch, J Prickaerts. 7,8-Dihydroxyflavone improves memory consolidation processes in rats and mice. Behavioral Brain research, 2013, 257:8-12.

E Bollen, J Prickaerts. Phosphodiesterases in neurodegenerative disorders. IUBMB Life, 2012; 64(12):965-70. (REVIEW)

O A H Reneerkens, K Rutten, Eva Bollen, T Hage,A Blokland, H W M Steinbusch, J Prickaerts. Inhibition of phoshodiesterase type 2 or type 10 reverses object memory deficits induced by scopolamine or MK801. Behavoral Brain Research, 2013; 236(1):16-22.

S Akkerman, A Blokland, O Reneerkens, N P van Goethem, E Bollen, Hieronymus J M Gijselaers, Cindy K J Lieben, Harry W M Steinbusch, J Prickaerts. Object recognition testing: methodological considerations on exploration and discrimination measures. Behavioral Brain Research. 2012; 232(2):335-47.

A Hosseini-Sharifabad, M Hossein Ghahremani, $\mathrm{O}$ Sabzevari, $\mathrm{Nr}$ Naghdi, M Abdollahi, C Beyer, E Bollen, J Prickaerts, A Roghani, M Sharifzadeh. Effects of protein kinase $A$ and $G$ inhibitors on hippocampal cholinergic markers expressions in rolipram- and sildenafil-induced spatial memory improvement. British Journal of Pharmacology, 2011; 164(8):2054-2063. 
O Bruno, E Fedele, J Prickaerts, L A Parker, E Canepa, C Brullo, A Cavallero, E Gardella, A Balbi, C Domenicotti, E Bollen, H J M Gijselaers, T Vanmierlo, K Erb, C L Limebeer, F Argellati, U M Marinari, M A Pronzato, R Ricciarelli. GEBR-7b, a novel PDE4D selective inhibitor that improves memory in rodents at non-emetic doses. British Journal of Pharmacology, 2011; 164(8):2054-2063.

K Rutten, E L Van Donkelaar, L Ferrington, A Blokland, E Bollen, H Wm Steinbusch, PI Kelly, J Prickaerts. Phosphodiesterase inhibitors enhance object memory independent of cerebral blood flow and glucose utilization in rats. Neuropsychopharmacology, 2009 34(8):1914-25.

\section{Invited book chapter}

E Bollen, K Rutten, O Reneerkens, HWM Steinbusch, J Prickaerts. Beyond erectile dysfunction: Understanding PDE5 activity in the central nervous system. in Cyclic-Nucleotide Phosphodiesterases In The Central Nervous System: From Biology to Drug Discovery (eds N. J. Brandon and A. R. West), John Wiley \& Sons, Inc., Hoboken, New Jersey, 2014, doi: 10.1002/9781118836507.ch09 

ACKNOWLEDGEMENTS 
"Surround yourself with the dreamers and the doers, the believers and thinkers, but most of all; surround yourself with those who see the greatness within you, even when you don't see it yourself." Edmund Lee

Beste lezer, als je net dit boekje in handen hebt gekregen, is de kans heel groot dat je op één of andere manier hebt bijgedragen aan deze thesis. Ik wil mij op het einde van dit boekje dan ook nog even richten tot jullie, zonder wie dit niet gelukt was.

In de eerste plaats wil ik natuurlijk mijn promotoren bedanken. Prof. Steinbusch, beste Harry, bedankt dat u mij de mogelijkheden hebt geboden om met dit onderzoek te starten en gedurende de gehele periode te waken over het verloop van mijn traject. Prof. D'Hooge, beste Rudi, ik heb anderhalf jaar lang deel mogen uitmaken van het lab voor Biologische Psychologie, een tijd die mij heel veel heeft geleerd. Ik wil je bedanken om je oprechte wetenschappelijke interesse en je menselijke begrip.

Mijn copromotor, Dr. Prickaerts, beste Jos, jij was de drijvende kracht achter dit project. En ook wel de drijvende kracht achter mij, als ik weer eens het geloof in een goede afloop had verloren. Met jouw onstuitbaar optimisme kreeg je het steeds voor mekaar dat ik met hernieuwde energie je bureau uitstapte. Bedankt voor je onwrikbare geloof in dit project en in mij.

Dr. Rutten, Kris, jij stond aan de wieg van dit project; je werd "my scientific godfather". Jouw steun en geloof in mij als wetenschapper heeft mij destijds het zelfvertrouwen gegeven om voluit voor een wetenschappelijke carriere te kiezen, en ik ben je daar nog steeds erg dankbaar om!

I'm very obliged to Prof. Balschun and Dr. Ahmed at the Laboratory of Biological Psychology, who dedicated so much of their time to teaching me electrophysiology. Thank you!

I also would like to thank our Sicilian collaborators, Dr. Daniela Puzzo, Prof. Agostino Palmeri and dr. Lucy Privitera from the University of Catania, not only for our pleasant collaberation, their hard work and beautiful results, but also for those unforgettable December days 
which made me fall deeply in love with Sicily and its people. Grazie mille!

Mijn paranimfen, mijn ere-dames.

Lieve Annerieke, ik heb jou altijd bewonderd om je wetenschappelijke instelling en jouw vrolijke vastberadenheid. Maar het was pas toen we na ons contract in Maastricht allebei in Leuven waren gestrand, dat ik echt inzag wat voor een geweldig mens je eigenlijk wel bent. Bedankt om de laatste jaren zo vaak mijn klankbord te zijn, in boekjes en andere perikelen. Het is voor mij echt een grote geruststelling te weten dat je vandaag langs mij zal staan.

Lieve Bieke, lieve zusje, ik heb je écht nooit willen na-apen (behalve toen met Take That misschien) maar daar stonden we plots dan, allebei afgestudeerd als psycholoog, allebei doctoreren in de neurowetenschappen, werken in hetzelfde lab dan nog wel én elke dag samen op de trein. Voor anderen zou het teveel van het goede zijn, maar ik voelde mij zoveel completer met jou in de buurt. Bedankt om mij altijd te begrijpen en om zo'n geweldige wetenschapster, mama en zus te zijn!

De In-vivo-kern. Voor jullie schieten woorden tekort. Voor mij zal er altijd een soort magie rond dit collectief blijven hangen. Het uberteam met veel koffieklets, heerlijke humor, vlammende pannenkoeken, gezellige gehaktdagen, wilde feestjes, wilde plannen en echte vriendschap. Sven, Nick, Jochen en Tim, bedankt om mijn wetenschappelijke en persoonlijke groeipijnen te delen. Verder wil ik Olga en Inge bedanken - voor de gezellige avonden samen - en alle andere MHeNS'ers die mijn tijd in Maastricht voorbij hebben doen vliegen: Marlies, Pim, andere Pim, Eva, Cindy, Marisela, Jody, Rianne, Leonidas, Caroline, Nicole, Fabien, Eshan, Evelien, Evi, Marijke, Rinske, Kathleen, Pablo, Ali, Dagmar, Mark, Youssef, Jo, Alejandro, Bart en alle anderen. It was great working with you all; I hope our paths will cross again!

Mijn masterstudenten Claudia Schreiner en Caroline Wouters, het was een fijne samenwerking! Jannie, je was ook een geweldig plezante collega. Ik hoop je nog vaak tegen te komen, en wens je veel succes in de toekomst! Denise, Marjan en Hellen, bedankt voor jullie ondersteuning, hulp en expertise. 
Ik had het geluk om in het Laboratorium voor Biologische Psychologie ook terecht te komen in een groep van hele bijzondere mensen. Adam, Stijn, Ann, Enrico, Adrian, Sandra, Hannelore en Arne, bedankt voor de lange en gezellige lunches, alledaagse absurditeiten en voor het volledig uit de bol gaan op de legendarische bureau/retraite/7oaks feestjes. Lize, jij verdient een aparte vermelding voor je mede-chaotisme, dansmoves én voor je onvertroffen matchmaking skills. Ik kijk alvast uit naar een volgende post-PhD-night, samen met het dozijn aan kindjes!

To my current boss, prof. Popik and my lovely co-workers at the Instute of Pharmacology at the Polish Academy of Science: Dziękuje bardzo za wsparcie!

Ook buiten mijn werkomgeving zijn er een heel wat mensen die meegeleefd hebben. In de eerste plaats mijn vriendinnetjes, Yonca, Stéphanie, Marij en Zoë: jullie zijn echt een stel prachtdames! De Leuvense Mensheid: bedankt om mij prompt op te nemen in de familie, voor jullie interesse en voor het gevarieerde programma aan afleidende activiteiten. Peter, bedankt om mij jarenlang te steunen in al mijn beslissingen.

Ik wil ook nog mijn oma's, schoonbroers, familie en schoonfamilie bedanken die vanaf de zijlijn enthousiast hebben gesupporterd.

Een heel bijzondere vermelding gaat naar mijn petekind Gust. Lieve Gust, 5 jaar geleden zat ik elke dag bij je mama op de trein en kon ik jou al voelen wriemelen in haar ronde buik. Toen al was je de perfecte remedie tegen elke soort van frustratie, en dat ben je nog steeds. Ik ben heel fier dat je ondertussen zo'n flinke jongen en een geweldige grote broer bent!

Lieve Ruth, liefste zussie. Ik ben het allertrotst op jou. Je bent tijdens mijn doctoraatsjaren een hele bijzondere vrouw geworden, en ook nog eens een fantastische dokter. Ondanks dat je altijd mijn kleine zusje zal blijven, ben je zonder meer uitgegroeid tot één van mijn grootste voorbeelden.

Mama, papa, de laatste van het gezin komt met de dr-titel naar huis... Allereerst, bedankt om het bio/medische gen door te geven, en mijn nieuwsgierigheid naar wetenschap al van jongs af met boeken, chemiedozen en microscopen te voeden. Maar vooral bedankt voor 
jullie zorgen - de vitamientjes -, om er onvoorwaardelijk voor mij te zijn, en om mij beter te kennen dan mezelf.

Tenslotte Geert, jouw aandeel in dit boekje is zoveel groter dan je denkt. Tijdens die moeilijke laatste jaren was jij er dag in dag uit, als mijn coach, mijn fanatiekste fan, mijn strenge manager, mijn enthousiaste PR-man of mijn grootste criticus. Elke dag daag je mij uit om net iets meer uit mezelf te halen. Jouw geloof in mij maakt mij sterker en beter. En onder andere daarom zie ik je zo oneindig graag. Bedankt!

En hiermee is dit verhaal nu dan echt uit. Op naar het volgende avontuur! 
